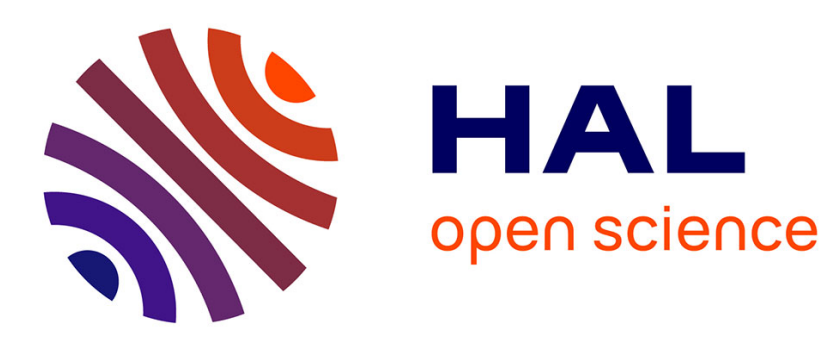

\title{
Lewis Pairing and Frustration of Group 13/15 Elements Geometrically Enforced by (Ace)Naphthalene, Biphenylene and (Thio)Xanthene Backbones
}

\author{
Omar Sadek, Ghenwa Bouhadir, Didier Bourissou
}

\section{- To cite this version: \\ Omar Sadek, Ghenwa Bouhadir, Didier Bourissou. Lewis Pairing and Frustration of Group 13/15 Elements Geometrically Enforced by (Ace)Naphthalene, Biphenylene and (Thio)Xanthene Backbones. Chemical Society Reviews, 2021. hal-03430133}

\author{
HAL Id: hal-03430133 \\ https://hal.science/hal-03430133
}

Submitted on 16 Nov 2021

HAL is a multi-disciplinary open access archive for the deposit and dissemination of scientific research documents, whether they are published or not. The documents may come from teaching and research institutions in France or abroad, or from public or private research centers.
L'archive ouverte pluridisciplinaire HAL, est destinée au dépôt et à la diffusion de documents scientifiques de niveau recherche, publiés ou non, émanant des établissements d'enseignement et de recherche français ou étrangers, des laboratoires publics ou privés. 


\title{
Lewis Pairing and Frustration of Group 13/15 Elements Geometrically Enforced by (Ace)Naphthalene, Biphenylene and (Thio)Xanthene Backbones
}

\author{
Omar Sadek, ${ }^{[a] *}$ Ghenwa Bouhadir ${ }^{[a]}$ and Didier Bourissou ${ }^{[a] *}$ \\ [a]CNRS/Université Toulouse III - Paul Sabatier, Laboratoire Hétérochimie Fondamentale et \\ Appliquée (LHFA, UMR 5069) \\ 118 Route de Narbonne, 31062 Toulouse Cedex 09 (France) \\ E-mail: dbouriss@chimie.ups-tlse.fr \\ Homepage: http://lhfa.cnrs.fr/index.php/equipes/lbpb/accueil-Ibpb
}

\begin{abstract}
:
The synthesis, structure, and reactivity of mixed group 13/group 15 compounds $\left(E^{13}=B, A l, G a, I n\right.$; $\left.E^{15}=N, P, S b, B i\right)$ featuring a rigid (ace)naphthalene or (thio)xanthene backbone are discussed in this review. The backbone may either enforce or prevent $E^{15} \rightarrow E^{13}$ interactions, resulting in Lewis pairing or frustration. The formation of strong $E^{15} \rightarrow E^{13}$ interactions is possible upon peri-substitution of (ace)naphthalenes. This gives the opportunity to access and study highly reactive species, as exemplified by P-stabilised borenium salts and boryl radicals. In turn, rigid expanded spacers such as biphenylenes, (thio)xanthenes and dibenzofurans impose long distances and geometrically prevent $E^{15} \rightarrow E^{13}$ interactions. Such $P-B$ derivatives display ambiphilic coordination properties and frustrated Lewis pair behaviour towards small molecules, their preorganised structure favouring reversible interaction/activation. Throughout the review, the importance of the scaffold in enforcing or preventing $E^{15} \rightarrow E^{13}$ interactions is highlighted and discussed based on experimental data and theoretical calculations.
\end{abstract}




\section{Introduction}

Donor-acceptor $(D \rightarrow A)$ interactions is a field of huge interest and intense research. They are present in a broad range of chemical structures that find applications in many fields including organic synthesis, catalysis and materials science.

Connecting donor and acceptor moieties through an organic linker is very appealing. This provides a degree of control over the $D \rightarrow A$ interaction by tuning the length and rigidity of the spacer. In this context, rigid carbon-based scaffolds have attracted much interest over the last two decades. This review summarizes the advances made on mixed group 13/group 15 compounds ( $E^{13}=B, A l, G a$, In; $E^{15}=\mathrm{N}, \mathrm{P}, \mathrm{Sb}, \mathrm{Bi}$ ) in which the $\mathrm{D}$ and $\mathrm{A}$ sites are maintained in proximity (as with naphthalene or acenaphthalene) or far from each other (as with biphenylene, xanthene, thioxanthene or dibenzofuran) (Chart 1).

Emphasis is given to the synthetic access to these derivatives, as well as their electronic and structural features. Their reactivity is also discussed, particularly in the context of small molecule activation and generation of highly reactive $B$ species thanks to geometrically enforced, stabilising $P \rightarrow B$ interactions.

Throughout the review, the ability of the rigid backbone to enforce or prevent intramolecular $\mathrm{E}^{15} \rightarrow \mathrm{E}^{13}$ interaction is discussed and analysed based on spectroscopic, structural and theoretical considerations. In general, peri-substitution of (ace)naphthalenes tends to enforce $\mathrm{E}^{15} \rightarrow \mathrm{E}^{13}$ interaction (Lewis pairing), but the juxtaposition of the $\mathrm{E}^{15}$ - and $\mathrm{E}^{13}$-based groups induces strong constraints. In contrast, xanthene, thioxanthene and dibenzofuran prevent $E^{15} \rightarrow E^{13}$ interaction (Lewis pair frustration) due to the imposed distance between the $D$ and $A$ sites. Of note, the (ace)naphthalene, xanthene and dibenzofuran scaffolds are essentially planar, whereas the large size of $S$ and the presence of a $\mathrm{sp}^{3}$-hybridized carbon atom in the central ring make thioxanthenes to fold. The geometric difference between the various spacers is clearly apparent from the corresponding $\mathrm{H} \cdots \mathrm{H}$ distance in the respective frameworks, from $\sim 2.45$ and $2.67 \AA$ in naphthalene ${ }^{1}$ and acenaphthalene, ${ }^{2}$ to $3.82,4.55,5.11$ and $5.22 \AA$ in biphenylene, ${ }^{3}$ xanthene, ${ }^{4}$ thioxanthene ${ }^{5}$ and difenzofuran, ${ }^{6}$ respectively (Chart 1 ).

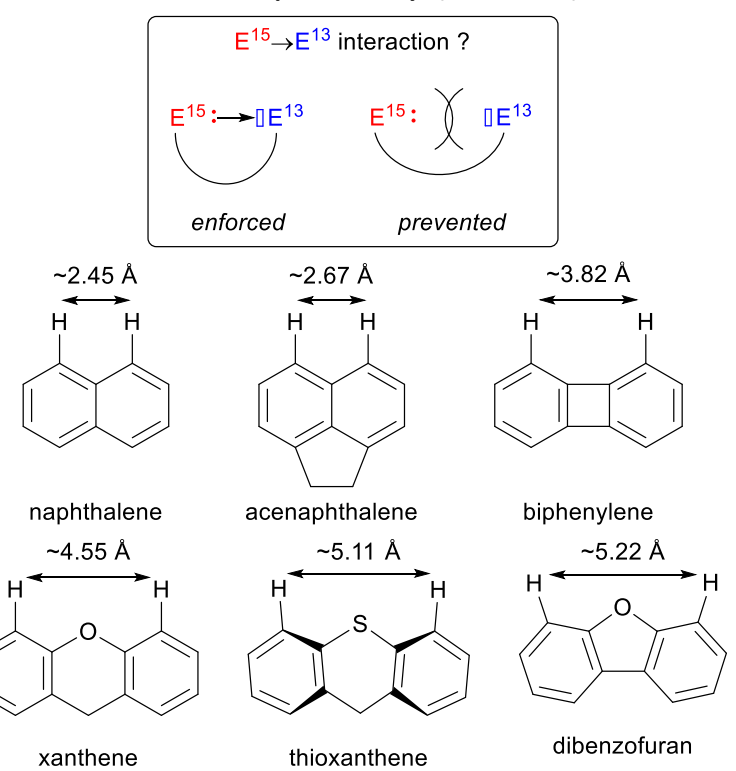

Chart 1 Schematic representation of the mixed group 13/group 15 compounds covered in this review in their two limit forms (with/without $\mathrm{E}^{15} \rightarrow \mathrm{E}^{13}$ interaction); corresponding carbon-based spacers with the nominal distance between the peri (and peri-like) positions. 


\section{Generalities}

Synthesis of (ace)naphthalenes, (thio)xanthenes and dibenzofurans featuring group 13/15 elements. For brevity and to avoid repetition, the synthetic pathways used to access these derivatives are presented below.

Directed lithiation and halogen-lithium exchange reactions followed by electrophilic trapping. Most compounds discussed in this review were prepared by ionic coupling, as illustrated schematically in Scheme 1 for (ace)naphthalene derivatives. Functionalisation of the (ace)naphthyl framework usually begins by the incorporation of the group 15 moiety followed by the group 13 atom, although in certain cases, the order can be reversed (vide infra). The key step is the electrophilic trapping of a $E^{15}$-functionalized organometallic intermediate, typically an organolithium derivative, with an appropriate $\mathrm{E}^{13}$-based electrophile. The organolithium species is generated either by direct lithiation ( $\mathrm{N}$-directed metalation) or halogen-lithium exchange. Occasionally, the $E^{13}$-based electrophile is reacted after lithium-tin exchange. The same methodology was used to obtain the related biphenylene, (thio)xanthene and dibenzofuran compounds, in which the two positions to functionalize with $E^{15} / E^{13}$ elements are far from each other.

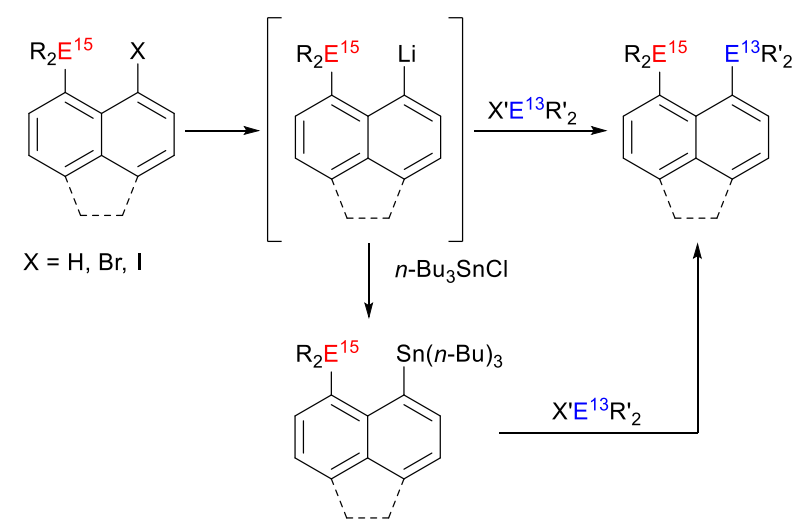

Scheme 1 Schematic representation of the general synthetic route used to access $E^{15} / E^{13}$ peri substituted (ace)naphthyl derivatives and related compounds.

Two other synthetic routes have been developed in the case of N-B derivatives. They are far less general but are briefly discussed hereafter for sake of comprehensiveness.

Transition-metal-catalysed borylation reactions. Among the numerous transition-metal-catalysed borylation reactions described in the literature, ${ }^{7,8}$ one example deals with a naphthalene compound peri-substituted with dimethylamino and pinacolborane moieties (Scheme 2, top). ${ }^{9}$ It is obtained in high yield by $\mathrm{C}-\mathrm{Br}$ activation and $\mathrm{C}-\mathrm{B}$ coupling from the respective naphthyl amine. Also noteworthy is the possibility to achieve direct $\mathrm{C}-\mathrm{H}$ borylation. This approach has been applied to benzo[h]quinoline (affording naphthalene-like $\mathrm{N}\left(\mathrm{sp}^{2}\right)$ - $\mathrm{B}$ compounds) using $\mathrm{Pd}, \mathrm{Ru}$ or Rh catalysts (Scheme 2, bottom). ${ }^{10-15}$ This borylation is efficient in the case of pinacol- and catecholboranes, but only poor yield was achieved with 9-borabicyclo[3.3.1]nonane (9-BBN). 

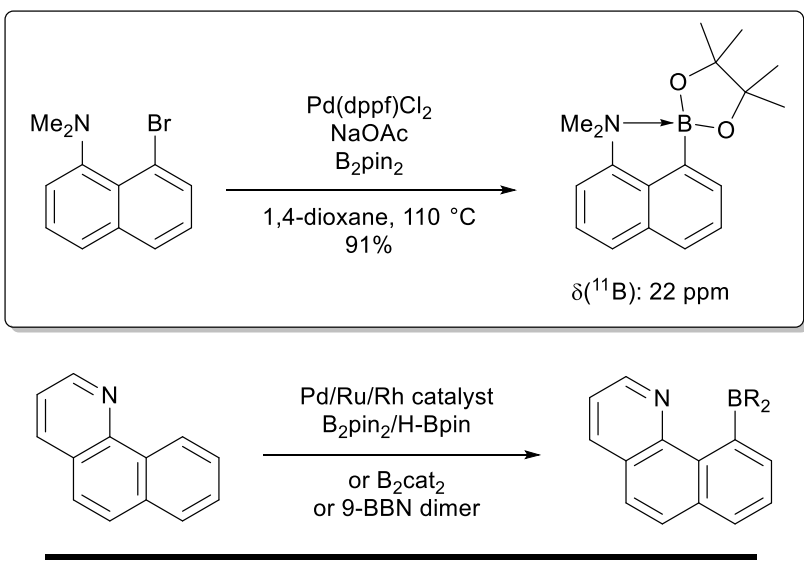

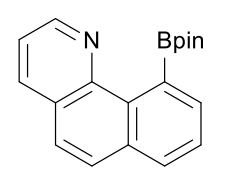

$10-90 \%$ $\delta\left({ }^{11} \mathrm{~B}\right): 30 \mathrm{ppm}$

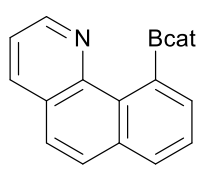

$82 \%$

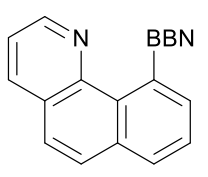

$10 \%$

Scheme 2 Transition-metal-catalysed borylations of naphthalene (top) and benzo[h]quinoline (bottom) scaffolds.

Diels-Alder reactions with borylbenzynes. Akai et al. reported in 2010 a two-step synthesis of a functionalized naphthyl-bridged amine-borane. It starts by Diels-Alder (DA) reaction of borylbenzynes with pyrroles (Scheme 3). ${ }^{16}$ Using borylated o-iodophenyl triflates as benzyne precursors, the DA adducts were prepared in good to excellent yields and high regioselectivity. According to DFT calculations, the regioselectivity of these DA reactions is controlled by electrostatic effects and the aryne distortion induced by the boryl group. ${ }^{17}$ Acid-catalysed isomerization with $p$ $\mathrm{TsOH}$ then proceeds easily and quantitatively to give the corresponding N-B naphthyl compound.

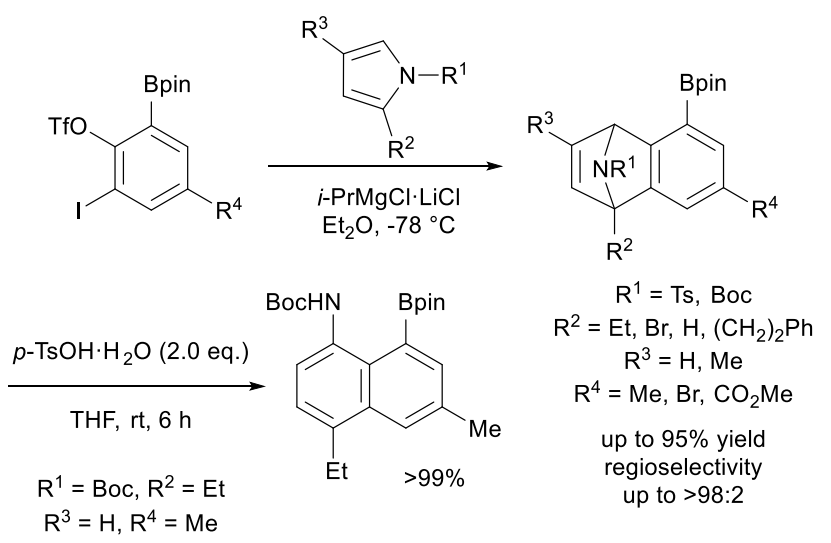

Scheme 3 Synthesis of a naphthyl-bridged amine-borane by Diels-Alder reaction of borylbenzynes with substituted pyrroles, followed by acid-catalysed isomerization.

Probing the presence and strength of $\mathrm{E}^{15} \rightarrow \mathrm{E}^{13}$ interactions.

Spectroscopic parameters. NMR spectroscopy is a very powerful tool in the assessment of the electronic state of both peri substituents, providing valuable insight into their $D \rightarrow A$ relationship and allowing for (preliminary) evaluation of the structural and bonding situation as well as potential reactivity. Whenever possible, relevant NMR data will be summarized, compared and discussed. Notably, in the case of boron, ${ }^{11} \mathrm{~B}$ NMR is highly sensitive and diagnostic with respect to the degree 
of coordination about the B centre. Tricoordinate B centres typically display NMR signals in the range of $80-30$ ppm while tetracoordinate $B$ centres display signals from 20 to -20 ppm, depending on the substituents on $\mathrm{B}$. Similarly, the signal observed by ${ }^{31} \mathrm{P} N M R$ is highly indicative of the $P$ environment. It is a good probe for the interaction of the $\mathrm{P}$ lone pair (Ip) with the acceptor moiety. Note that typical coupling descriptors have been used to describe the NMR signals (s, singlet; $d$, doublet; t, triplet; q, quartet; pseudo q: 1:1:1:1 P-B coupling; br: broad).

Structural parameters. Two limit forms can be envisioned for peri-substituted (ace)naphthalenes: one open form, free of a $E^{15} \rightarrow E^{13}$ interaction, and one closed form, with a $E^{15} \rightarrow E^{13}$ interaction. When suitable crystals can be obtained, $\mathrm{X}$-ray diffraction analysis is the most diagnostic way to assess the structure adopted by a given compound, although in some cases crystal packing may come into play and the solid-state structure may not be representative of the ground state. Whenever available, the relevant structural parameters (Chart 2) will be highlighted and compared to assess the bonding situation, particularly with respect to the possible $\mathrm{E}^{15} \rightarrow \mathrm{E}^{13}$ interaction. The distance between the two elements $\left(\mathrm{E}^{15}-\mathrm{E}^{13}\right)$ is a pivotal indicator. In addition, the ratio between the $E^{15}-E^{13}$ distance and the sum of the covalent radii of the respective elements, referred to as $r$, is most useful when comparing the strength of $D \rightarrow A$ interactions across different elements. The stronger the $\mathrm{E}^{15} \rightarrow \mathrm{E}^{13}$ interaction is, the closer the $r$ value to 1 is.

The propensity of the (ace)naphthene framework to enforce or prevent the formation of $\mathrm{E}^{15} \rightarrow \mathrm{E}^{13}$ donor-acceptor interactions can also be assessed by the geometry of the $\mathrm{E}^{13}$ centre. When possible, the sum of angles about $\mathrm{E}^{13}\left(\Sigma_{\alpha} \mathrm{E}^{13}\right)$ will be reported as an evaluation of the pyramidalization of the $\mathrm{E}^{13}$ centre. A trigonal planar centre free of $\mathrm{E}^{15} \rightarrow \mathrm{E}^{13}$ interaction has $\Sigma_{\alpha} \mathrm{E}^{13}=360^{\circ}$ and the sum of angles $\Sigma_{\alpha} \mathrm{E}^{13}$ decreases as the $\mathrm{E}^{15} \rightarrow \mathrm{E}^{13}$ interaction strengthens. When dealing with four-coordinate $\mathrm{E}^{13}$ elements, the tetrahedral character (THC), as introduced by Höpfl et al. to evaluate $N \rightarrow B$ interactions, $^{18}$ is a valuable complementary descriptor. Whenever relevant, it is reported and correlated to the $\mathrm{E}^{15} \rightarrow \mathrm{E}^{13}$ bond length, to assess the strength of the $\mathrm{E}^{15} \rightarrow \mathrm{E}^{13}$ interaction.

The bay angles, $\mathrm{E}^{15}-\mathrm{C}_{\text {peri }}-\mathrm{C}_{\text {bridge }}, \mathrm{C}_{\text {peri }}-\mathrm{C}_{\text {bridge }}-\mathrm{C}_{\text {peri }}$ and $\mathrm{C}_{\text {bridge }}-\mathrm{C}_{\text {peri }}-\mathrm{E}^{13}$, and their deviation from the ideal $120^{\circ}$ value provides an idea of the extent of in-plane distortion of the (ace)naphthalene scaffolds. On the other hand, out-of-plane distortion can be evaluated using torsion angles, most commonly $\varphi=E^{15}-C_{\text {peri }} \cdots C_{\text {peri }}-E^{13}$, as well as the deviations of the peri groups from the mean (ace)naphthalene plane $\left(\alpha / \alpha^{\prime}\right.$ or $d / d^{\prime}$, recall Chart 2). The (ace)naphthalene scaffold itself can distort to respond to and accommodate significant steric crowding imposed by both peri substituents. This is generally assessed by torsion angles of the two six-membered rings around the central $\mathrm{C}-\mathrm{C}$ bond. 


$$
r=\frac{d\left(E^{15}-E^{13}\right)}{r_{\operatorname{cov}}\left(E^{15}\right)+r_{c o v}\left(E^{13}\right)}
$$
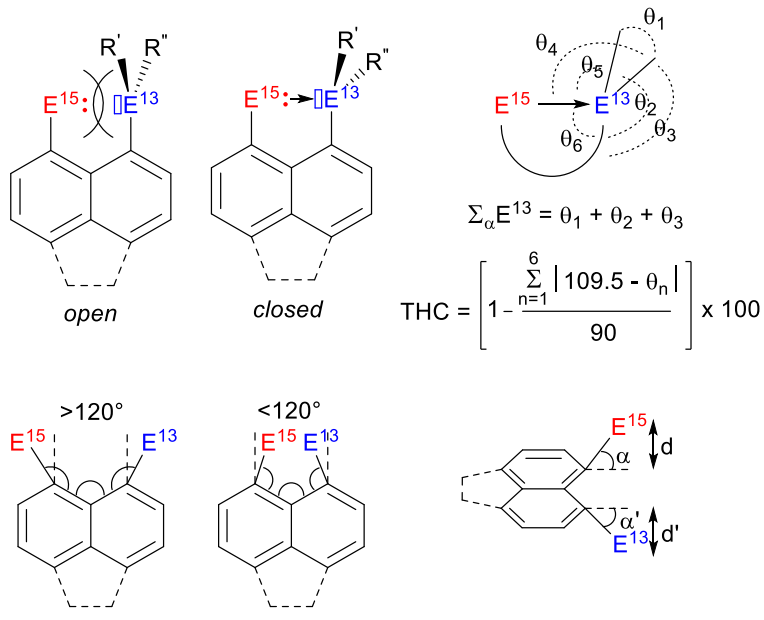

out-of plane distortion

in-plane distortion of bay angles

measured by $\alpha / \alpha^{\prime}$ and/or $d / d^{\prime}$

Chart 2 Schematic representation of the most relevant structural parameters used to describe the $\mathrm{E}^{15} \rightarrow \mathrm{E}^{13}$ interaction and the (ace)naphthalene distortion.

Peri-Interaction Energy. To assess the stabilisation/destabilisation induced by the presence of $\mathrm{E}^{15} / \mathrm{E}^{13}$ peri substituents in (ace)naphthalene scaffolds, Mebs, Beckmann et al. refer to the periinteraction energy $(\alpha-P I E) .{ }^{19}$ This calculation involves an isodesmic reaction between the disubstituted compound $\mathrm{E}^{15}-\mathrm{E}^{13}$, the unsubstituted compound $\mathrm{HH}$ and the two monosubstituted compounds $E^{15} \mathrm{H}$ and $E^{13} \mathrm{H}$ (Scheme 4). This parameter accounts for the stabilization achieved through the $\mathrm{D} \rightarrow \mathrm{A}$ interaction between $\mathrm{E}^{15}$ and $\mathrm{E}^{13}$ while also considering the loss in energy via the steric repulsion encountered by the peri substituents and the distortion induced by the presence of $\mathrm{E}^{15}$ and $\mathrm{E}^{13}$ in such close proximity. In effect, the $\alpha$-PIE is a measure of the gain or loss in energy upon the juxtaposition of $E^{15}$ and $E^{13}$. Negative $\alpha$-PIE energies are indicative of regular Lewis pairs with attractive peri interactions, while repulsive peri interactions result in positive $\alpha$-PIE values, classifying these derivatives as frustrated Lewis pairs (FLPs). As highlighted by Mebs and Beckmann, in certain cases, regular Lewis pairs may display positive $\alpha$-PIE values. This is when peri interactions are predominantly repulsive despite the presence of $a \mathrm{E}^{15} \rightarrow \mathrm{E}^{13}$ interaction.

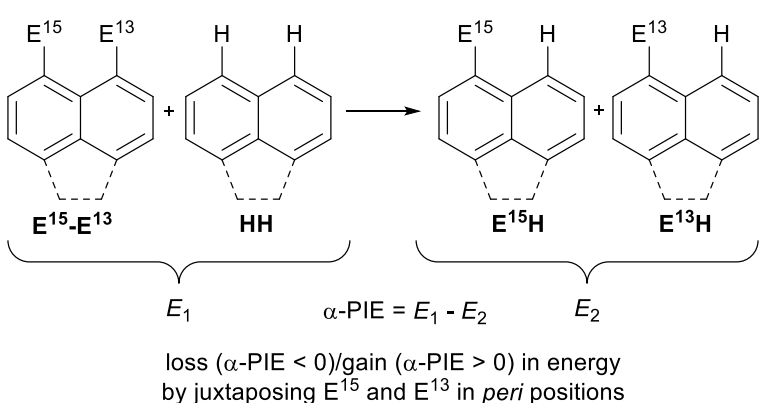

Scheme 4 Isodesmic reaction for the calculation of $\alpha$-PIE.

\section{1. (Ace)naphthalene N-B derivatives}

One of the first $\mathrm{E}^{15}-\mathrm{E}^{13}$ peri-substituted naphthalene compound described was the amine-borane 1, synthesised in 1988 in low yield by quenching 8-lithio- $N, N$-dimethyl-1-naphthylamine with $\mathrm{BF}_{3} \cdot \mathrm{OEt}_{2}$ in the presence of excess $n$-BuLi (Scheme 5). ${ }^{20}$ While not characterised in the solid-state, ${ }^{11} \mathrm{~B}$ NMR spectroscopy points to the presence of a tetracoordinate $B$ centre with an upfield signal at $9.1 \mathrm{ppm}$. 
The strength of the $\mathrm{N} \rightarrow \mathrm{B}$ interaction was evidenced by the resistance of this derivative to oxidation even under harsh conditions (refluxing with $3 \mathrm{M} \mathrm{NaOH}$ and $30 \% \mathrm{H}_{2} \mathrm{O}_{2}$ ).

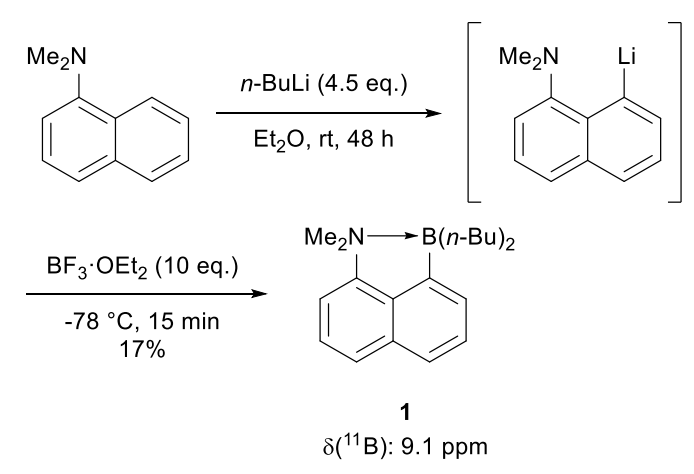

Scheme 5 Synthesis of the N-B naphthalene derivative 1.

Boronic acid derivative $\mathbf{2}^{21}$ (Scheme 6) also displays intramolecular $\mathrm{N} \rightarrow \mathrm{B}$ interaction as apparent from its ${ }^{11} \mathrm{~B}$ NMR signal at $10.6 \mathrm{ppm}$ which is shifted upfield by $18 \mathrm{ppm}$ with respect to that of 1 naphthaleneboronic acid $(28.6 \mathrm{ppm}) .^{22}$ The strong $\mathrm{N} \rightarrow \mathrm{B}$ interaction prevents 2 from undergoing Suzuki-Miyaura coupling reactions. Whatever the conditions used, the boronic acid was recovered unreacted. When the reaction of the lithiated amine with $\mathrm{B}(\mathrm{OMe})_{3}$ was followed by basic instead of acidic work-up, the corresponding boroxine 3 was obtained in 69\% isolated yield, as described by Whiting et al. in 2003 (Scheme 6). ${ }^{23}$ Boroxines are usually planar and aromatic due to delocalization of three $\mathrm{O}$ lone pairs over the six-membered ring. In marked contrast, the $\mathrm{X}$-ray diffraction analysis performed on 3 revealed that the amino-naphthyl group forces intramolecular $\mathrm{N} \rightarrow \mathrm{B}$ interactions and distorts the central $(\mathrm{BO})_{3}$ ring from planarity. All three $\mathrm{N}-\mathrm{B}$ distances are similar $(1.902(4)$ to $1.978(4) \AA)$ and are relatively long compared to the sum of $N$ and $B$ covalent radii $\left(1.55 \AA^{24}, r=1.23\right.$ to 1.28 ) while the $B$ centres are significantly pyramidalized $\left(\Sigma_{\alpha} B=348.96^{\circ}, \mathrm{THC}=45 \%\right)$.

The $N \rightarrow B$ interaction does not quench reactivity of the $B$ centre in $\mathbf{3}$ as illustrated by the formation of the corresponding pinacol boronate ester $\mathbf{4}$ and difluoroborane $\mathbf{5}$ (Scheme 6). The boron centre of $\mathbf{4}$ is more Lewis acidic than that of the boroxine $\mathbf{3}$, resulting in a stronger intramolecular $\mathrm{N} \rightarrow \mathrm{B}$ interaction. This is apparent from the shorter $N-B$ distance $(1.832(7) \AA, r=1.18)$ and a more pyramidalized $\mathrm{B}$ centre $\left(\Sigma_{\alpha} \mathrm{B}=342.8^{\circ}, \mathrm{THC}=59 \%\right)$. Compound 5 is an interesting case that highlights the faculty of the naphthyl scaffold to enforce and strengthen $\mathrm{N} \rightarrow \mathrm{B}$ interactions. Accordingly, the reaction with $\mathrm{KHF}_{2}$ stops at the amine-difluoroborane and the corresponding ammonio trifluoroborate was not formed even under forcing conditions. ${ }^{9,23}$ The number of fluorine atoms introduced at boron is easily deduced from the coupling pattern of the ${ }^{11} \mathrm{~B} N M R$ signal (triplet in the case of 5 with ${ }^{1} J_{B-F}=56.4 \mathrm{~Hz}$ ). The X-ray structure of 5 was reported recently by Pla, Gras et al. ${ }^{8}$ The $\mathrm{N}-\mathrm{B}$ distance is short $(1.726(2) \AA, r=1.11)$ and the $\mathrm{B}$ centre is highly pyramidalized $\left(\Sigma_{\alpha} \mathrm{B}=341.8^{\circ}\right.$, THC $=68 \%$ ). In addition, the naphthyl scaffold distorts to respond the increased Lewis acidity at $B$ and accommodate the strong $\mathrm{N} \rightarrow \mathrm{B}$ interaction: the bond angles at the peri positions significantly deviate from the ideal value of $120^{\circ}$ to $111.55^{\circ}\left(\mathrm{N}-\mathrm{C}_{\text {peri }}-\mathrm{C}_{\text {bridge }}\right)$ and $108.99^{\circ}\left(\mathrm{B}-\mathrm{C}_{\text {peri }}-\mathrm{C}_{\text {bridge }}\right) .^{9}$ Calculations by Mebs, Beckmann et al. accurately reproduce the N-B bond length in $\mathbf{5}(1.798 \AA$ ), and classify this derivative as a regular Lewis pair with an attractive peri interaction as determined through a negative $\alpha$-PIE $(-43.6 \mathrm{~kJ} / \mathrm{mol}) .{ }^{25}$ Conversely and contrary to experimental results, all attempts to optimize a Lewis pair form with $\mathrm{N} \rightarrow \mathrm{B}$ interaction for 4 resulted in an open FLP form. The computed $\mathrm{N}-\mathrm{B}$ distance is long $(2.526 \AA)$ and $\alpha$-PIE is positive $(21.2 \mathrm{~kJ} / \mathrm{mol}) .{ }^{25}$ Dispersion effects 
and crystal packing are presumed to be responsible for the closed structure observed experimentally.

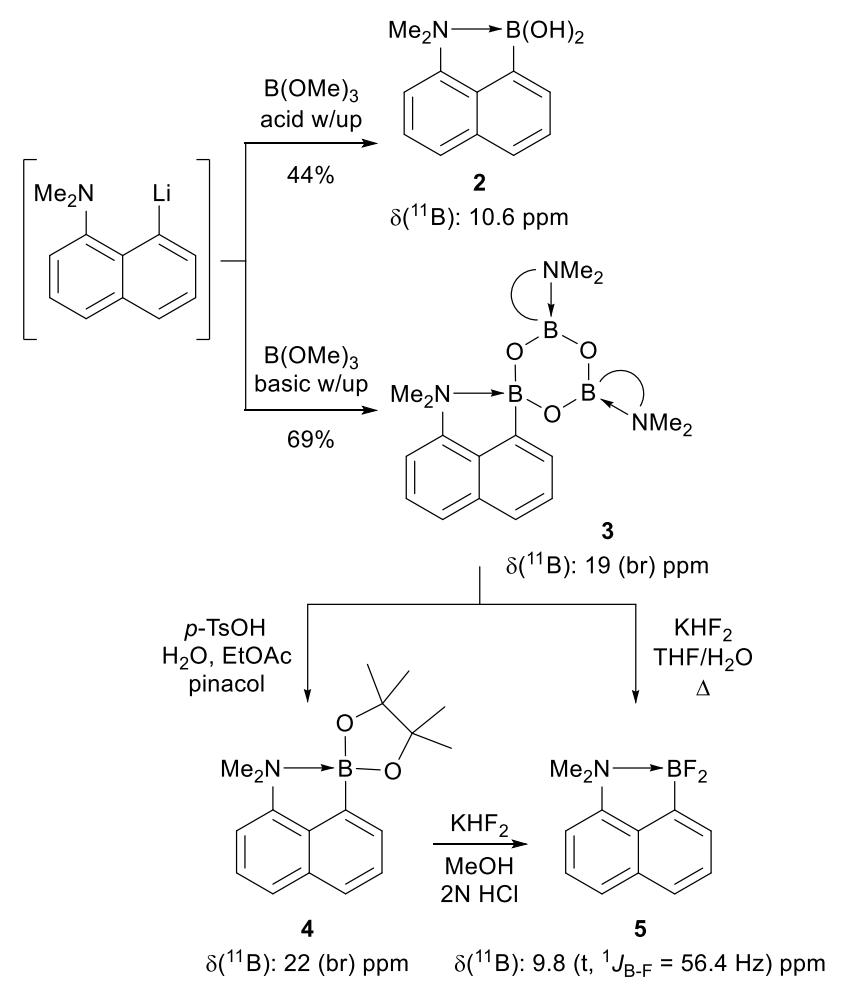

Scheme 6 Synthesis of the boronic acid 2 and boroxine 3, subsequent reactivity at boron.

The same report by Pla, Gras et al. highlighted the importance of the scaffold in enforcing or preventing the formation of intramolecular $\mathrm{N} \rightarrow \mathrm{B}$ interactions. ${ }^{9}$ Using the more rigid acenaphthyl limits possible distortions in the scaffold and deviations of the peri positions from their ideal geometry. This framework maintains $\mathrm{N}$ and $\mathrm{B}$ at longer distance than the naphthyl backbone, which given the size of the two atoms, prevents the formation of strong $N \rightarrow B$ interaction. This situation was first exemplified by pinacol derivative 6 (Scheme 7). Its ${ }^{11} B$ NMR signal is $\sim 10 \mathrm{ppm}$ downfield to that of 4 , the geometry at $B$ remains trigonal planar $\left(\Sigma_{\alpha} B=360^{\circ}\right)$ and the $N-B$ distance $(2.773(2) \AA)$ is far away from the sum of covalent radii $(r=1.79)$. The absence of $N \rightarrow B$ interaction was confirmed computationally: the $\mathrm{N}-\mathrm{B}$ distance is long $(2.855 \AA)$ and $\alpha$-PIE is positive $(26.9 \mathrm{~kJ} / \mathrm{mol}) .{ }^{25}$ Contrary to what was observed with the naphthyl scaffold and due to the lack of $N \rightarrow B$ interaction in the acenaphthyl boronate ester $\mathbf{6}$, treatment with $\mathrm{KHF}_{2}$ gave access to the ammonio trifluoroborate 7 .

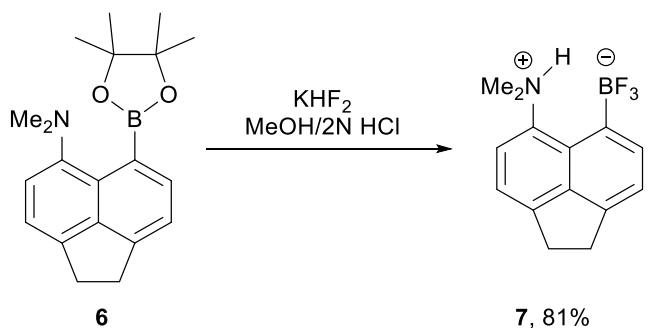

$\delta\left({ }^{11} \mathrm{~B}\right): 31.9 \mathrm{ppm}$ $\delta\left({ }^{11} \mathrm{~B}\right): 4.0\left(\mathrm{q},{ }^{1} \mathrm{~J}_{\mathrm{B}-\mathrm{F}}=54.4 \mathrm{~Hz}\right) \mathrm{ppm}$

Scheme 7 Structure of the pinacol ester 6 and its conversion into the ammonio trifluoroborate 7.

Mesityl groups were then introduced at boron to prevent $\mathrm{N} \rightarrow \mathrm{B}$ interaction (Scheme 8). ${ }^{9}$ They are less electron donating than pinacol, but impart huge steric protection. Derivatives $\mathbf{8}$ and $\mathbf{9}$ have downfield ${ }^{11} \mathrm{~B}$ chemical shifts, 68.1 and $74.0 \mathrm{ppm}$, respectively, suggesting trigonal planar $\mathrm{B}$ centres 
with minimal $\mathrm{N} \rightarrow \mathrm{B}$ interactions. This bonding situation is confirmed in the solid state with $\mathrm{N}-\mathrm{B}$ distances of 2.866(2) $\AA(r=1.85)$ and 3.025(2) $\AA(r=1.95)$ for 8 and 9, respectively (the acenaphthalene spacer increases the peri distance). The upfield ${ }^{11} \mathrm{~B}$ signal of $\mathbf{8}$, compared to $\mathbf{9}$, is consistent with the significantly shorter $N-B$ distance and is indicative of a very weak $N \rightarrow B$ interaction. This was corroborated by Natural Bond Orbital (NBO) analyses where calculated $D \rightarrow A$ interactions show the $\mathrm{N} \rightarrow \mathrm{B}$ stabilization energy to be twice as large in 8 than in $\mathbf{9}$ (8.3 and 4.4 $\mathrm{kcal} / \mathrm{mol}$, respectively). ${ }^{9}$ Additional calculations by Mebs, Beckmann et al. classify both $\mathbf{8}$ and $\mathbf{9}$ as FLPs: the N-B distances are well-reproduced (2.992 and $3.095 \AA$, respectively) and the $\alpha$-PIE are very positive ( 33.2 and $31.5 \mathrm{~kJ} / \mathrm{mol}$, respectively). ${ }^{25}$ The weakness of these interactions explains that the $\mathrm{B}$ centre remains about trigonal planar in 8 and $9\left(\Sigma_{\alpha} \mathrm{B}=358.2\right.$ and $358.4^{\circ}$, respectively). Nonetheless, steric congestion causes significant deviations of the peri groups from the mean (ace)naphthalene planes. The most significant displacement is the out-of-plane deviation of B (by 0.343 and $0.310 \AA$ for $\mathbf{8}$ and $\mathbf{9}$, respectively).

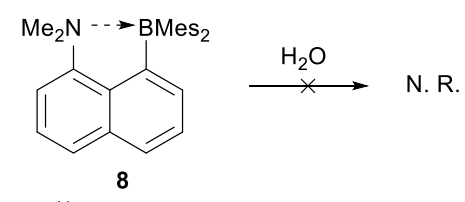

$\delta\left({ }^{11} \mathrm{~B}\right): 68.1 \mathrm{ppm}$

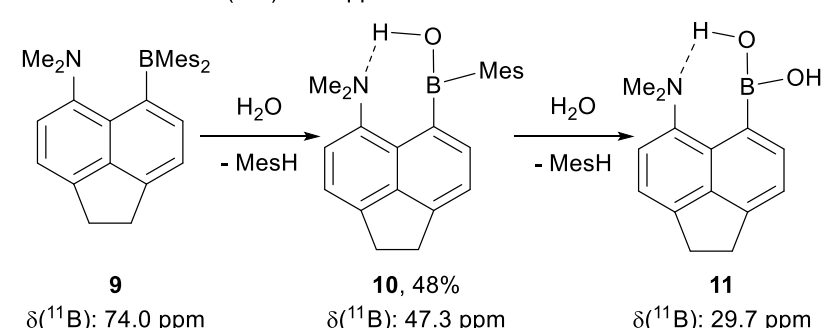

Scheme 8 Structures of the N-BMes 2 acenapthalene compounds 8 and $\mathbf{9}$, reaction of $\mathbf{9}$ with $\mathrm{H}_{2} \mathrm{O}$.

Of note, the slight difference in stereoelectronics between 8 and $\mathbf{9}$ confers drastically different reactivity profiles. While 8 is unreactive towards $\mathrm{H}_{2} \mathrm{O}, 9$ reacts with $\mathrm{H}_{2} \mathrm{O}$ in a stepwise fashion to give the borinic acid $\mathbf{1 0}$ and finally the boronic acid $\mathbf{1 1}$ (Scheme 8). This reaction most likely involves FLP activation of water, resulting in the proto-deboronation of the mesityl groups. The structures of the borinic and boronic acids 10 and 11, with long N-B distances of $3.140 \AA(r=2.03)$ and $3.170 \AA(r=$ 2.05), respectively, further evidence the role of the acenaphthalene scaffold in preventing $N \rightarrow B$ interactions. Instead, and in contrast to what was observed in the naphthyl boronic acid 2, compounds $\mathbf{1 0}$ and $\mathbf{1 1}$ are engaged in intramolecular $\mathrm{Me}_{2} \mathrm{~N} \cdots \mathrm{H}-\mathrm{O}$ hydrogen bonding.

Steric repulsions at $\mathrm{B}$ can be overcome and $\mathrm{N} \rightarrow \mathrm{B}$ interaction can be enforced by increasing Lewis acidity at $\mathrm{B}$ with electron-withdrawing pentafluorophenyl groups, as shown by Mitzel et al. ${ }^{26}$ in 2012 with the amine-borane 12 (Chart 3). The upfield ${ }^{11} \mathrm{~B} N M R$ signal at $4.8 \mathrm{ppm}$ is indicative of a tetracoordinate and pyramidalized $B$ centre. This is further corroborated by the small separation in chemical shifts between the $m$ - and $p$ - F signals by ${ }^{19} \mathrm{~F}$ NMR spectroscopy $\left(\Delta \delta^{19} \mathrm{~F}_{\mathrm{m}-\mathrm{p}}=6.6<10 \mathrm{ppm}\right) .{ }^{27}$ The presence of strong intramolecular $\mathrm{N} \rightarrow \mathrm{B}$ interaction in $\mathbf{1 2}$ was confirmed crystallographically. The N-B distance is short at 1.742(2) $\AA(r=1.12)$ but not as much as in the related unconstrained derivative $\mathrm{Me}_{2} \mathrm{~N}\left(\mathrm{CH}_{2}\right)_{3} \mathrm{~B}\left(\mathrm{C}_{6} \mathrm{~F}_{5}\right)_{2}\left(1.672(2) \mathrm{A}^{\circ}, r=1.08\right) .{ }^{28}$ The $\mathrm{B}$ centre is in a strongly pyramidalized environment $\left(\Sigma_{\alpha} \mathrm{B}=337.9^{\circ}\right.$, THC $\left.=63 \%\right)$ while the naphthalene scaffold remains fairly coplanar $\left(C_{1^{-}}\right.$ $\mathrm{C}_{9}-\mathrm{C}_{10}-\mathrm{C}_{5}$ torsion angle of $\left.0.77^{\circ}\right)$. Small displacements out of the mean naphthalene plane for $\mathrm{N}$ and $\mathrm{B}(0.140$ and $0.203 \AA$, respectively $)$ enable the substituents at $\mathrm{N}$ and $\mathrm{B}$ to not be eclipsed and thereby 
minimize steric repulsions. The flexibility of the naphthalene scaffold to accommodate the $N \rightarrow B$ interaction is evidenced by distortions in the peri bond angles of $110.6(1)^{\circ}\left(\mathrm{B}-\mathrm{C}_{\text {peri }}-\mathrm{C}_{\text {bridge }}\right)$ and $109.6(1)^{\circ}\left(\mathrm{N}-\mathrm{C}_{\text {peri }} \mathrm{C}_{\text {bridge }}\right)$. The strength of this interaction was confirmed by calculations which accurately reproduced the $\mathrm{N}-\mathrm{B}$ bond length $(1.753 \AA$ ) and classify 12 as a regular Lewis pair with a very negative $\alpha$-PIE $(-42.7 \mathrm{~kJ} / \mathrm{mol}) .{ }^{25}$

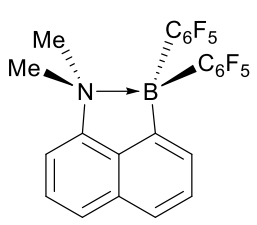

12

$\delta\left({ }^{11} \mathrm{~B}\right): 4.8 \mathrm{ppm}$ $\Delta \delta\left({ }^{19} \mathrm{~F}_{\mathrm{m}-\mathrm{p}}\right): 6.6 \mathrm{ppm}$
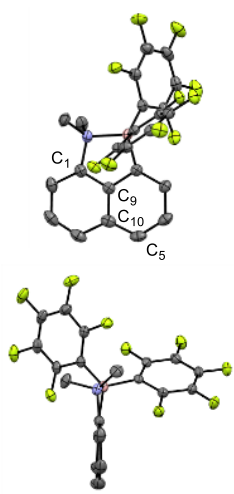

Chart 3 Structure of the $\mathrm{N}-\mathrm{B}\left(\mathrm{C}_{6} \mathrm{~F}_{5}\right)_{2}$ derivative 12 (front and side views); carbon in grey, nitrogen in blue, boron in pink, fluorine in green and $\mathrm{H}$ atoms omitted for clarity.

Yamamoto, Akiba et al. reported in 2002 the only N-B compounds based on an anthracene scaffold, obtained in six steps from commercially available 1,8-dichloroanthroquinone (Scheme 9). ${ }^{29}$ As substantiated by $X$-ray diffraction analyses, only one $N$ atom interacts with $B$, the other remains at non-bonding distance ( $2.90 \AA$ ). Comparison of the structural parameters for the three derivatives revealed significant differences according to the boron Lewis acidity at $B$ : the $N-B$ bond length decreases from 1.809(2) Å for 13, to 1.739(2) Å for 14, and 1.664(3) Å for 15, $(r=1.17,1.12$ and 1.07, respectively) while the pyramidalization at $B$ increases $\left(\Sigma_{\alpha} B=346.2,344.4\right.$ and $342.3^{\circ} ; \mathrm{THC}=53 \%$, $55 \%$ and $57 \%$ for 13,14 and 15 , respectively). Thus, despite the rigidity of the anthracene moiety, the $\mathrm{N} \rightarrow \mathrm{B}$ interaction responds to the $\mathrm{B}$ Lewis acidity and strengthens in the series $\mathrm{B}\left(1,2-\mathrm{O}_{2} \mathrm{C}_{6} \mathrm{H}_{4}\right)<$ $\mathrm{BMe}_{2}<\mathrm{BCl}_{2}$.

Given the presence of two equivalent N-donors, a switch of boron from one side to the other was expected to occur. At room temperature, the ${ }^{1} \mathrm{H}$ NMR spectra of all compounds showed symmetrical anthracene patterns, and peaks maintained their sharpness, even upon cooling to $-80{ }^{\circ} \mathrm{C}$. These observations indicate that the switch of $\mathrm{B}$ between the coordination of either $\mathrm{N}$ is rapid on the NMR timescale in solution even at low temperature. The energy barrier associated with this process is too low to be measured. The structure with the two $\mathrm{N}$ atoms interacting with $\mathrm{B}$ (pentacoordinate, $\mathrm{S}_{\mathrm{N}}^{2}$-type transition state) does not lie much higher in energy than the unsymmetrical tetracoordinate ground-state form.

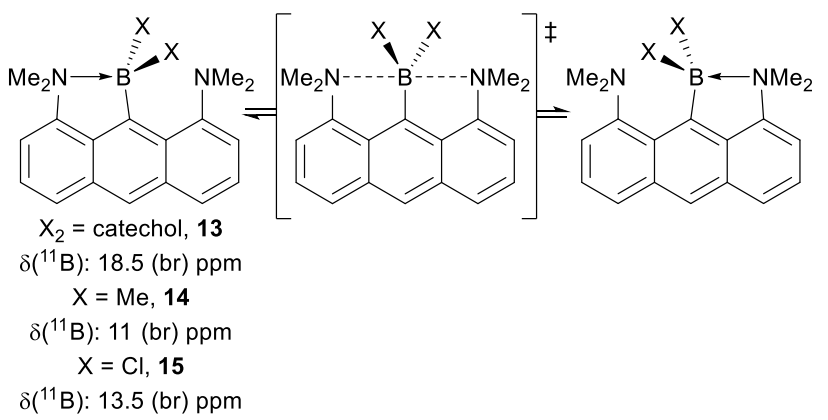

Scheme 9 Anthracene derivatives 13-15 and their dynamic equilibrium. 


\section{2. (Ace)naphthalene $\mathrm{N}-\mathrm{E}^{13}$ derivatives $\left(\mathrm{E}^{13}=\mathrm{Al}, \mathrm{Ga}, \mathrm{In}, \mathrm{TI}\right)$}

In parallel to amine-boranes, the naphthyl scaffold has also been shown to support intramolecular $\mathrm{N} \rightarrow \mathrm{E}^{13}$ interactions with heavier group 13 elements ( $\mathrm{Al}, \mathrm{Ga}, \mathrm{In}$ and $\mathrm{Tl}$ ). The synthetic route used to access these derivatives parallels that developed for their $\mathrm{B}$ homologues. They were prepared by trapping a peri lithiated naphthyl amine with an electrophilic $\mathrm{E}^{13} \mathrm{Cl}_{\mathrm{n}}$ derivative.

Among the first examples were the amine dichloro and dibromo-alanes 16 and $\mathbf{1 7}$ reported by Meiler et al. in 1998 (Chart 4). ${ }^{30}{ }^{27} \mathrm{Al}$ NMR spectroscopic data ( $\delta 129-131 \mathrm{ppm}$ ) are consistent with tetracoordinate $\mathrm{Al}$ centres, supporting the presence of $\mathrm{N} \rightarrow \mathrm{Al}$ interactions. Cowley, Jones et al. crystallographically confirmed this bonding situation for 16 in 2000. ${ }^{31}$ The N-Al distance (2.016(4) $\AA$ ) only marginally exceeds the sum of the covalent radii $\left(1.92 \AA,{ }^{24} r=1.05\right)$. It is slightly longer than that observed in the related unconstrained derivative $o-\left(\mathrm{Me}_{2} \mathrm{NCH}_{2}\right) \mathrm{C}_{6} \mathrm{H}_{4} \mathrm{AlCl}_{2}(1.994(2) \AA, r=1.04){ }^{30}$ The Al centre of 16 is noticeably pyramidalized $\left(\Sigma_{\alpha} \mathrm{Al}=347.12^{\circ}, \mathrm{THC}=52 \%\right)$ while the $\mathrm{N}$ and $\mathrm{Al}$ centres only slightly deviate from the mean naphthyl plane (displacements of 0.208 and $0.107 \AA$, respectively). Of note, aluminum is generally a stronger Lewis acid than boron towards nitrogen Lewis bases. Combined with the larger size of Al compared to B (by about 43\%), this makes the formation of $\mathrm{N} \rightarrow \mathrm{E}^{13}$ interaction more favoured with $\mathrm{Al}$ than with $\mathrm{B}$ because bridging the peripositions requires less distortions with $\mathrm{Al}$. This is apparent from the smaller deviations of the $\mathrm{N}-\mathrm{C}_{\text {peri- }}$ $\mathrm{C}_{\text {bridge }}$ and $\mathrm{E}^{13}-\mathrm{C}_{\text {peri }}-\mathrm{C}_{\text {bridge }}$ bond angles from the ideal $120^{\circ}$ values observed in 16 (116.16 and $107.48^{\circ}$, respectively) than in the corresponding amine dichloroborane 15 (109.45 and $\left.104.47^{\circ}\right)$.

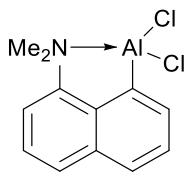

16

$\delta\left({ }^{27} \mathrm{Al}\right): 129 \mathrm{ppm}$

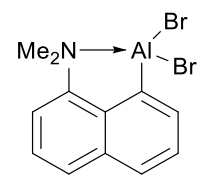

17

$\delta\left({ }^{27} \mathrm{Al}\right): 131 \mathrm{ppm}$

Chart 4 Dichloro- and dibromo-alane derivatives 16 and 17.

Despite the strong $\mathrm{N} \rightarrow \mathrm{Al}$ interaction, 16 maintains reactivity at the Al centre. The reaction of 16 with $\mathrm{LiAlH}_{4}$ provided the corresponding aluminum dihydride derivative $\mathbf{1 8}$ (Scheme 10). ${ }^{31}$ The solidstate structure of $\mathbf{1 8}$ shows it to be dimeric and centrosymmetric. The geometry about Al is best described as distorted trigonal bipyramidal with the $\mathrm{N}$ and one of the bridging $\mathrm{H}$ atoms in axial positions $\left(168.9(2)^{\circ}\right)$. The sum of the angles of the remaining equatorial ligands $\left(H_{\text {bridge }} H\right.$ and $\mathrm{C}_{\text {Naphthyl }}$ ) about $\mathrm{Al}$ is $359.7^{\circ}$, indicating coplanarity. The Al-N bond distance in 18 (2.118(3) $\left.\AA, r=1.10\right)$ is slightly longer than that observed in the dichloroalane precursor $\mathbf{1 6}$, in line with reduced Lewis acidity at $\mathrm{Al}$.

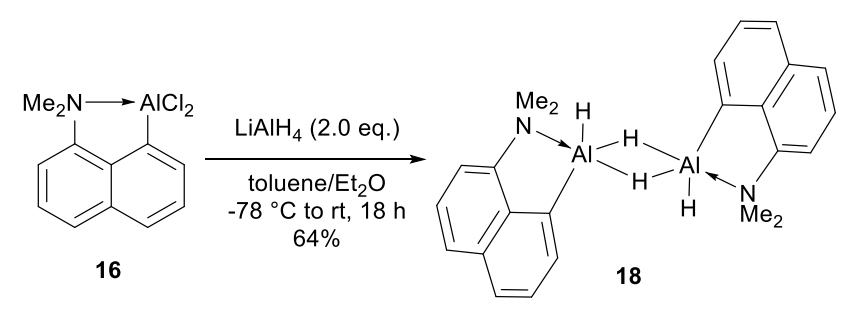

Scheme 10 Reaction of 16 with $\mathrm{LiAlH}_{4}$ to give the aluminum dihydride 18.

The reaction of 16 with organolithium reagents ( $M$ eLi and $t$-BuLi) resulted in redistribution reactions and formation of the bis-naphthyl N-Al-N complexes (19 and 20), as established by ${ }^{1} \mathrm{H}$ NMR 
spectroscopy, elemental analysis and mass spectrometry (Scheme 11). ${ }^{31}$ The dinaphthyl-ethylalane derivative $\mathbf{2 1}$ was independently synthesised by Schumann et al. in 2004 by reacting two equivalents of 8-lithio- $\mathrm{N}, \mathrm{N}$-dimethyl-1-naphthylamine with EtAlCl $2 .{ }^{32}$ The ${ }^{27} \mathrm{Al} \mathrm{NMR}$ chemical shift for 21 is significantly upfield (113 ppm), indicative of pentacoordination of the Al centre. In the solid-state structure of 21, $\mathrm{N} \rightarrow \mathrm{Al}$ interactions with larger and slightly different bond lengths $(2.244(2)$ and 2.265(2) $\AA, r=1.17$ and 1.18) were observed. The geometry at $\mathrm{Al}$ is an almost perfect trigonal bipyramid, the axial $\mathrm{NMe}_{2}$ ligands form an angle of $174.62(6)^{\circ}$ about Al. However, steric repulsions between the substituents at $\mathrm{N}$ and Al force strong out-of-plane deviations (by 0.628 and $0.863 \AA$ for Al, by 0.299 and $0.399 \AA$ for $N$, the two atoms sitting on opposite sides of the mean naphthyl planes). One naphthyl backbone itself is significantly twisted in the core (torsion angle: $11.49^{\circ}$ ), while the other remains fairly planar (torsion angle: $4.72^{\circ}$ ).

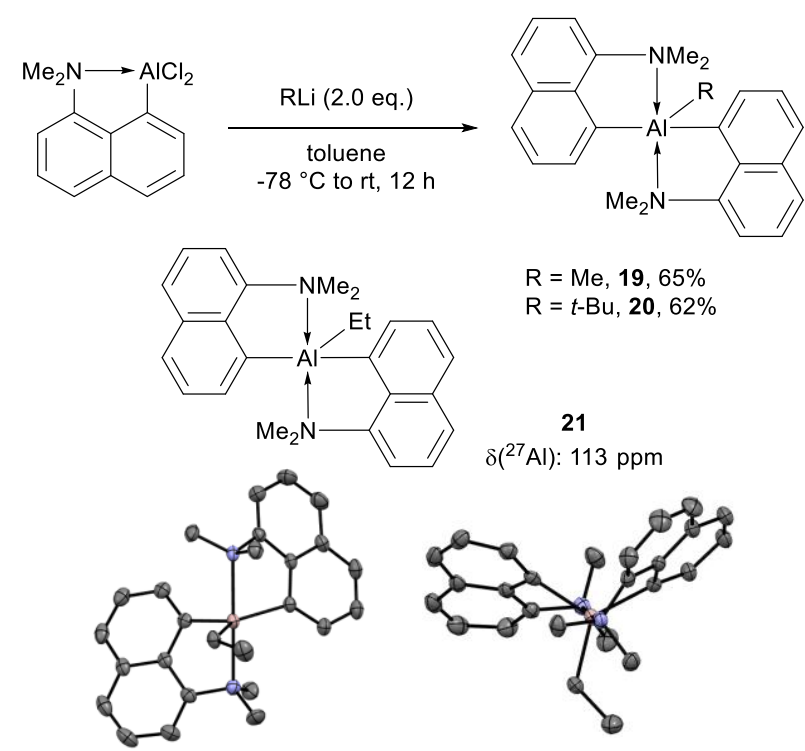

Scheme 11 Synthesis of derivatives 19 and $\mathbf{2 0}$ and structure of $\mathbf{2 1}$ (front and top views), with carbon in grey, nitrogen in blue, aluminum in pink and $\mathrm{H}$ atoms omitted for clarity.

The related $\mathrm{N}$-Al dialkylalanes 22-24 were synthesized by reacting 8-lithio- $N, N$-dimethyl-1naphthylamine with one equivalent of $\mathrm{R}_{2} \mathrm{AICl}\left(\mathrm{R}=\mathrm{Me}\right.$, Et, $i$-Bu). The observed ${ }^{27} \mathrm{Al} N \mathrm{NM}$ chemical shifts are all consistent with tetracoordinate Al centres (Chart 5). ${ }^{30,32,33}$ The presence of $\mathrm{N} \rightarrow \mathrm{Al}$ interactions was further established by X-ray diffraction analyses in the case of $\mathbf{2 2}$ and $\mathbf{2 3}$. The $\mathrm{N}-\mathrm{Al}$ bond distances are slightly longer than that found in the related dichloro-alane 16, in line with the reduced Lewis acidity of Al when substituted by alkyl groups. Interestingly, dimethylalane 22 crystallizes with four independent molecules in the unit cell. Two of the four molecules display high planarity with dihedral $\mathrm{N}-\mathrm{C}_{\text {peri }}-\mathrm{C}_{\text {peri- }} \mathrm{Al}$ angles of 0.9 and $-2.1^{\circ}$, while the other two molecules are significantly distorted with dihedral angles of 16.8 and $-13.9^{\circ}$. These distortions minimize the steric repulsions between the methyl substituents on the $\mathrm{Al}$ and $\mathrm{N}$ centres, as observed in the planar eclipsed conformation (Chart 5). Overall, there is little variation in the $\mathrm{N}-\mathrm{Al}$ bond length (ranging from 2.056(2) to 2.070(2) $\AA, r=1.07$ to 1.08 ) and Al pyramidalization ( $\Sigma_{\alpha} \mathrm{Al}=348.5$ to $350.5^{\circ}, \mathrm{THC}=$ $44 \%$ to $51 \%$ ). The molecule has some conformational flexibility, but the $\mathrm{N} \rightarrow \mathrm{Al}$ interaction remains about the same. The AlEt 2 derivative $\mathbf{2 3}$ displays similar behaviour. $X$-ray diffraction analysis showed little variation in N-Al bond lengths, ranging from 2.068(2) to 2.071(5) $\AA$ ( $r=1.077$ to 1.078), and pyramidalization of the $\mathrm{Al}$ environment $\left(\Sigma_{\alpha} \mathrm{Al}=346.6\right.$ to $347.9^{\circ}, \mathrm{THC}=48 \%$ to $\left.54 \%\right)$. The $\mathrm{N}-\mathrm{C}_{\text {peri }}-\mathrm{C}_{\text {peri- }}$ Al torsion angles range from $7.7^{\circ}$ to $-13.2^{\circ}$, while the naphthalene backbone itself remains fairly 
planar. Comparison of the intramolecular $\mathrm{N} \rightarrow \mathrm{Al}$ Lewis pair $\mathbf{2 2}$ with the corresponding intermolecular (naphthyl) $\mathrm{NMe}_{2} \rightarrow \mathrm{AlMe}_{3}$ adduct $25^{32}$ revealed noticeable differences. In the latter compound, the $\mathrm{N} \rightarrow \mathrm{Al}$ dative bond is rotated out of the naphthyl plane (Al- $\mathrm{N}-\mathrm{C}_{\text {peri }}-\mathrm{C}_{\text {bridge }}$ torsion angle $\left.=62.67^{\circ}\right)$ and the $\mathrm{N}-\mathrm{Al}$ bond length is much longer at $2.157(2) \AA(r=1.12)$ although the Al centre is more pyramidalized $\left(\Sigma_{\alpha} \mathrm{Al}=340.3^{\circ}, \mathrm{THC}=67 \%\right)$ (Chart 5). Bridging the peri positions of the naphthyl backbone as in $\mathbf{2 2}$ results in a more constrained and shorter $\mathrm{N} \rightarrow \mathrm{Al}$ interaction.

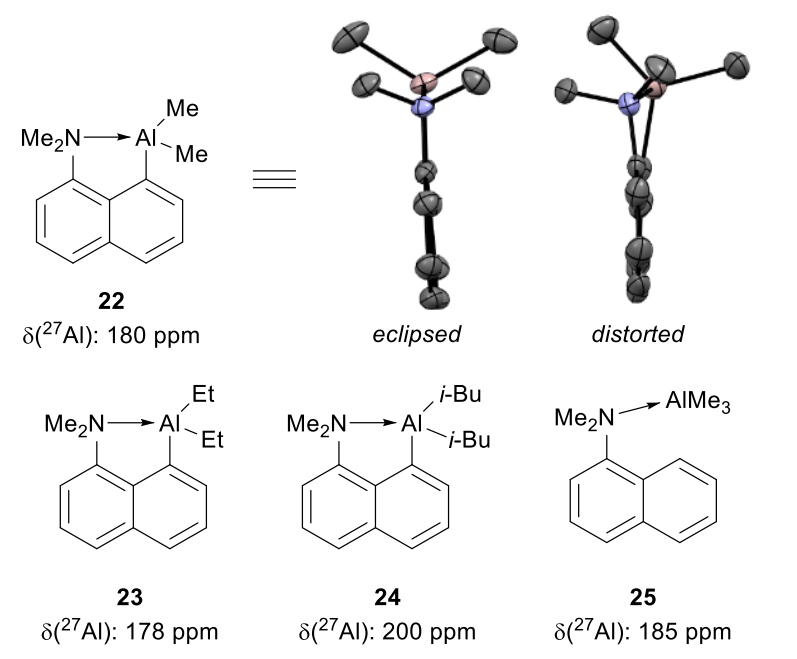

Chart 5 Dialkyl-alane derivatives 22-24 and intermolecular adduct 25; structure of 22 (two of the molecules found in the unit cell) with carbon in grey, nitrogen in blue, aluminum in pink and $\mathrm{H}$ atoms omitted for clarity.

Besides boron and aluminium, a few $\mathrm{Ga}$, In and TI derivatives featuring 8-dimethylamino-naphthyl substituents were reported. ${ }^{31,34}$ The dichlorogalane $\mathbf{2 6}$ was obtained as a monomer, while the corresponding indium derivative $\mathbf{2 7}$ formed a dimer with bridging $\mathrm{Cl}$ ligands (Chart 6). Both compounds were structurally characterised. They are sensitive to air and decompose when exposed to atmosphere. As expected from the similar size and Lewis acidity of $\mathrm{Ga}$ as to compared with Al, compound 26 displays strong intramolecular $\mathrm{N} \rightarrow \mathrm{Ga}$ interaction. The $\mathrm{N}-\mathrm{G}$ a distance in 26 (2.071(7) $\AA, r=1.07)$ is slightly longer than the $\mathrm{N}-\mathrm{Al}$ distance in $16(2.016(4) \AA, r=1.05)$ and the geometry around $\mathrm{Ga}$ is slightly less pyramidalized ( $\Sigma_{\alpha} \mathrm{Ga}=349.82^{\circ}, \mathrm{THC}=42 \%$ vs. $\Sigma_{\alpha} \mathrm{Al}=347.12^{\circ}, \mathrm{THC}=52 \%$ ). The $\mathrm{N}$ and $\mathrm{Ga}$ centres marginally deviate from the naphthalene plane (by 0.168 and $0.09 \AA$, respectively), resulting in a small $\mathrm{N}-\mathrm{C}_{\text {peri }}-\mathrm{C}_{\text {peri- }}-\mathrm{Ga}$ torsion angle of $-7.0^{\circ}$. In the solid state, $\mathbf{2 7}$ displays a distorted $\mathrm{In}_{2} \mathrm{Cl}_{2}$ centrosymmetric core with significantly different bridging $\mathrm{In}-\mathrm{Cl}$ distances, 2.473(2) and 2.746(3) $\AA$. The terminal $\mathrm{In}-\mathrm{Cl}$ bond lengths are shorter in length $(2.352(3) \AA)$. The intramolecular $N \rightarrow$ In interactions are identical, being 2.406(8) $\AA(r=1.13)$ in length, and the geometry at each In centre is best described as trigonal bipyramidal. The axial $\mathrm{N}$ and $\mathrm{Cl}$ ligands form an angle of $173.0(2)^{\circ}$ with In. Small out-of-plane distortions of the $\mathrm{N}$ and In centres are observed: 0.072 and $0.183 \AA$, respectively. In 2012, Beckmann et al. reported dinaphthyl substituted In and TI derivatives $\mathbf{2 8}$ and $\mathbf{2 9}$ (Chart 6). ${ }^{34}$ The two compounds adopt similar dimeric structures in the solid state with bridging $\mathrm{Cl}$ ligands. Both In and $\mathrm{Tl}$ are six-coordinate and sit in distorted octahedral geometries, with the two naphthyl substituents occupying trans positions $\left(\mathrm{C}-\mathrm{E}^{13}-\mathrm{C}\right.$ bond angles $=$ 158.1(1) for In and 171.1(3) for TI). The $N-\ln (2.550(4)-2.620(5) \AA, r=1.20-1.23)$ and $\mathrm{N}-\mathrm{TI}$ (2.701(7)-2.711(6) $\AA, r=1.250-1.255)$ bond lengths are very comparable, suggesting $N \rightarrow \mathrm{E}^{13}$ interactions similar in strength with In and Tl. Of note, a single set of ${ }^{1} \mathrm{H}$ and ${ }^{13} \mathrm{C} N M R$ signals was 
observed for the $\mathrm{NMe}_{2}$ groups, suggesting fast $\mathrm{E}^{13}-\mathrm{Cl}$ dissociation/association on the NMR timescale.

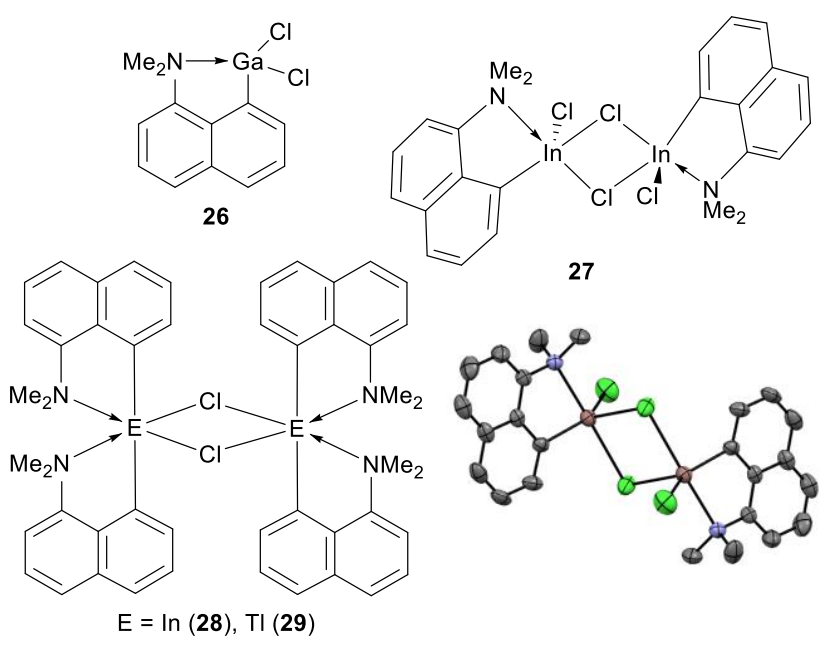

Chart $6 \mathrm{~N}-\mathrm{Ga}$, In and TI derivatives 26-29; structure of 27 with carbon in grey, nitrogen in blue, indium in purple, chlorine in green, and $\mathrm{H}$ atoms omitted for clarity.

\section{1. (Ace)naphthalene P-B derivatives}

The description of (ace)naphthyl supported phosphine-boranes in the literature parallel those of their amine-borane congeners with intensifying research dedicated to these derivatives in the past two decades. The synthetic route used to access these derivatives is similar to that employed for their $\mathrm{N}$ homologues, ie electrophilic trapping of peri lithiated naphthyl phosphines with in some cases Li to Sn transmetalation (vide infra).

We described in 2013 a series of naphthyl-bridged phosphine-boranes with varying substituents on the $\mathrm{B}$ centre (Chart 7). ${ }^{35}$ Both ${ }^{11} \mathrm{~B}\left(16.2,0.1\right.$ and $-8.5 \mathrm{ppm}$ for 30, 31 and 32, respectively) and ${ }^{31} \mathrm{P}$ NMR chemical shifts (17.4, 23.4 and $25.1 \mathrm{ppm}$ for 30, 31 and 32, respectively) indicate intramolecular $\mathrm{P} \rightarrow \mathrm{B}$ interactions and tetracoordinate $\mathrm{B}$ centres. This is confirmed in the solid state with short P-B bond lengths (2.173(4), 2.076(2) and 2.011(2) $\AA$ for 30, 31 and 32, respectively) that are slightly longer than the sum of $P$ and $B$ covalent radii $\left(1.91 \AA^{24}, r=1.14,1.07\right.$ and 1.05, respectively) and reflect the increasing Lewis acidity at $\mathrm{B}$. The geometry at $\mathrm{B}$ is pyramidalized $\left(\Sigma_{\alpha} \mathrm{B}=\right.$ $341.9(9)^{\circ}, 340.7(2)^{\circ}$ and $338.5(5)^{\circ}, \mathrm{THC}=39,60$ and $50.4 \%$ for 30, 31 and 32, respectively). Additionally, the naphthyl scaffold was found to respond to increasing Lewis acidity at $\mathrm{B}$ in the order Mes $<\mathrm{Cy}<$ fluorenyl through distortions in $\mathrm{B}-\mathrm{C}_{\text {peri }}-\mathrm{C}_{\text {bridge }}$ peri bond angles from the ideal $120^{\circ}$ (from $111.4(3)^{\circ}$ in $\mathbf{3 0}$, to $109.0(2)^{\circ}$ in 32 ) as well as $\mathrm{P}-\mathrm{C}_{\text {peri }}-\mathrm{C}_{\text {peri }}-\mathrm{B}$ torsion angles $\left(2.6(2)^{\circ}\right.$ to $11.9(2)^{\circ}$ for 30 and 32, respectively). Theoretical calculations are in good agreement with experimental observations, ${ }^{35}$ where Natural Population Analysis (NPA) charges indicate electron transfer from $P$ to $B$ with increasing positive and negative charges on $P$ and $B$, respectively, following the increasing $B$ Lewis acidity $(\mathbf{3 0}<\mathbf{3 1 < 3 2})$. Consistently, the $P-B$ Wiberg bond index $(W B I)$ increases from 0.74 in $\mathbf{3 0}$ to 0.88 in $\mathbf{3 2}$ and atoms-in-molecules (AIM) calculations show a noticeable increase of the electron density at the $\mathrm{P}-\mathrm{B}$ bond critical point (BCP) from 0.06 in $\mathbf{3 0}$ to 0.10 e.bohr $\mathrm{h}^{-3}$ in $\mathbf{3 2}$. Of note, a positive $\alpha$-PIE (39.4 kJ/mol) was computed by Mebs, Beckmann et al. for $30,{ }^{25}$ despite the bonding $P \rightarrow B$ interaction, which highlights the repulsive interactions induced by the juxtaposition of the bulky $(i-\mathrm{Pr})_{2} \mathrm{P}$ and $\mathrm{BMes}_{2}$ groups. Contrary to the weak $\mathrm{N} \rightarrow \mathrm{B}$ interaction observed with derivative 8 , 
strong $\mathrm{P} \rightarrow \mathrm{B}$ interactions are enforced despite steric shielding induced by substituents at $\mathrm{P}$ and $\mathrm{B}$. The size of $P$ is better suited for the formation of intramolecular $P \rightarrow B$ interactions without requiring significant distortions of the backbone. The naphthyl scaffold and the $P \rightarrow B$ interaction retain sufficient flexibility to remain responsive to the Lewis acidity at $B$.

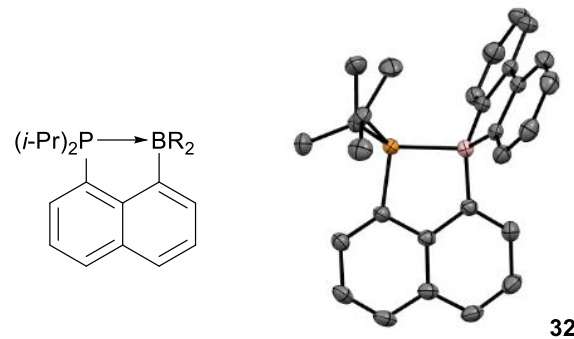

\begin{tabular}{r|rrrrr} 
& $\mathrm{R}$ & $\delta\left({ }^{11} \mathrm{~B}\right)$ & $\delta\left({ }^{31} \mathrm{P}\right)$ & $\mathrm{P}-\mathrm{B}$ length $(\AA)$ & $\mathrm{WBI}$ \\
\hline $\mathbf{3 0}$ & Mes & 16.2 & 17.4 & $2.173(4)$ & 0.74 \\
$\mathbf{3 1}$ & $\mathrm{Cy}$ & 0.1 & 23.4 & $2.076(2)$ & 0.81 \\
$\mathbf{3 2}$ & fluorenyl & -8.5 & 25.1 & $2.011(2)$ & 0.88 \\
$\begin{array}{c}\text { increasing } \\
\text { B Lewis acidity }\end{array}$ & & & & &
\end{tabular}

Chart 7 Derivatives 30-32 with key analytical data for the $\mathrm{P} \rightarrow \mathrm{B}$ interaction; structure of $\mathbf{3 2}$ with carbon in grey, boron in pink and phosphorous in orange and $\mathrm{H}$ atoms omitted for clarity.

A strong intramolecular $\mathrm{P} \rightarrow \mathrm{B}$ interaction is maintained while keeping high steric demand at $\mathrm{B}$ and weakening the Lewis basicity of $\mathrm{P}$, as demonstrated by Wang, Beckmann and Mebs, with the $\mathrm{Ph}_{2} \mathrm{P}$ BMes2 derivative 33 (Scheme 12). ${ }^{36,37}$ In solution, ${ }^{11} \mathrm{~B}$ (13.6 ppm) and ${ }^{31} \mathrm{P}$ NMR data (11.1 ppm) suggest the presence of a $P \rightarrow B$ interaction and a tetracoordinate $B$ centre. $\mathbf{3 3}$ shows six distinct Me signals over the two Mes groups suggesting a highly congested structure, as expected. However, VT ${ }^{1} \mathrm{H}$ and NOESY/EXSY NMR experiments indicate that despite steric congestion, $\mathbf{3 3}$ is highly fluxional in solution. The $\mathrm{P} \rightarrow \mathrm{B}$ interaction, however, is quite stable. It remains intact, albeit weaker $\left({ }^{11} \mathrm{~B}\right.$ signal shifts from $\sim 15$ to $\sim 22 \mathrm{ppm}$, and ${ }^{31} \mathrm{P}$ signal shifts from $\sim 11$ to $\left.\sim 9 \mathrm{ppm}\right)$, upon heating to $80{ }^{\circ} \mathrm{C}$. The presence of a $\mathrm{P} \rightarrow \mathrm{B}$ bond was confirmed in the solid state. The $\mathrm{P}-\mathrm{B}$ distance is short at 2.1612(16) $\AA$ $(r=1.13)$ and the geometry at $B$ is pyramidalized $\left(\Sigma_{\alpha} B=346.8^{\circ}\right.$, THC $\left.=37 \%\right)$. The flexibility of the naphthyl scaffold allows it to adapt to the steric congestion imposed by the bulky substituents with significant deviations of the peri groups from the mean naphthalene plane $(0.278$ and $0.275 \AA$ for $P$ and $B$, respectively). DFT calculations by Wang et al. ${ }^{37}$ found both the open and closed forms of 33 as minima on the potential energy surface. In the open form, the P-B distance is $3.00 \AA$, with the lone pair on $\mathrm{P}$ still pointing towards $\mathrm{B}$, while the closed form was found to have a $\mathrm{P}-\mathrm{B}$ length of 2.23 $\AA$ A. In agreement with experimental observations, the open form was found more stable computationally, but the two forms are very close in energy $(\Delta E=4.43 \mathrm{~kJ} / \mathrm{mol})$ with an accessible transition state $(5.28 \mathrm{~kJ} / \mathrm{mol})$, suggesting rapid interconversion. Comparable $\alpha$-PIE values were computed by Mebs, Beckmann et al. for the two forms $(30.7$ and $34.4 \mathrm{~kJ} / \mathrm{mol}$ for the closed and open forms, respectively). ${ }^{25}$ The presence of the $\mathrm{Ph}_{2} \mathrm{P}$ and BMes 2 groups in the peri positions is overall repulsive, irrespective of the presence, or not, of a bonding $P \rightarrow B$ interaction. 


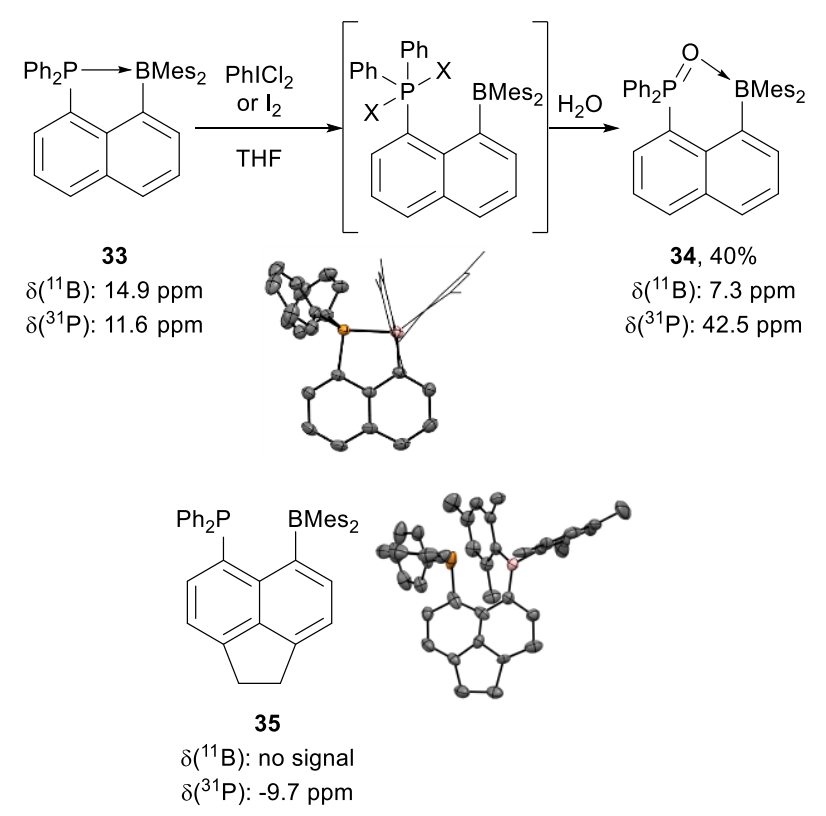

Scheme 12 Oxidation of $\mathbf{3 3}$ to $\mathbf{3 4}$ and corresponding acenaphthyl-bridged derivative 35; structures of $\mathbf{3 3}$ (Mes groups simplified) and $\mathbf{3 5}$ with carbon in grey, phosphorus in orange, boron in pink and $\mathrm{H}$ atoms omitted for clarity.

Although involved in an intramolecular $\mathrm{P} \rightarrow \mathrm{B}$ interaction, the $\mathrm{P}$ centre of $\mathbf{3 3}$ maintains reactivity, as exemplified by its reaction with $\mathrm{I}_{2}$ or $\mathrm{PhICl}_{2}$ to give the phosphineoxide-borane 34 (Scheme 12). ${ }^{37}$ This is thought to occur through initial oxidation of $P$ to the halo phosphorane species which then hydrolyses to 34 . The ${ }^{31} \mathrm{P}$ chemical shift $(42.5 \mathrm{ppm})$ is highly indicative of oxidation of $\mathrm{P}$ and the ${ }^{11} \mathrm{~B}$ chemical shift $(7.3 \mathrm{ppm})$ indicates a tetracoordinate $B$ centre. 34 was characterized in the solid state, finding $\mathrm{P}=\mathrm{O}$ and $\mathrm{O}-\mathrm{B}$ bond lengths of $1.532(3)$ and $1.621(6) \AA$, respectively, while the geometry about $B$ is highly pyramidalized $\left(\Sigma_{\alpha} B=342.0(4)^{\circ}, \mathrm{THC}=68 \%\right)$.

In line with that discussed in the previous section on $N \rightarrow E^{13}$ derivatives, the acenaphthyl scaffold can be used to disrupt peri interactions. This is also the case with phosphine-borane $\mathbf{3 5}$ (Scheme 12). ${ }^{36}$ While a ${ }^{11} \mathrm{~B}$ NMR signal could not be observed, the ${ }^{31} \mathrm{P} N M R$ chemical shift $(-9.7 \mathrm{ppm})$ is indicative of the lack of intramolecular $P \rightarrow B$ interaction. This bonding situation was confirmed in the solid state, with a long $\mathrm{P}-\mathrm{B}$ distance of 3.050(3) $\AA$ ( $r=1.60)$ and trigonal planar geometry at $\mathrm{B}$ $\left(\Sigma_{\alpha} \mathrm{B}=358.4^{\circ}\right)$, classifying 35 as a FLP. Despite increased peri distances, $\mathbf{3 5}$ still experiences significant deviations of both peri groups from the mean acenaphthalene plane $(0.129$ and $0.456 \AA$ for $P$ and $B$, respectively). Theoretical calculations compared real-space bonding indicators (RSBIs) between $\mathbf{3 3}$ and 35. All RSBIs could clearly discriminate bonding and non-bonding P-B contacts in $\mathbf{3 3}$ and $\mathbf{3 5}$, respectively. This is attributed to the enhanced rigidity of the acenaphthyl backbone, compared to the naphthyl framework which is flexible enough to allow shorter peri interactions. Of note, the $\alpha$ PIE calculated for the FLP $35(30.2 \mathrm{~kJ} / \mathrm{mol})^{25}$ is very similar to those of the open and closed forms of 33, indicating that the nature of the backbone, acenaphthyl or naphthyl, has little overall impact on the repulsive interactions generated by the juxtaposition of the $\mathrm{Ph}_{2} \mathrm{P}$ and $\mathrm{BMes}_{2}$ groups.

This effect of the rigid acenaphthene backbone was also exemplified very recently by Beckmann et al. in related boronic esters $\mathbf{3 6}$ and $\mathbf{3 7}$ (Scheme 13). ${ }^{38} \mathbf{3 6}$ was found to be sensitive to water and hydrolyses to the corresponding boronic acid 38. Subjected to elevated temperatures and reduced pressure, $\mathbf{3 8}$ is prone to condensation and forms the corresponding boroxine $\mathbf{3 9}$, which while relatively stable undergoes slow oxidation at one P-site to yield boroxine 40 . As opposed to $\mathrm{N} \rightarrow \mathrm{B}$ 
boronic acid $\mathbf{2}$ and boroxine 3, the acenaphthene framework here prevents the formation of any $P \rightarrow B$ interactions. All these derivates show spectroscopic signatures of tricoordinate $B$ centres (downfield ${ }^{11} \mathrm{~B}$ NMR chemical shifts) and lack of $\mathrm{P} \rightarrow \mathrm{B}$ interactions (upfield ${ }^{31} \mathrm{P}$ NMR chemical shifts). These bonding situations were confirmed in the solid-state, finding long $P-B$ distances for 36-40 (>2.762 $\AA, r>1.5$ ) and trigonal planar $\mathrm{B}$ centres. Despite the lack of $\mathrm{P} \rightarrow \mathrm{B}$ interactions, these derivatives were found to be inert towards Suzuki-Miyaura cross-coupling reactions.

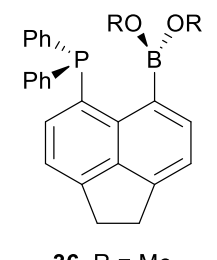

36, $\mathrm{R}=\mathrm{Me}$ $\delta\left({ }^{11} \mathrm{~B}\right): 30.6(\mathrm{br}) \mathrm{ppm}$ $\delta\left({ }^{31} \mathrm{P}\right):-20.5(\mathrm{~s}) \mathrm{ppm}$ 37, $\mathrm{R}=i-\mathrm{Pr}$ $\delta\left({ }^{11} \mathrm{~B}\right): 29.8(\mathrm{br}) \mathrm{ppm}$ $\delta\left({ }^{31} \mathrm{P}\right):-20.3$ (s) ppm

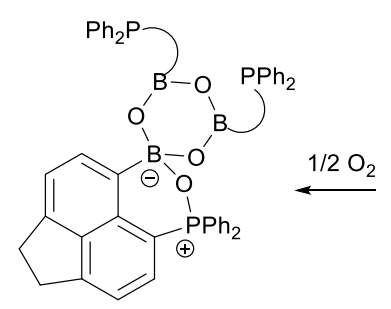

40

$\delta\left({ }^{11} \mathrm{~B}\right): 30.4(\mathrm{br}), 1.6(\mathrm{br}) \mathrm{ppm}$ $\delta\left({ }^{31} \mathrm{P}\right): 45.3-44.9(\mathrm{~m}, \mathrm{P}-\mathrm{O}),-21.5(\mathrm{~s}) \mathrm{ppm}$

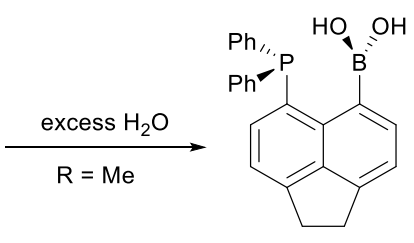

38

$\delta\left({ }^{11} \mathrm{~B}\right): 32.7(\mathrm{br}) \mathrm{ppm}$ $\delta\left({ }^{31} \mathrm{P}\right):-21.6(\mathrm{~s}) \mathrm{ppm}$
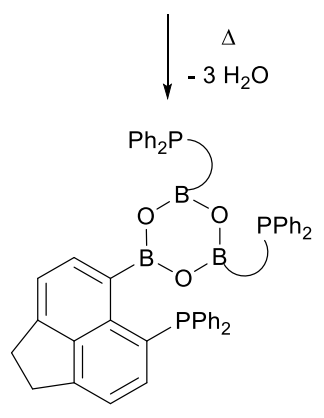

39

$\delta\left({ }^{11} \mathrm{~B}\right): 30.4(\mathrm{br}) \mathrm{ppm}$ $\delta\left({ }^{31} \mathrm{P}\right):-20.1$ (s) ppm

Scheme 13 Hydrolysis of $\mathbf{3 6}$ into $\mathbf{3 8}$ and formation of boroxines $\mathbf{3 9}$ and $\mathbf{4 0 .}$

The rigidity of the acenaphthalene scaffold can be overcome and the formation of $P \rightarrow B$ interactions promoted by increasing the Lewis acidity at $B$, as demonstrated by Mebs, Chęcińska and Beckmann with phosphine-boranes $\mathbf{4 1 - 4 5}$ (Scheme 14). ${ }^{25,39}$ Transmetalation of (6diphenylphosphinoacenaphth-5-yl)tributylstannane with $\mathrm{Me}_{2} \mathrm{~S} \cdot \mathrm{BH}_{3}$ provided the phosphine-borane $\mathbf{4 1}$ with the smallest boryl site, as a reasonably air-stable solid. Through redistribution, $\mathbf{4 1}$ reacted with tris(pentafluorophenyl)borane to provide $\mathbf{4 2}$ (sensitive to air and moisture) which could be chlorinated with $\mathrm{SO}_{2} \mathrm{Cl}_{2}$ to give the corresponding chloroborane 43. While a second pentafluorophenyl substituent could not be introduced from $\mathbf{4 3}$, the bis(pentafluorophenyl)borane 44 was independently synthesised by directly trapping (6-diphenylphosphinoacenaphth-5-yl)lithium with $\mathrm{ClB}\left(\mathrm{C}_{6} \mathrm{~F}_{5}\right)_{2}$, to provide 44 as an air stable solid. 


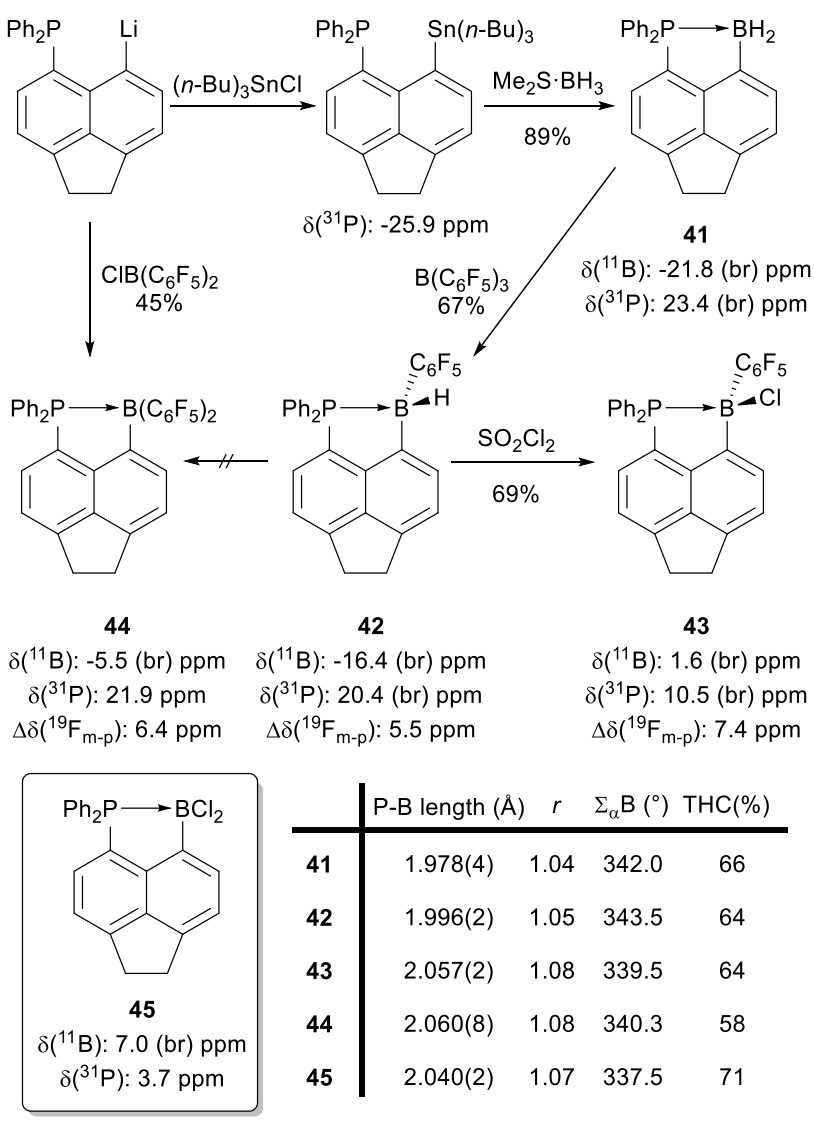

Scheme 14 P-B acenaphthalene derivatives with highly Lewis acidic B centers 41-45.

All derivatives 41-45 show spectroscopic evidence of intramolecular $\mathrm{P} \rightarrow \mathrm{B}$ interactions and tetracoordinate $\mathrm{B}$ centres, as apparent from upfield ${ }^{11} \mathrm{~B}$ and downfield ${ }^{31} \mathrm{P} N M R$ signals. This is further evidenced in $\mathrm{C}_{6} \mathrm{~F}_{5}$-containing derivatives $\mathbf{4 2 - 4 4}$ by small separations in chemical shifts between the ${ }^{19} \mathrm{~F} N M R m$ - and $p$ - $\mathrm{F}$ signals $\left(\Delta \delta^{19} \mathrm{~F}_{\mathrm{m}-\mathrm{p}}=5.5,7.4\right.$ and $6.4 \mathrm{ppm}$ for 42, 43 and 44, respectively). ${ }^{27}$ These bonding situations were confirmed in the solid state with short $\mathrm{P}-\mathrm{B}$ bond lengths and pyramidalized B centres (see table in Scheme 14). Despite its rigidity, the acenaphthyl scaffold responds to the Lewis acidity at $B$ through distortions from the ideal $120^{\circ}$ in peri bond angles (up to $107.10^{\circ}$ for $\mathrm{P}-\mathrm{C}_{\text {peri }}-\mathrm{C}_{\text {bridge }}$ and $113.45^{\circ}$ for $\mathrm{B}-\mathrm{C}_{\text {peri }}-\mathrm{C}_{\text {bridge }}$ ), while the core acenaphthyl scaffold itself remains fairly coplanar. Theoretical calculations supported these findings, with no open or FLP structures found as minima on potential energy surfaces for any of these derivatives. 41-45 were all classified as regular Lewis pairs with overall attractive peri interactions (negative $\alpha$-PIE of -80.3, 84.6, $-45.3,-51.6$ and $-43.8 \mathrm{~kJ} / \mathrm{mol}$ were computed for 41, 42, 43, 44 and 45, respectively). In addition, topological analyses (AIM calculations) of the P-B bonding show in all cases high degree of covalency. ${ }^{25}$

Formation of $\mathrm{P} \rightarrow \mathrm{B}$ interactions is highly sensitive to steric congestion at $\mathrm{B}$ centres as well as the donating ability of $\mathrm{P}$, as demonstrated by Sasamori, Tokitoh et al. with the dichlorophosphineboranes 46a-48a (Scheme 15). ${ }^{40}$ Placement of bulky $t$-Bu groups in meta positions of the Ar groups in 46a allows formation of $\mathrm{a} P \rightarrow \mathrm{B}$ interaction and a tetracoordinate $\mathrm{B}$ centre, as demonstrated by an upfield ${ }^{11} B$ NMR signal at $10 \mathrm{ppm}$. However, di-ortho substituents $A$ r prevent $P \rightarrow B$ interactions in 47a and 48a and maintain tricoordinate $B$ centres (evidenced by downfield ${ }^{11} B$ NMR signals of 63.9 and $64.3 \mathrm{ppm}$, respectively). These bonding situations were confirmed in the solid state, finding a short P-B contact for 46a (2.108(2) A, $r=1.10)$ but a long P-B distance in 47a (2.961(2) A, $r=$ 
1.55)..$^{41}$ Calculations accurately reproduce the long P-B distance in $47 \mathrm{a}$ ( $\left.2.912 \AA\right)$ and classify this derivative as a FLP with a positive $\alpha$-PIE $(12.9 \mathrm{~kJ} / \mathrm{mol}) .{ }^{25}$

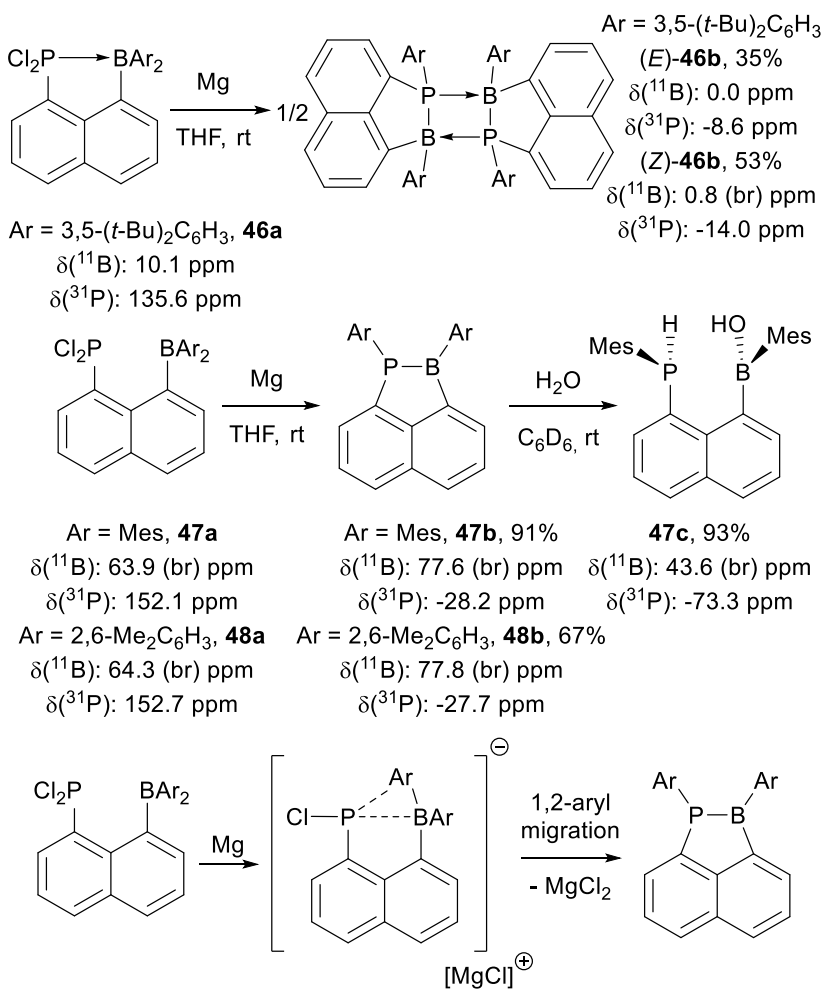

Scheme 15 Reduction of the $\mathrm{Cl}_{2} \mathrm{P}-\mathrm{B}$ naphthyl derivatives $46 \mathrm{a}-48 \mathrm{a}$ to give $46 \mathrm{~b}-\mathbf{4 8 b}$, activation of $\mathrm{H}_{2} \mathrm{O}$ by $47 \mathrm{~b}$ to give $47 \mathrm{c}$, and proposed mechanism of reductive 1,2-aryl migration.

These derivatives displayed unique reactivity under reducing conditions (with $\mathrm{Mg}$ ) involving the formation of a P-B bond and 1,2-aryl migration to give the corresponding 1-phospha-2boraacenaphthenes $\mathbf{4 6 b}-\mathbf{4 8 b}$ (Scheme 15). Due to reduced steric congestion about the $B$ centre in $46 \mathrm{a}$, head-to-tail dimerization occurs to provide the dimeric product $46 \mathrm{~b}$ as a mixture of $E(35 \%)$ and $Z(53 \%)$ isomers with tetracoordinate $B$ centres, as suggested by ${ }^{11} B$ NMR spectroscopy $(0.0$ and 0.8 $\mathrm{ppm}$ for $E$ and $Z$ isomers, respectively). Conversely, reduction of $47 \mathrm{a}$ and $48 \mathrm{a}$ provides the corresponding 1-phospha-2-boraacenaphthenes $\mathbf{4 7 b}$ and $\mathbf{4 8 b}$ as monomers. Here, head-to-tail dimerization is prevented by steric congestion at the B centres. Tricoordinate B centres are evidenced by downfield ${ }^{11} \mathrm{~B}$ NMR signals ( 77.6 and $77.8 \mathrm{ppm}$ for $\mathbf{4 7 \mathrm { b }}$ and $\mathbf{4 8 b}$, respectively) while upfield ${ }^{31}$ P NMR signals (-28.2 and $-27.7 \mathrm{ppm}$ for $\mathbf{4 7 b}$ and $\mathbf{4 8 b}$, respectively) support monomeric structures. This was further confirmed crystallographically for $\mathbf{4 7 b}$, finding a trigonal planar $B$ centre $\left(\Sigma_{\alpha} \mathrm{B}=359.5(6)^{\circ}\right)$ and a very short $\mathrm{P}-\mathrm{B}$ bond $(1.889(3) \AA ⿻ \AA, r=0.99)$. The $\mathrm{P}$ centre is pyramidalized $\left(\Sigma_{\alpha} \mathrm{P}\right.$ $\left.=328.4(3)^{\circ}\right)$ and deviates significantly from the mean naphthalene plane $(0.356 \AA)$. This structural arrangement does not allow for $\pi(P B)$-bonding (donation of the lone pair on $P$ into the vacant $2 p$ orbital on $\mathrm{B}$ ). $\mathrm{Sp}^{2}$ hybridization of $\mathrm{P}$ is energetically demanding so that the lone pair at $\mathrm{P}$ retains high $s$ character and hardly overlaps with the vacant $2 p(B)$ orbital.

The presence of proximal Lewis basic and acid sites allows $47 \mathbf{b}$ to activate $\mathrm{H}_{2} \mathrm{O}$ in a FLP-like fashion to afford 1-hydroxy(mesityl)boryl-8-mesitylphosphinonaphthalene $47 \mathrm{c}$ in excellent yield, representing the formal addition of $\mathrm{H}_{2} \mathrm{O}$ across the $\mathrm{P}-\mathrm{B}$ bond. No $\mathrm{P} \rightarrow \mathrm{B}$ interaction is observed in 47c as shown by the downfield ${ }^{11} \mathrm{~B}(43.6 \mathrm{ppm})$ and upfield ${ }^{31} \mathrm{P} N M R$ signals $(-73.3 \mathrm{ppm})$ (Scheme 15). ${ }^{40}$ 47b also demonstrated reactivity in chalcogenation reactions with $\mathrm{S}_{8}$ 
and Se to give derivatives $49-53$ (Scheme 16). ${ }^{41}$ The $\mathrm{P}-\mathrm{B}$ bond is broken in all derivatives to accommodate the newly formed $\mathrm{P}-\mathrm{S}(\mathrm{Se})-\mathrm{B}$ motif and the $\mathrm{P}$ atom is eventually oxidized to the corresponding sulfide or selenide, leaving tricoordinate $B$ centres, as evidenced by downfield ${ }^{11} B$ NMR signals. This was unambiguously verified in the solid state, with long P-B distances (> $3 \AA, r>$ 1.60) and trigonal planar $B$ centres $\left(\Sigma_{\alpha} B=360^{\circ}\right)$ for 49-53.

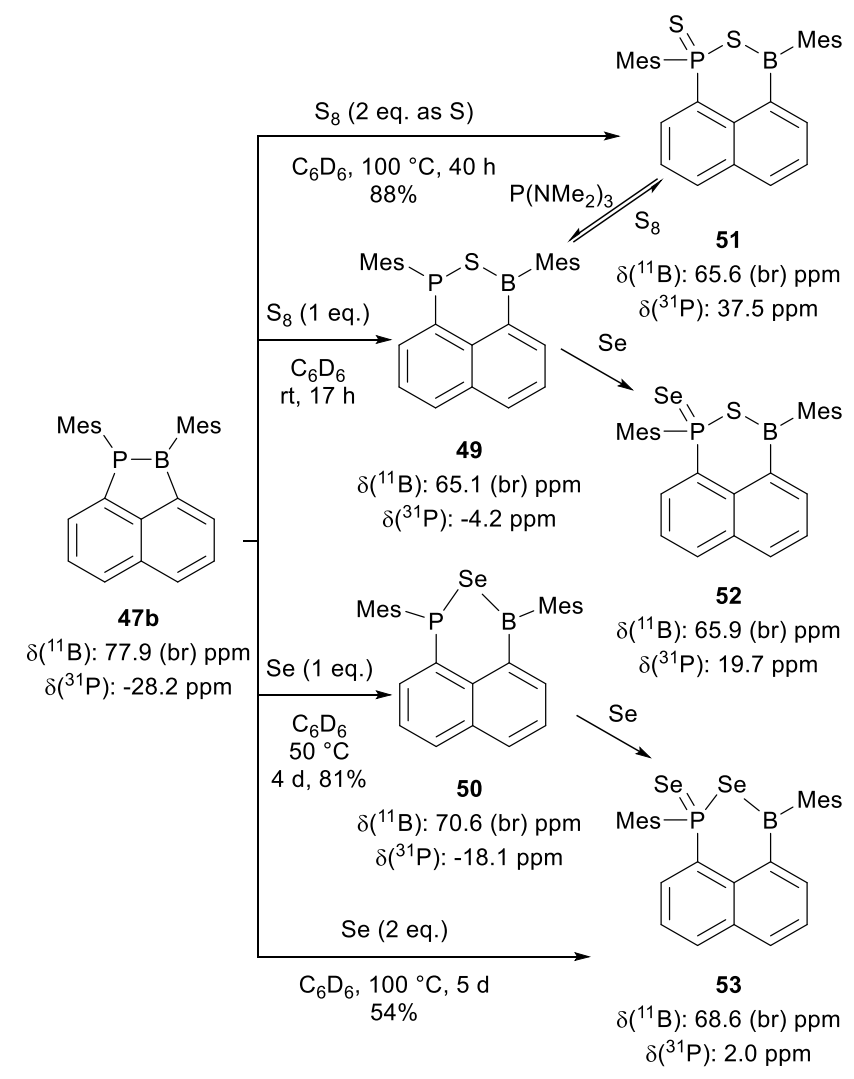

Scheme 16 Chalcogenation reactions of $47 \mathrm{~b}$.

Related to their work on anthracene-bridged N-B-N derivatives (13-15), Yamamoto, Akiba et al. reported in 2001 an analogous system 54 using $\mathrm{P}(i-\mathrm{Pr})_{2}$ as the Lewis base (Scheme 17). ${ }^{42}$ It was obtained in six steps from 1,8-dichloroanthraquinone. In solution, ${ }^{11} \mathrm{~B}$ NMR spectroscopy (15.0-25.0 $\mathrm{ppm}$ ) suggests a weak $\mathrm{P} \rightarrow \mathrm{B}$ interaction. This is verified in the solid state, and as observed with the N-B-N derivatives 13-15, only one $\mathrm{P}$ atom interacts with $\mathrm{B}(2.15 \AA, r=1.13)$. The other remains at a long non-bonding distance $(3.17(3) \AA)$ and the geometry at $B$ is slightly pyramidalized $\left(\Sigma_{\alpha} B=345.6^{\circ}\right.$, $\mathrm{THC}=55 \%)$. Only very slight distortions in peri bond angles from the ideal $120^{\circ}$ are observed in 54 $\left(112.5^{\circ}-114.8^{\circ}\right)$ compared to the $\mathrm{N}$-analogues $13-15$ previously described $\left(104.5^{\circ}-111.6^{\circ}\right)$. Given the presence of two equivalent P-donors, a switch of boron from one side to the other was expected. At room temperature, the ${ }^{1} \mathrm{H}$ NMR spectrum showed a symmetrical anthracene pattern, and peaks maintained their sharpness, even upon cooling to $-80^{\circ} \mathrm{C}$. These observations indicate that the switch of $B$ between the coordination of either $\mathrm{P}$ is also rapid at the NMR timescale in solution, even at low temperature. The energy barrier associated with this process is too low to be measured. 


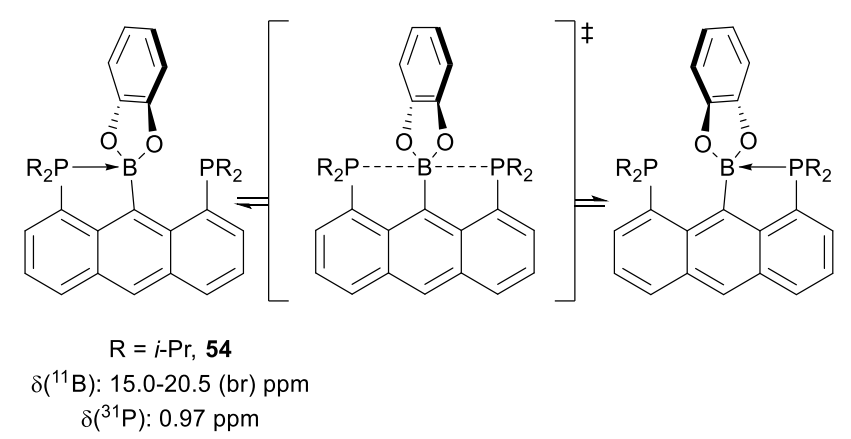

Scheme 17 P-B-P Anthracene derivative 54 and its dynamic equilibrium.

\section{2. (Ace)naphthalene $P-E^{13}$ derivatives $\left(E^{13}=A l, G a, I n, T I\right)$}

Mirroring contributions and reports on $\mathrm{N} \rightarrow \mathrm{E}^{13}$ derivatives previously discussed, $\mathrm{P} \rightarrow \mathrm{E}^{13}$ interactions have also been extended to heavier group 13 elements $\left(\mathrm{E}^{13}=\mathrm{Al}, \mathrm{Ga}\right.$, In and $\mathrm{Tl}$ ) using the acenaphthalene scaffold, as reported by Chęcińska, Beckmann et al. (Chart 8). ${ }^{39}$ Access to these derivatives is generally achieved by $\mathrm{Li}$ to $\mathrm{Sn}$ transmetalation and reaction of (6diphenylphosphinoacenaphth-5-yl)tributylstannane with the desired $\mathrm{E}^{13} \mathrm{Cl}_{n}$ reagent. Mono-, di- and trisubstituted alanes 55-57 could only be obtained by reacting $\mathrm{AlCl}_{3}$ with (6diphenylphosphinoacenaphth-5-yl)lithium (no reactivity with the tin derivative) while varying the stoichiometry and order of addition of reactants. These derivatives are sensitive and decompose immediately upon exposure to moist air. Their structures were confirmed in the solid state. Compound $\mathbf{5 5}$ displays a short P-Al bond (2.4305(6) $\AA$ ) which is slightly longer than the sum of $\mathrm{P}$ and Al covalent radii $(2.28 \AA, r=1.07)$. The Al centre is only slightly pyramidalized $\left(\Sigma_{\alpha} \mathrm{Al}=346.77^{\circ}, \mathrm{THC}=\right.$ 47\%). Both 56 and 57 display elongated $\mathrm{P}-\mathrm{Al}$ bonds with small variations in each derivative (2.6934(7) and 2.7405(7) $\AA, r=1.18$ and 1.20 for 56, and 2.831(1), 2.909(1) and 2.943(2) $\AA, r=1.24$, 1.28 and 1.29 for $\mathbf{5 7}$ ). The geometry at $\mathrm{Al}$ in $\mathbf{5 6}$ is best described as trigonal bipyramidal. The axial $\mathrm{P}$ ligands form an angle of $170.96(2)^{\circ}$ with $\mathrm{Al}$, and the third equatorial position is occupied by $\mathrm{Cl}$ ( $\mathrm{Al}-$ $\mathrm{Cl}$ bond length: $2.1658(7) \AA$ ). In 57, the Al centre adopts a distorted octahedral geometry with a facial arrangement of the $(P, C)$ ligands. Expectedly, due to similar size and Lewis acidity of $\mathrm{Ga}$ as to compared with $\mathrm{Al}$, dichlorogalane $\mathbf{5 8}$ displays a strong intramolecular $\mathrm{P} \rightarrow \mathrm{Ga}$ interaction. The $\mathrm{P}-\mathrm{Ga}$ distance in $\mathbf{5 8}(2.411(2) \AA, r=1.05)$ is marginally shorter than the P-Al distance in $\mathbf{5 5}(2.4305(6) \AA, r$ $=1.07$ ) and the geometry around $\mathrm{Ga}$ is similarly pyramidalized $\left(\Sigma_{\alpha} \mathrm{Ga}=345.78^{\circ}, \mathrm{THC}=48 \%\right)$. In the solid state, 59 displays analogous geometry to its $\mathrm{NMe}_{2}$-analogue 27, with a distorted $\operatorname{In}_{2} \mathrm{Cl}_{2}$ centrosymmetric core and significantly different bridging $\mathrm{In}-\mathrm{Cl}$ distances (2.4429(4) and 2.7855(5) $\AA$ ). The intramolecular $\mathrm{P} \rightarrow$ In interactions are identical being $2.7042(5) \AA(r=1.09)$ in length and the geometry at each In centre is best described as trigonal bipyramidal. The axial $\mathrm{P}$ and $\mathrm{Cl}$ ligands form an angle of $168.96(1)^{\circ}$ with In. In the solid state, the TI derivative 60 displays a short P-TI bond $(2.7726(6) \AA, r=1.10)$ and the geometry at $\mathrm{TI}$ is planar $\left(\Sigma_{\alpha} \mathrm{TI}=359.12^{\circ}\right)$. Calculated RSBIs identify derivatives 55-60 as regular Lewis pairs with attractive peri interactions. The $P \rightarrow A l$ interaction of $\mathbf{5 5}$ shows the highest degree of ionicity (based on electron density RSBIs derived from AIM and electron localizability indicator (ELI-D) parameters). Calculations did not find any minima on potential energy surfaces corresponding to open/FLP structures of 55-60, highlighting that the size and diffuse nature of $P$ and the electronic character of heavier group 13 elements match very well and combine in a synergistic fashion resulting in strong $P \rightarrow E^{13}$ interactions. 


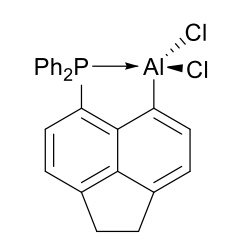

55

$\delta\left({ }^{31} \mathrm{P}\right):-35.0 \mathrm{ppm}$

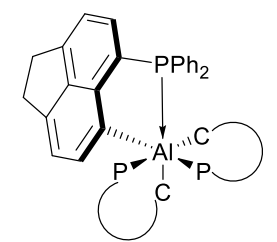

57

$\delta\left({ }^{31} \mathrm{P}\right):-26.7 \mathrm{ppm}$

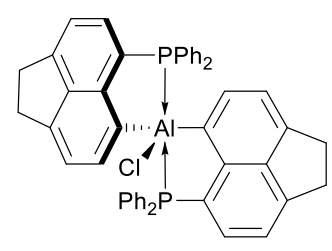

56

$\delta\left({ }^{31} \mathrm{P}\right):-28.6 \mathrm{ppm}$

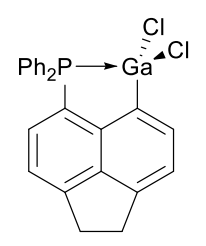

58 $\delta\left({ }^{31} \mathrm{P}\right):-34.0 \mathrm{ppm}$

$\delta\left({ }^{31} \mathrm{P}\right):-36.0 \mathrm{ppm}$

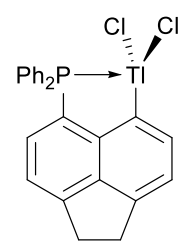

60

18.0 (d) ppm

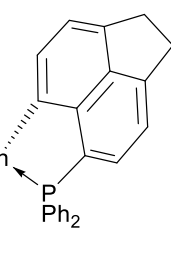

${ }^{1} J\left({ }^{205 / 203} \mathrm{TI}-\mathrm{P}\right)=4516.3 / 4474.3 \mathrm{~Hz}$

Chart 8 Acenaphthalene-bridged $\mathrm{P} \rightarrow \mathrm{E}^{13}$ derivatives 55-60.

\subsection{P-stabilised borenium cations}

Considering the propensity of the naphthyl backbone to enforce strong intramolecular $\mathrm{P} \rightarrow \mathrm{B}$ interactions, our group investigated the ability of these systems to stabilise borenium cations, as surrogates for electron deficient boranes. Our synthetic strategy begins with classical formation of neutral P-B adducts starting from lithiation of the 1-iodo-8-phosphinonaphthalene followed by trapping with a dibromoborane to furnish bromoboranes 61-63 with varying donating ability of the P centre (Scheme 18). ${ }^{43-45}$ Notably, derivative 63 is a rare example of a stable and isolable phosphine-borane with an alkyl substituent on $\mathrm{B}$. The cyclohexyl group is a weaker donor compared to Mes and previously described aromatic substituents. In line with related phosphine-boranes, the naphthyl scaffold enforces strong intramolecular $P \rightarrow B$ interactions resulting in tetracoordinate $B$ centres, as evidenced by upfield ${ }^{11} \mathrm{~B}(0.3,-1.5$ and $2.0 \mathrm{ppm}$ for 61,62 and 63 , respectively) and downfield ${ }^{31}$ P NMR signals $(1.8,14.1$ and 16.4 ppm for 61,62 and 63 , respectively). This bonding situation was confirmed in the solid state for $\mathbf{6 1}$ and $\mathbf{6 3}$, finding short $P-B$ bond lengths (2.05(1) and 2.021(3) $\AA, r=1.07$ and 1.06 , respectively) and strongly pyramidalized $B$ centres $\left(\Sigma_{\alpha} B=339.4\right.$ and $336.8^{\circ}$, THC $=58$ and $65 \%$, respectively). Here again, the flexibility of the naphthyl scaffold accommodates steric congestion in $\mathbf{6 1}$ through significant deviations of the peri groups from the mean naphthalene plane ( 0.332 and $0.235 \AA$ for $P$ and $B$, respectively), as well as significant distortions from ideal peri bond angles of $120^{\circ}\left(<117^{\circ}\right.$ in both 61 and 63). Calculations accurately reproduced the short P-B bond length observed in $61(2.071 \AA)$ and classify this derivative as a regular Lewis pair with attractive peri interactions (negative $\alpha$-PIE of $-25.6 \mathrm{~kJ} / \mathrm{mol}$ ). ${ }^{25}$

The corresponding borenium cations could then be formed by abstracting the $\mathrm{Br}$ atom from $\mathrm{B}$ using $\mathrm{GaBr}_{3}$ or $\mathrm{AgNTf}_{2}$ as dual-purpose Br scavengers and counteranion sources (Scheme 18). All borenium cations 64-68 display spectroscopic hallmarks of tricoordinate B centres supported by significantly 
downfield shifted ${ }^{11} B$ NMR signals (71.4-77.9 ppm). Stronger P lone-pair donation to B, responding to increased electrophilicity upon cationisation, is indicated by an upfield shift of the ${ }^{31} \mathrm{P}$ NMR signals for 65, 66 and 68 (19.2, 21.4 and 19.3 ppm, respectively). This was confirmed in the solid state for borenium tetrabromogallates 65 and 66 , with very short $P-B$ distances $(1.997(6)$ and $2.004(4) \AA, r=$ 1.045 and 1.049 , respectively) and trigonal planar $B$ centres $\left(\Sigma_{\alpha} B=359.4\right.$ and $360.0^{\circ}$, respectively). Considering these structural parameters, the bonding situation in these borenium cations is best described as a combination of two canonical or mesomeric structures: a phosphine-stabilised borenium cation and a phosphonio-borane form (Scheme 18). Importantly, these derivatives represent a departure from previously reported borenium cations stabilised by Lewis bases incorporating $\mathrm{N}$ (amines or pyridines) or C (NHCs, NHOs or carbodiphosphoranes) donors. They are scarce examples of P-stabilised borenium cations, which had been previously limited to a few intermolecular $\left[\left(\mathrm{R}_{3} \mathrm{P}\right) \rightarrow\right.$ Bcat $^{+}$adducts. $^{46}$

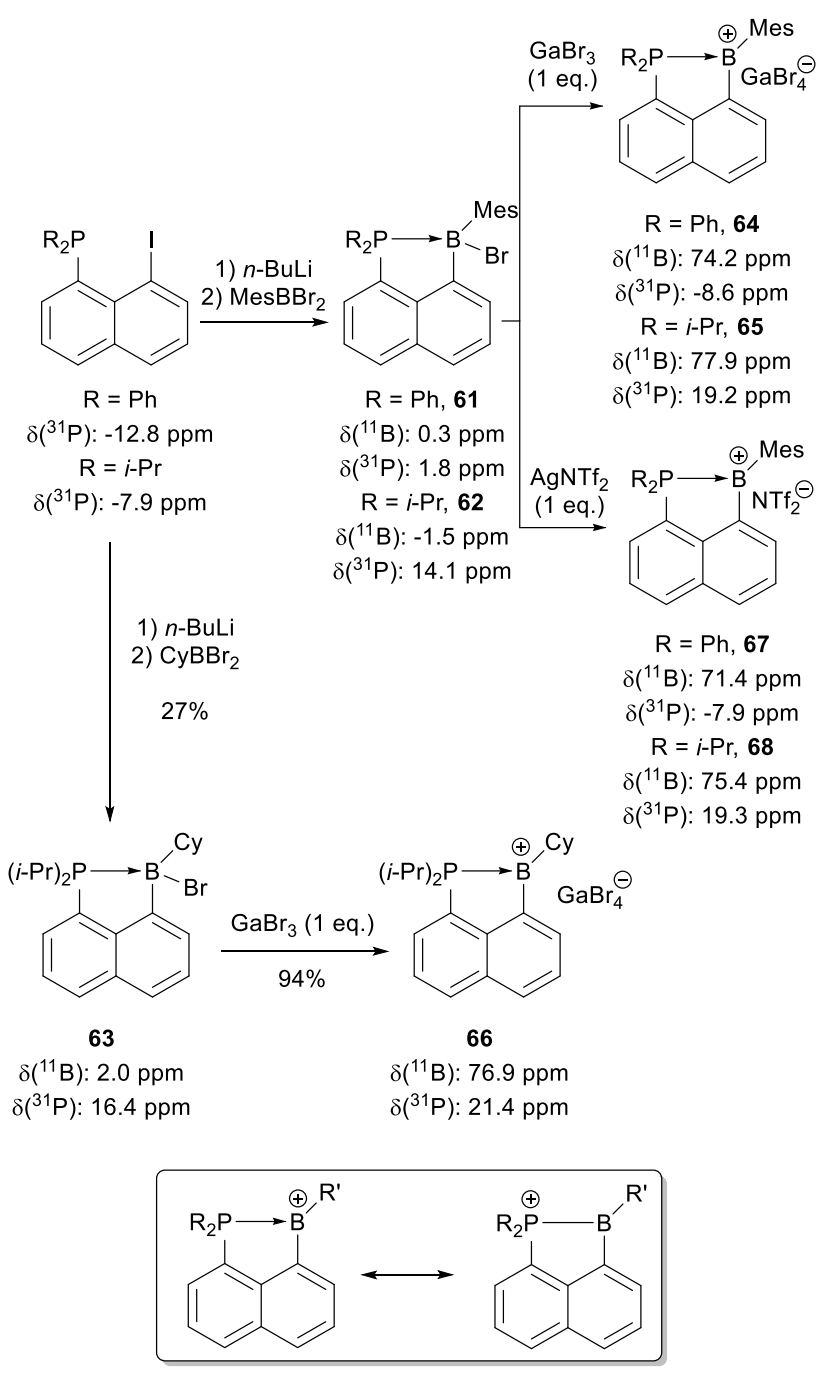

Scheme 18 Synthesis of the naphthyl-bridged phosphine-bromoboranes 61-63 and corresponding P-stabilised borenium cations 64-68.

The reactivity of these borenium cations was then investigated with respect to small molecule activation. Borenium bistriflimide 67 was found to form a FLP with $t-\mathrm{Bu}_{3} \mathrm{P}$, due to steric congestion, and could activate $\mathrm{H}_{2}$ with quantitative conversion of the borenium into the corresponding phosphine-hydroborane 69 over 39 hours at room temperature (Scheme 19). ${ }^{43} 31 \mathrm{P}$ NMR monitoring shows the apparition of a new signal at $\delta 11.2 \mathrm{ppm}$ attributed to 69 and a signal at $\delta 56.7 \mathrm{ppm}$ 
corresponding to $t-\mathrm{Bu}_{3} \mathrm{PH}^{+}$. The ${ }^{11} \mathrm{~B}$ NMR chemical shift of 69 at $-13.3 \mathrm{ppm}$ suggests a tetracoordinate $\mathrm{B}$ centre. Remarkably, borenium $\mathbf{6 7}$ was also found to react with $\mathrm{H}_{2}$ in the absence of an external base (Scheme 19). Under more forcing conditions, and without an external base, a new derivative $\mathbf{7 0}$ is formed quantitatively along with mesitylene. The presence of a $P \rightarrow B$ interaction and tetracoordinate $B$ centre is apparent from the low field ${ }^{11} B(-6.4 \mathrm{ppm})$ and high field ${ }^{31} \mathrm{P}$ NMR signals (4.7 ppm). This bonding situation is confirmed in the solid state, finding a very short P-B bond (1.982(3) $\AA, r=1.04)$ and a pyramidalized $B$ centre $\left(\Sigma_{\alpha} B=336^{\circ}\right.$, THC $\left.=66 \%\right)$ due to coordination of the $\mathrm{NTf}_{2}$ anion to $\mathrm{B}\left(\mathrm{B}-\mathrm{N}\right.$ bond length $1.602(4) \AA$ ). Mechanistic studies using $\mathrm{D}_{2}$ shows formation of the deuterated analogue of 70 ( $\left.{ }^{31} \mathrm{P} 4.8 \mathrm{ppm}\right)$ along with deuterated mesitylene (Scheme 19). DFT studies were employed to elucidate the reaction mechanism. Accordingly, the reaction is proposed to involve side-on coordination of $\mathrm{H}_{2}$ to $\mathrm{B}$, akin to transition metals, followed by heterolytic cleavage of $\mathrm{H}_{2}$ and concomitant transfer of a hydride to the $\mathrm{B}$ centre and protonation of the Mes substituent. This represents a rare example of heterolytic $\mathrm{H}_{2}$ activation at a unique nonmetallic reactive site.

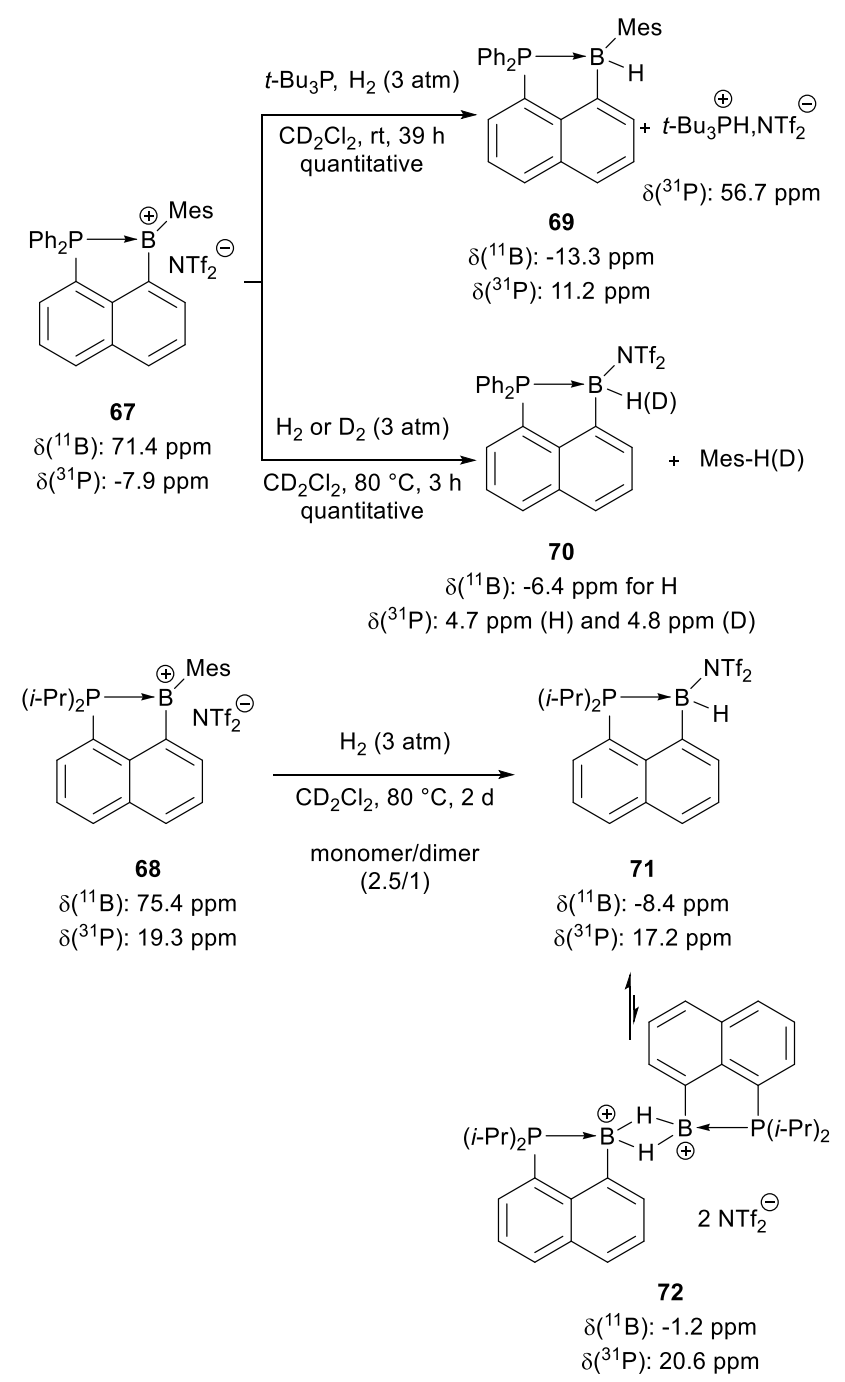

Scheme 19 Activation of $\mathrm{H}_{2}$ by 67 and 68 .

Similar reactivity was observed with borenium $68 .{ }^{44}$ In this case however, longer reaction times were required ( $48 \mathrm{~h}$ vs. $3 \mathrm{~h}$ for 67 ) due to stronger donation of the $(i-\mathrm{Pr})_{2} \mathrm{P}$ moiety to $\mathrm{B}$, decreasing the $\mathrm{B}$ electron-deficiency (Scheme 19). The reaction with $\mathrm{H}_{2}$ provides a mixture of two spectroscopically similar compounds in a 2.5/1 ratio attributed to the phosphine-hydroborane monomer $\mathbf{7 1}$ and the 
corresponding dicationic dimer 72. The high field ${ }^{11} \mathrm{~B}$ (-8.4 and -1.2 ppm for $\mathbf{7 1}$ and $\mathbf{7 2}$, respectively) and low field ${ }^{31}$ P NMR signals (17.2 and 20.6 ppm for 71 and $\mathbf{7 2}$, respectively) are indicative of strong $P \rightarrow B$ interactions and tetracoordinate $B$ centres. The bonding situation in $\mathbf{7 1}$ was unambiguously determined in the solid state with a short P-B bond length (2.000(4) $\AA, r=1.05)$ and a pyramidalized $\mathrm{B}$ centre $\left(\Sigma_{\alpha} \mathrm{B}=334.6^{\circ}, \mathrm{THC}=60 \%\right)$ with coordination of $\mathrm{NTf}_{2}$ to $\mathrm{B}$. Dimerisation is only observed with the $(i-\mathrm{Pr})_{2} \mathrm{P}$ derivative (only the monomeric covalent form is observed with $\mathrm{Ph}_{2} \mathrm{P}$ ), and is thought to be the result of stronger donating ability and higher steric demand of the phosphino group which in turn results in a less Lewis acidic B centre in 71 (compared to 70) making $\mathrm{NTf}_{2}$ dissociation and formation of the 2-electron 3-centre B-H bridging interactions more favourable. These studies serve to highlight the effects of remote modulation of Lewis acidity at $B$ by varying the substituents on the P centre.

Besides the ability to activate $\mathrm{H}_{2}$, the high Lewis acidity of 64 , coupled with the propensity of Mes to fix a proton, allow activation of $\mathrm{N}-\mathrm{H}$ bonds, as substantiated by its reactivity with diphenylamine $\left(\mathrm{Ph}_{2} \mathrm{NH}\right)$ to provide the corresponding amino borenium salt 73 (Scheme 20). The ${ }^{11} \mathrm{~B}$ NMR signal (42.2 ppm) suggests a tricoordinate B centre, which is $32 \mathrm{ppm}$ upfield from 64 due to $\pi$-donation by the amino substituent. This bonding situation was confirmed in the solid state, evidenced by a short P-B bond (1.972(2) $\AA, r=1.03)$ as well as a short $N-B$ bond $(1.381(8) \AA, r=1.55)$ indicative of double bond character. The geometry at $B$ is trigonal planar $\left(\Sigma_{\alpha} B=359.9^{\circ}\right)$. This reaction is thought to occur in two steps: coordination of the amine to $B$, then elimination of Mes- $H$ through intramolecular aminolysis of the B-Mes bond.

Seeking to characterize the presumed intermediate of this aminolysis reaction, we reacted 67 with $\mathrm{NH}_{3}$ as a less acidic analogue of $\mathrm{Ph}_{2} \mathrm{NH}$. When 67 was treated with a $\mathrm{NH}_{3}$ atmosphere, the corresponding aminoborane $\mathbf{7 4}$ was obtained, with retention of the Mes group on $\mathrm{B}$ (Scheme 20). The ${ }^{11} \mathrm{~B}$ NMR signal $(40.4 \mathrm{ppm})$ is characteristic of a tricoordinate $B$ centre with a $31 \mathrm{ppm}$ upfield shift compared to 67 due to $\pi$-donation from $\mathrm{NH}_{2}$. The lack of a $\mathrm{P} \rightarrow \mathrm{B}$ interaction is supported by an upfield ${ }^{31} \mathrm{P}$ NMR signal (-12.6 ppm). This is confirmed in the solid state. The P-B distance (2.971(2) $\AA, r=1.56)$ is long while the N-B bond is short (1.390(3) $\AA, r=0.90)$ suggesting double bond character. The geometry at $B$ is trigonal planar $\left(\Sigma_{\alpha} B=359.03^{\circ}\right)$. Interestingly, reacting 67 with only one equivalent of $\mathrm{NH}_{3}$ allows formation of the corresponding boronium salt 75 (Scheme 20). The shifts of the ${ }^{11} \mathrm{~B}$ (highfield, at $-2.1 \mathrm{ppm}$ ) and ${ }^{31} \mathrm{P} \mathrm{NMR}$ signals (downfield, at $3.9 \mathrm{ppm}$ ) are diagnostic of a tetracoordinate $B$ centre and $P \rightarrow B$ interaction. This was confirmed in the solid state with a short P-B bond length (2.047(6) $\AA, r=1.07)$ and a longer $N-B$ bond (1.602(8) $\AA, r=1.03)$ indicative of single bond character. The geometry about $B$ is pyramidalized $\left(\Sigma_{\alpha} B=340.19^{\circ}, \mathrm{THC}=57 \%\right) .74$ and 75 can be interconverted by removing or adding excess ammonia to solutions of both derivatives. 


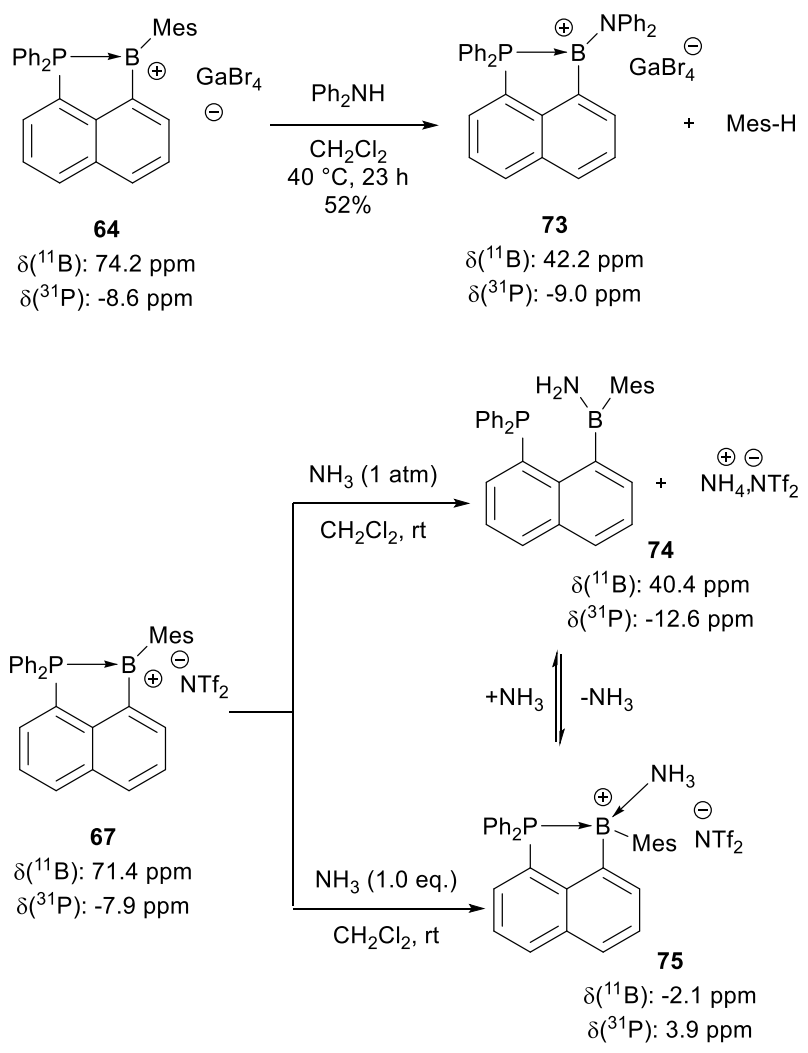

Scheme 20 Reaction of 64 with $\mathrm{Ph}_{2} \mathrm{NH}$ (substituent exchange at a borenium center), and reactivity of 67 with $\mathrm{NH}_{3}$ (coordination of $\mathrm{N}$ and $\mathrm{N}-\mathrm{H}$ bond activation).

Additionally, the reactivity of $\mathbf{6 4}$ with more acidic $\mathrm{N}-\mathrm{H}$ compounds could be leveraged by reacting $\mathrm{HNTf}_{2}$ in the presence of two equivalents of $\mathrm{Et}_{3} \mathrm{P}(\mathrm{O})$ to access 76, a rare example of a stable and isolable dicationic boron compound (Scheme 21$)$. The highly upfield ${ }^{11} \mathrm{~B} N M R$ signal (8.6 ppm) suggests a tetracoordinate $B$ centre while the ${ }^{31} \mathrm{P} N M R$ signal at $-8.7 \mathrm{ppm}$ evidences the persistence of the $\mathrm{P} \rightarrow \mathrm{B}$ interaction. The highly downfield shifted ${ }^{31} \mathrm{P} N \mathrm{NMR}$ signal attributed to (O) $\mathrm{PEt}_{3}(90.8 \mathrm{ppm})$ indicates the strength of the $O \rightarrow B$ interactions, due to the high Lewis acidity of the dicationic $B$ centre.

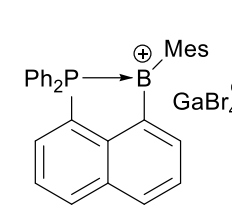

64

$\delta\left({ }^{11} \mathrm{~B}\right): 74.2 \mathrm{ppm}$ $\delta\left({ }^{31} \mathrm{P}\right):-8.6 \mathrm{ppm}$

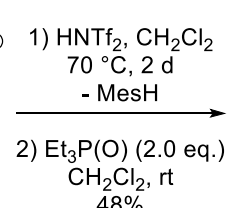
$48 \%$

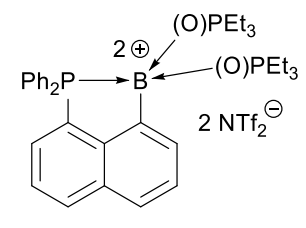

76

$\delta\left({ }^{11} \mathrm{~B}\right): 8.6 \mathrm{ppm}$ $\delta\left({ }^{31} \mathrm{P}\right):-8.7\left(\mathrm{br}, \mathrm{Ph}_{2} \mathrm{P}\right)$

$90.8\left(\mathrm{OPEt}_{3}\right) \mathrm{ppm}$

Scheme 21 Formation of the dicationic boron compound 76.

Our group has also developed an alternative synthesis to amino borenium salts. It starts by the installation of a chloro(diisopropylamino)boryl moiety on the naphthyl phosphine to give 77a (Scheme 22). ${ }^{45}$ In $\mathrm{C}_{6} \mathrm{D}_{6}$ as solvent, the downfield ${ }^{11} \mathrm{~B}$ NMR signal (33.3 ppm) suggests a tricoordinate $B$ centre and the upfield ${ }^{31} \mathrm{P} N M R$ signal $(-11.8 \mathrm{ppm})$, which is similar to that of the parent compound, was indicative of the lack of $P \rightarrow B$ interaction. This is most likely the effect of strong $N \rightarrow B \pi$-donation effectively decreasing the $B$ Lewis acidity. However, in a more polar solvent, such as $\mathrm{CDCl}_{3}$, the ${ }^{31} \mathrm{P}$ NMR signal moves downfield to $11.3 \mathrm{ppm}$, while the ${ }^{11} \mathrm{~B}$ NMR signal remains downfield at $37.9 \mathrm{ppm}$, 
suggesting the dissociation of $\mathrm{Cl}$ from $\mathrm{B}$ and concomitant formation of an intramolecular $\mathrm{P} \rightarrow \mathrm{B}$ interaction to stabilise the borenium salt form $\mathbf{7 7 b}$. This was supported by DFT calculations taking solvent into account using the PCM model, finding that $77 \mathbf{a}$ is more stable than $\mathbf{7 7 b}$ in benzene $\left(\Delta \mathrm{E}_{77 \mathrm{a} \rightarrow 77 \mathrm{~b}}=4.9 \mathrm{kcal} / \mathrm{mol}\right)$, while $77 \mathrm{~b}$ is slightly more stable than $77 \mathrm{a}$ in $\mathrm{CHCl}_{3}\left(\Delta \mathrm{E}_{77 \mathrm{a} \rightarrow 77 \mathrm{~b}}=-0.8\right.$ $\mathrm{kcal} / \mathrm{mol})$. The bonding situation in 77a was confirmed in the solid state, with a long $\mathrm{P}-\mathrm{B}$ distance $(2.867(2) \AA, r=1.50)$ and a trigonal planar $B$ centre $\left(\Sigma_{\alpha} B=359.7^{\circ}\right)$. In turn, the $N-B$ bond length is short (1.385(3) $\AA$, $r=0.89)$ indicating double bond character.

The nature of $\mathbf{7 7 b}$ as a borenium salt was confirmed by independent synthesis of borenium salt $\mathbf{7 8}$ through irreversible abstraction of $\mathrm{Cl}$ from $\mathrm{B}$ with $\mathrm{GaCl}_{3}$. The salts $\mathbf{7 7} \mathrm{b}$ and $\mathbf{7 8}$ present nearly identical spectroscopic data, suggesting a tricoordinate $B$ centre and $\mathrm{P} \rightarrow \mathrm{B}$ interaction (both the ${ }^{11} \mathrm{~B}$ and ${ }^{31} \mathrm{P}$ NMR signals shift downfield to 37.9 and $13.0 \mathrm{ppm}$, respectively). The structure of the borenium salt 78 was confirmed in the solid state, finding a short $\mathrm{P}-\mathrm{B}$ bond (1.989(2) $\AA$, $r=1.04)$ and a trigonal planar $\mathrm{B}$ centre $\left(\Sigma_{\alpha} \mathrm{B}=360^{\circ}\right)$. The $\mathrm{N}-\mathrm{B}$ bond is short $(1.384(2) \AA, r=0.89)$ again suggesting double bond character.

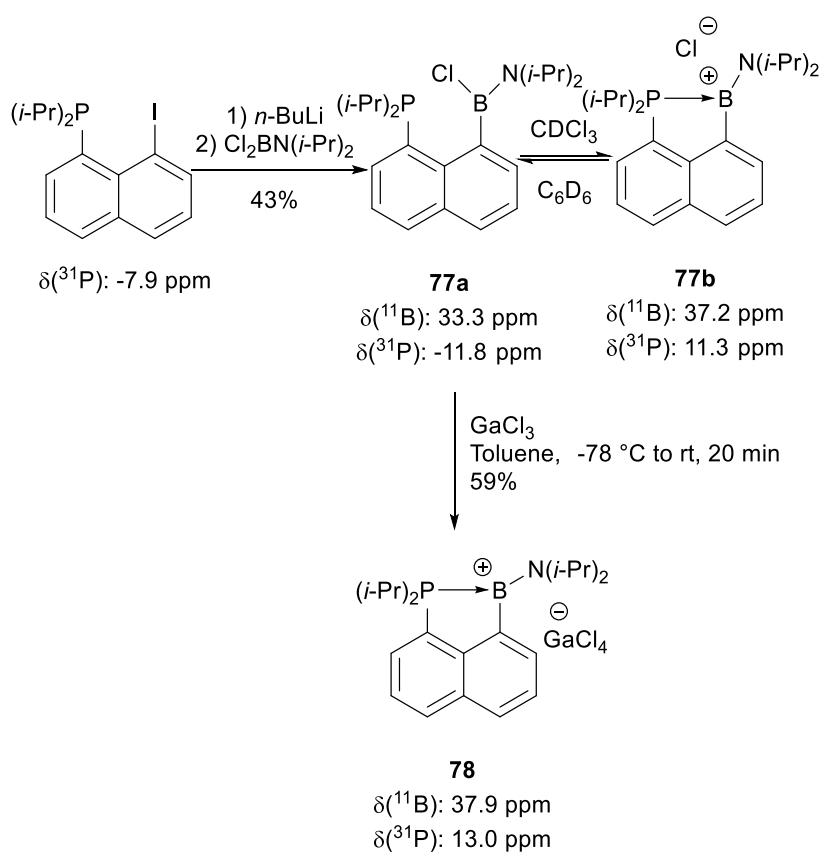

Scheme 22 Synthesis of the aminochloroborane $77 \mathrm{a} / \mathrm{b}$ and corresponding P-stabilised borenium salt 78.

Given the lack of $P \rightarrow B$ interaction in $77 a$, we postulated that the lone pair on $P$ would be available for external reactivity. This was demonstrated by reacting 77a with (tht)AuCl forming the corresponding phosphine gold(I) chloride complex 79 (Scheme 23). The ${ }^{11} \mathrm{~B}$ NMR signal (35.4 ppm) remains almost identical to the parent compound suggesting the retention of a tricoordinate $B$ centre. This bonding situation was confirmed in the solid state, with a trigonal planar $B$ centre $\left(\Sigma_{\alpha} B\right.$ $\left.=358.9^{\circ}\right)$. The P-Au-Cl skeleton is almost linear $\left(173.1^{\circ}\right)$. There is significant distortion in this system to accommodate the steric congestion imposed by all substituents as a $\mathrm{P}-\mathrm{C}_{\text {peri }}-\mathrm{C}_{\text {peri }}-\mathrm{B}$ torsion angle of $-43.9(1)^{\circ}$ is observed. Interestingly, there is no spectroscopic or structural evidence of the presence of an $A u \rightarrow B$ interaction as may have been expected. This probably results from the reduced electrophilic character of the $B$ centre due to $\pi$-donation from the amino substituent. 


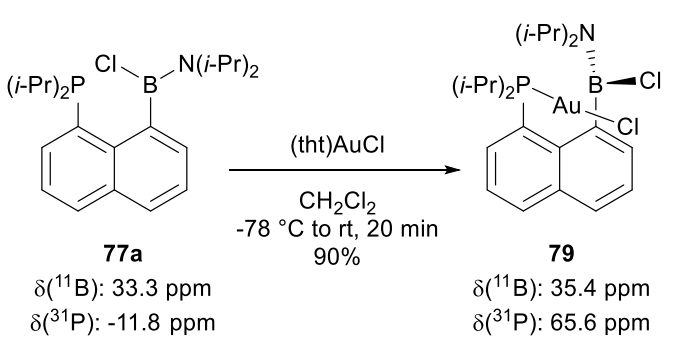

Scheme 23 Formation of phosphine gold(I) complex 79.

Finally, 67 was also found to readily react with 3-hexyne through a carboboration reaction furnishing the phosphonium-stabilised vinyl borenium salt $\mathbf{8 0}$, representing a rare example of $1,2-$ carboboration (Scheme 24). ${ }^{43}$ The spectroscopic data of $\mathbf{6 7}$ and 80 are very similar due to the exchange of the aromatic substituent on $B$ for a vinylic one. The upfield ${ }^{11} \mathrm{~B}$ NMR signal (64.9 ppm) suggests a tricoordinate $B$ centre. In a divergent reactivity pattern observed with the activation of $\mathrm{H}_{2}$ and $\mathrm{NH}_{3}$ bonds that yields neutral boranes, the 1,2-carboboration reaction transforms one borenium cation to another. However, in a similar fashion to the reaction with $\mathrm{H}_{2}$, the B-Mes bond is cleaved. Here, it adds stereospecifically in syn fashion across the $\mathrm{C} \equiv \mathrm{C}$ triple bond to form the vinyl borenium species 80 .

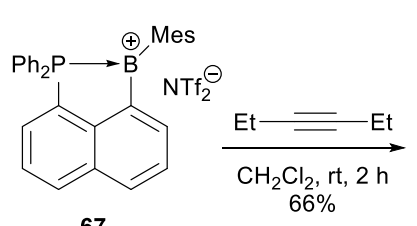

67

$\delta\left({ }^{11} \mathrm{~B}\right): 71.4 \mathrm{ppm}$

$\delta\left({ }^{31} \mathrm{P}\right):-7.9 \mathrm{ppm}$

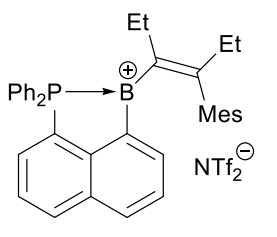

80

$\delta\left({ }^{11} \mathrm{~B}\right): 64.9 \mathrm{ppm}$ $\delta\left({ }^{31} \mathrm{P}\right):-4.0 \mathrm{ppm}$

Scheme 24 1,2-Carboboration of 3-hexyne with 67.

\subsection{P-stabilised boryl radicals}

Building on the body of work demonstrating the ability of naphthyl-enforced $P \rightarrow B$ interactions to stabilise reactive intermediates such as borenium cations, as described in the previous section, our group studied related boryl radicals. The ability to access such species was first assessed electrochemically by the reduction of the borenium cation $67 .{ }^{47} \mathrm{~A}$ quasi-reversible one-electron wave was observed at $-0.48 \mathrm{~V}\left(\mathrm{vs}\right.$. $\left.\mathrm{Fc}^{+} / \mathrm{Fc}\right)$, indicating much easier reduction than previously reported borenium/boryl couples whose potentials are significantly lower.

This encouraging result spurred the development of the chemical reduction of phosphinebromoboranes 61 and 62 with 1.2 equivalents of $1 \% \mathrm{Na}(\mathrm{Hg})$ amalgam in THF (Scheme 25). ${ }^{47,48} \mathrm{X}$ band EPR analysis of the ensuing species $\mathbf{8 1}$ and $\mathbf{8 2}$ revealed complex but well resolved signals centred at $g_{\text {iso }}=2.0026$. No change in the spectra was observed over days at room temperature, demonstrating the persistent character of these boryl radicals. Simulations successfully resolved the hyperfine structure taking into account couplings to ${ }^{11} \mathrm{~B}$ ( 11.0 and $10.9 \mathrm{G}$ for 81 and 82 , respectively) and ${ }^{31} \mathrm{P}$ nuclei (30.7 and $30.2 \mathrm{G}$ for 81 and $\mathbf{8 2}$, respectively) as well as two ${ }^{1} \mathrm{H}$ nuclei. The large $a\left({ }^{11} \mathrm{~B}\right)$ coupling indicates that spin density at B is unusually high. The values observed for $\mathbf{8 1}$ and $\mathbf{8 2}$ are in the upper range of previously reported persistent/isolable boryl radicals (7.3-13.2 G). ${ }^{49-53}$ They are also higher than those of triphenyl- and trimesityl-boron anion radicals (7.8 and 9.9 G, respectively). ${ }^{54-58}$ These coupling parameters were corroborated through theoretical calculations, which also allowed the attribution of the coupling to two ${ }^{1} \mathrm{H}$ nuclei on the naphthyl backbone (in 
ortho and para positions with respect to $B$ ). This indicates that the unpaired electron is partly delocalized over the naphthyl framework. Accordingly, the SOMOs of $\mathbf{8 1}$ and $\mathbf{8 2}$ were calculated to be mainly localized on $\mathrm{B}(45.5 \%$ and $57.3 \%$, respectively) with small contributions from $\mathrm{P}(8.9 \%$ and 9.3\%, respectively) as well as the naphthyl backbone itself (ipso- $\mathrm{C}$, ortho- $\mathrm{C}$ and para-C atoms with respect to $\mathrm{B})$. The optimized structures of both boryl radicals show trigonal planar $\mathrm{B}$ centres $\left(\Sigma_{\alpha}=\right.$ 359.6 and $360^{\circ}$ for $\mathbf{8 1}$ and $\mathbf{8 2}$, respectively) and short $\mathrm{P}-\mathrm{B}$ bond lengths ( 1.908 and $1.913 \AA, r=1.008$ and $1.002^{\circ}$ for $\mathbf{8 1}$ and $\mathbf{8 2}$, respectively). Intriguingly, the $P \rightarrow B$ interactions are shorter than in the corresponding borenium salts (1.997(6) and $2.006 \AA, r=1.05$ for 65 and 67 , respectively). This is surprising given that the boryl radicals are less electrophilic than the borenium salts and would therefore be expected to display weaker $\mathrm{P} \rightarrow \mathrm{B}$ interactions. The shorter $\mathrm{P}-\mathrm{B}$ bond length in $\mathbf{8 1}$ compared to $\mathbf{8 2}$ is also counterintuitive given the stronger $\mathrm{P}$ donation from $(i-\mathrm{Pr})_{2} \mathrm{P}$. However, these observations can be rationalized by reduced negative $2 \mathrm{p}(\mathrm{B}) \rightarrow \sigma^{*}(\mathrm{PC})$ hyperconjugation from $(i-\mathrm{Pr})_{2} \mathrm{P}$ compared to $\mathrm{Ph}_{2} \mathrm{P}$, this is supported by smaller contributions of $\mathrm{P}$ and $\mathrm{C}$ atoms in the Natural Localized Molecular Orbital (NLMO).

In the solid state, as determined unambiguously by X-ray crystallographic analyses, $\mathbf{8 1}$ and $\mathbf{8 2}$ dimerize to quinoid-type structures $\left[\mathbf{8 1}_{\mathbf{2}}\right.$ and $\left[\mathbf{8 2}_{\mathbf{2}}\right.$ (Scheme 25). The powders obtained upon crystallization are EPR silent confirming complete dimerization of the radicals. Dimerization occurs at the $\mathrm{B}$ centre of one unit and the $p$ - $\mathrm{C}_{\text {Naphthyl }}$ of another unit. Such Gomberg-type dimerization is quite rare for main group elements, as these radicals tend to dimerize through $\mathrm{E}-\mathrm{E}$ bond formation (the central atom $E$ is larger than $C$ ). The resulting C-B bond lengths (1.670(7) and 1.682(4) $\AA$ for $[81]_{2}$ and $[82]_{2}$, respectively) are typical of single $C-B$ bonds (sum of covalent radii $B-C\left(\mathrm{sp}^{3}\right) 1.60 \AA$, $r=1.04$ and 1.05 , respectively). The $B$ centre directly involved in dimerization is tetracoordinate and pyramidalized $\left(\Sigma_{\alpha} \mathrm{B}=345\right.$ and $342.2^{\circ}, \mathrm{THC}=49$ and $52 \%$, respectively), and the corresponding $\mathrm{P}-\mathrm{B}$ bond length increases (2.115(6) and 2.131(3) $\AA, r=1.11$ and 1.12 , respectively) due to steric hindrance. The other $B$ centre remains trigonal planar $\left(\Sigma_{\alpha} B=359.4\right.$ and $359.9^{\circ}$, respectively $)$ and the associated P-B bond length is short (1.934(6) and 1.935(3) $\AA, r=1.01$, respectively). The C-B bond is shortened in this unit (1.463(6) and 1.458(4) $\AA$ ) and is shorter than the sum of both covalent radii $\left(\mathrm{B}-\mathrm{C}\left(\mathrm{sp}^{2}\right)\right.$ 1.57, $r=0.93$, respectively) indicating double bond character.

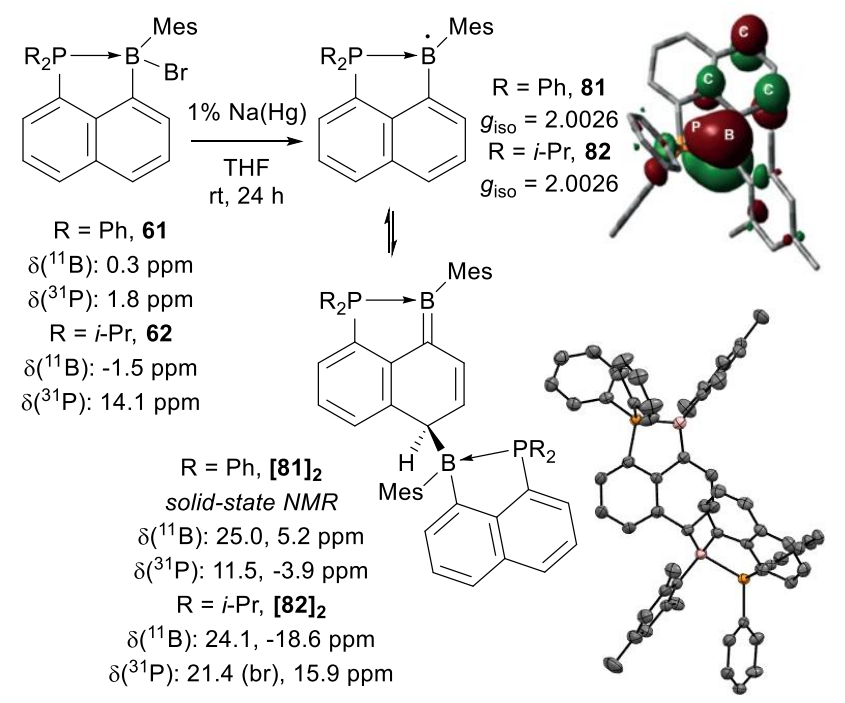

Scheme 25 Synthesis of the P-stabilised boryl radicals $\mathbf{8 1}$ and 82, and their Gomberg-type equilibrium, SOMO of 81; structure of the corresponding dimer [81 $]_{2}$ with carbon in grey, phosphorus in orange, boron in pink and $\mathrm{H}$ atoms omitted for clarity. 
Surprisingly, solutions of $\mathbf{8 1}$ and $\mathbf{8 2}$ are not NMR silent, the radical species are found to be in equilibrium with their corresponding dimeric quinoid-type structures [81 $]_{2}$ and [82 $]_{\mathbf{2}}$ (Scheme 25). Due to the low solubility of $\mathbf{8 1}$, the dimer $[\mathbf{8 1}]_{2}$ was fully characterized by solid state NMR, revealing two $B(25.0$ and $5.2 \mathrm{ppm})$ and $\mathrm{P}$ centres (11.5 and $-3.9 \mathrm{ppm}$ ) in different environments. Solution NMR spectra of 82 revealed similar characteristics with two distinct signals for both the ${ }^{11} B(24.1$ and $-18.6 \mathrm{ppm}$ ) and ${ }^{31} \mathrm{P}$ nuclei (21.4 and $\left.15.9 \mathrm{ppm}\right)$. The dimerization and equilibrium of both 81 and 82 with their respective dimers is analogous to that observed for the trityl radical $\left(\mathrm{Ph}_{3} \mathrm{C}^{\bullet}\right) \cdot{ }^{59,60}$ The monomer/dimer equilibrium was analysed by VT EPR spectroscopy in toluene or THF/toluene (1:1) and the dimerization energy $(\Delta G)$ was estimated to be -15 and $-12 \mathrm{kcal} / \mathrm{mol}$ for 81 and $\mathbf{8 2}$, respectively. Substituting $\mathrm{Ph}$ for $i$-Pr on $\mathrm{P}$ increases spin density at $\mathrm{B}$ and favours the radical over its dimer. Additionally, calculations found that head-to-tail dimerization was preferred over $\mathrm{B}-\mathrm{B}$ and $p$ $\mathrm{C}_{\text {Naphthyl }}-p-\mathrm{C}_{\text {Naphthyl }}$ coupling by $>10 \mathrm{kcal} / \mathrm{mol}$.

Aiming at exploring the effect of the substituent at B on the structure and stability of boryl radicals, novel phosphine-bromoboranes with highly sterically demanding aryl substituents at $B$, namely 2,4,6-triisopropylphenyl (Tip) and 2,6-dimesitylphenyl (Ter) were investigated (Scheme 26). ${ }^{61}$ Derivatives $\mathbf{8 3}$ and $\mathbf{8 4}$ were synthesised by trapping (6-diphenylphosphinonaphth-5-yl)lithium with $\mathrm{TipBBr}_{2}$ and $\mathrm{TerBBr}_{2}$, respectively. Despite the steric crowding imposed by these bulky groups, high field ${ }^{11} \mathrm{~B}$ (-0.1 and 0.7 ppm for 83 and 84 , respectively) and low field ${ }^{31} \mathrm{P}$ NMR signals (1.4 and 4.6 ppm, respectively) were maintained, indicative of tetracoordinate $B$ centres and $P \rightarrow B$ interactions. This bonding situation was confirmed in the solid state for both $\mathbf{8 3}$ and $\mathbf{8 4}$ finding short P-B distances (2.024(2) and 2.080(7) $\AA, r=1.06$ and 1.09, respectively) and pyramidalized $B$ centres $\left(\Sigma_{\alpha} B\right.$ $=337.7$ and $345.1^{\circ}, \mathrm{THC}=49 \%$, respectively). The naphthalene scaffold is found to respond to the steric bulk imposed by the Tip and Ter groups through significant distortions of both peri groups from the mean naphthalene plane $\left(\mathrm{P}-\mathrm{C}_{\text {peri }}-\mathrm{C}_{\text {peri }}-\mathrm{B}\right.$ torsion angles of $7.3(1)^{\circ}$ and $20.8(4)^{\circ}$ for 83 and $\mathbf{8 4}$, respectively). 


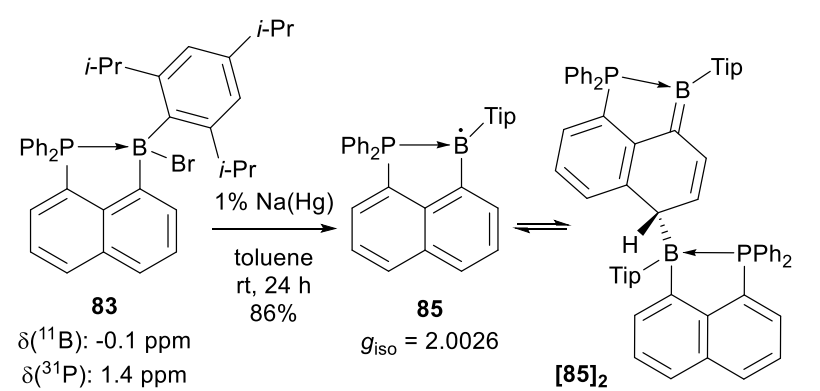

$\delta\left({ }^{11} \mathrm{~B}\right): 27.7,-3.6 \mathrm{ppm}$

$\delta\left({ }^{31} \mathrm{P}\right)$ : major $5.46,0.41(\mathrm{br}) \mathrm{ppm}$

minor: 9.58 (br), $4.98 \mathrm{ppm}$

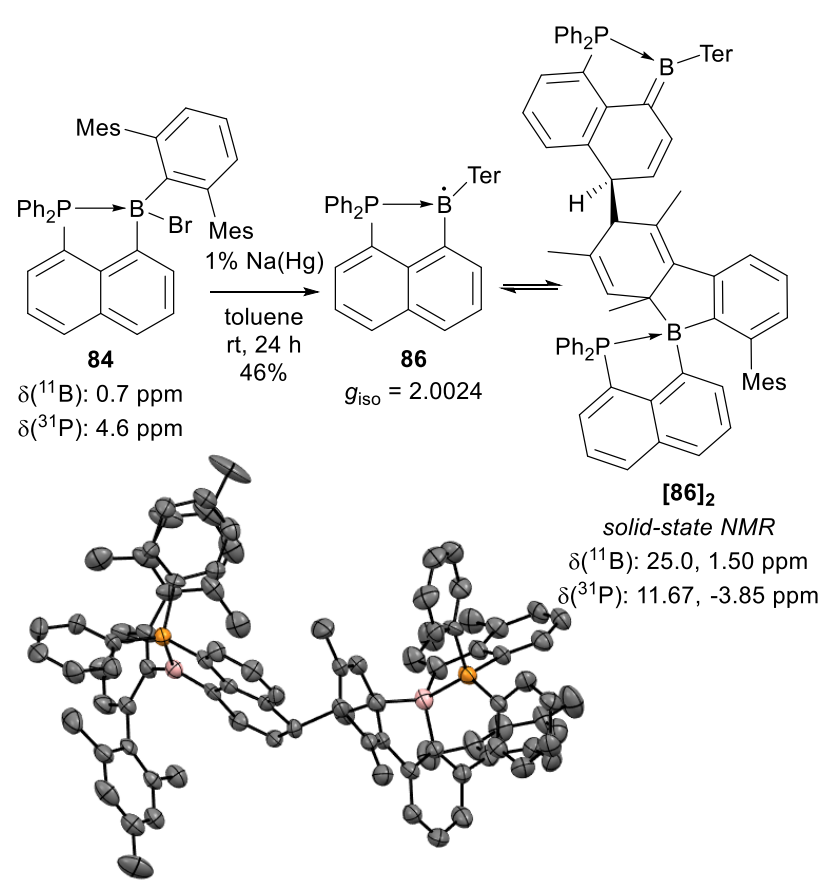

Scheme 26 Synthesis of the P-stabilised boryl radicals 85 and $\mathbf{8 6}$, and their dimerization equilibrium; structure of [86 $]_{2}$ with carbon in grey, phosphorus in orange, boron in pink and $\mathrm{H}$ atoms omitted for clarity.

Reduction of 83 and 84 with 1.3 equivalent of a $1 \% \mathrm{Na}(\mathrm{Hg})$ amalgam in toluene gave the corresponding boryl radicals 85 and 86 in moderate to high yields (Scheme 26). ${ }^{47,48}$ The X-band EPR spectrum of $\mathbf{8 5}$ is very similar to those of $\mathbf{8 1}$ and $\mathbf{8 2}$, with a well resolved signal centred at $g_{\text {iso }}=$ 2.0026. The EPR spectrum of 86 also shows a complex and well resolved signal centred $\left(g_{\text {iso }}=2.0024\right)$ but its hyperfine structure somewhat differs from those of $\mathbf{8 1 , 8 2}$ and $\mathbf{8 5}$. Larger couplings are found for 86 (11.5 and $31.4 \mathrm{G}$ for ${ }^{11} \mathrm{~B}$ and ${ }^{31} \mathrm{P}$, respectively). The $11.5 \mathrm{G}$ coupling to ${ }^{11} \mathrm{~B}$ is the largest reported so far for a persistent boryl radical, indicating particularly high concentration of the spin density on B. No changes in the EPR spectra of $\mathbf{8 5}$ and $\mathbf{8 6}$ were observed over days at room temperature, demonstrating the stability and persistence of these P-stabilised boryl radicals.

Like 81 and $\mathbf{8 2}$, solutions of $\mathbf{8 5}$ are not NMR silent, with spectra showing two sets of signals attributed to two diastereoisomers of the dimer [85] 2 (Scheme 26). Similarly, dimerization of [85] $]_{2}$ occurs at the $\mathrm{B}$ centre of one unit and the $p$ - $\mathrm{C}_{\text {Naphthyl }}$ of another unit and presents similar structural parameters to $\left[\mathbf{8 1}_{\mathbf{2}}\right.$ and $\left[\mathbf{8 2}_{2}\right]_{\mathbf{2}}$, as observed in the solid state. VT EPR spectroscopy was used to analyse the equilibrium between monomer and dimer finding $\Delta G=-9 \mathrm{kcal} / \mathrm{mol}$. This is smaller than the dimerization energy observed for $\mathbf{8 1}, 82$ and $\mathrm{Ph}_{3} \mathrm{C}^{\bullet}(-15,-12$ and $-11 \mathrm{kcal} / \mathrm{mol})$ indicating that 
the increased steric demand of the Tip moiety increases the thermodynamic stability of radical 85 but does not prevent its dimerization.

In the case of $\mathbf{8 6}$, characterization of the residue by solid state NMR similarly shows two different environments for both $B(25.0$ and $1.5 \mathrm{ppm})$ and $P$ centres (11.67 and $-3.85 \mathrm{ppm})$. However, the solid-state structure reveals an original dimerization not previously observed with other P-stabilised boryl radicals. Dimerization occurs in this case between the naphthyl carbon para to $B$ of one unit and the Ter substituent of another unit (Scheme 26). The B centre of the second unit couples with the ortho position of the Mes ring to form a quaternary $C$ centre and a 1,4-cyclohexadienyl moiety while generating a boron-centred spiro motif. The newly formed $C-C$ bond is long (1.61(1) $\AA, r=$ 1.06) and approaches the upper limit of known $\mathrm{C}\left(\mathrm{sp}^{3}\right)-\mathrm{C}\left(\mathrm{sp}^{3}\right)$ bonds. The new $\mathrm{B}-\mathrm{C}_{\text {Mes }}$ bond is long (1.66(1) $\AA, r=1.04)$ with a tetracoordinate and pyramidalized $B$ centre $\left(\Sigma_{\alpha} B=342.1^{\circ}, \mathrm{THC}=40 \%\right)$. The $\mathrm{P}-\mathrm{B}$ bond in this unit is short at 2.05(1) $\AA$ ( $r=1.07)$. The other $\mathrm{B}$ centre remains trigonal planar $\left(\Sigma_{\alpha} \mathrm{B}=359.9^{\circ}\right)$ and the corresponding $\mathrm{P}-\mathrm{B}$ bond is short (1.96(1) $\left.\AA, r=1.03\right)$. VT EPR experiments showed an equilibrium between monomer and dimer, but the kinetics were extremely slow, and the dimerization energy could not be estimated accurately. The Ter group imposes huge steric shielding to the $\mathrm{B}$ centre. This forces the boryl radical to react via remote positions although this dimerization pathway involves sites of low spin densities and disrupts the aromaticity of the naphthyl backbone and one Mes ring.

Given the similar dimerization energies of 82 and $\mathrm{Ph}_{3} \mathrm{C}^{\bullet}(-11 \mathrm{kcal} / \mathrm{mol})$, we postulated that heterocoupling could occur. This was confirmed by mixing both species in benzene. Crystals of $\mathbf{8 7}$ spontaneously deposited, enabling X-ray diffraction analysis (Scheme 27). Similar to the homocoupling dimers described above, heterocoupling occurs between the central carbon atom of $\mathrm{Ph}_{3} \mathrm{C}^{\bullet}$ and $p-\mathrm{C}_{\text {Naphthyl }}$ of $\mathbf{8 2}$. The resulting $\mathrm{C}-\mathrm{C}$ bond is very long (1.605(1) $\AA$ ). The $\mathrm{B}$ centre remains trigonal planar $\left(\Sigma_{\alpha} \mathrm{B}=359.46^{\circ}\right)$ and a short $\mathrm{P}-\mathrm{B}$ bond is maintained $(1.947(1) \AA \mathrm{A}, r=1.02)$. The $\mathrm{B}-\mathrm{C}_{\text {ipso }}$ bond is short (1.466(2) $\AA, r=0.93)$ signifying double bond character. To our knowledge, 87 is the first example of heterocoupling of $\mathrm{Ph}_{3} \mathrm{C}^{\bullet}$ with a persistent radical of a $\mathrm{p}$-block element. Calculations reproduced the coupling of the boryl and trityl radicals. Another minimum was located on the potential-energy surface for the $\mathrm{B}-\mathrm{C}_{\text {Trityl }}$ coupling product. It displays a long $\mathrm{B}-\mathrm{C}_{\text {Trityl }}$ bond (1.760 $\AA$, $r=1.10$ ) and sits $6.2 \mathrm{kcal} / \mathrm{mol}$ higher in energy compared to the $p-C_{\text {Naphtyl }}-C_{\text {Trityl }}$ coupling product.

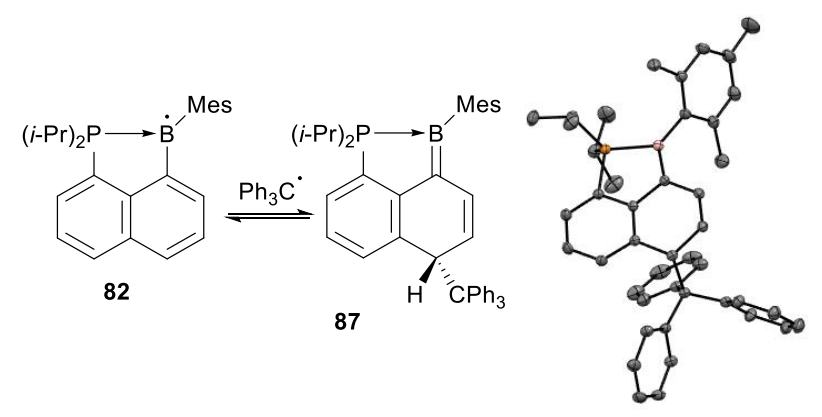

Scheme 27 Heterocoupling of $\mathbf{8 2}$ with $\mathrm{Ph}_{3} \mathrm{C}^{*}$; structure of $\mathbf{8 7}$ with carbon in grey, phosphorus in orange, boron in pink and $\mathrm{H}$ atoms omitted for clarity.

Prompted by the heterocoupling observed with $\mathrm{Ph}_{3} \mathrm{C}^{\bullet}$, we then investigated the trapping of the phosphine-boryl radicals $\mathbf{8 1}$ and $\mathbf{8 2}$ with the stable 2,2,6,6-tetramethylpiperidine-1-oxyl (TEMPO) radical (Scheme 28). Reactions occurred rapidly at room temperature to give $1: 1$ [ $\mathrm{R}_{2} \mathrm{P}$ (naph)BMes/TEMPO] adducts 88 and 89 in high yields. The observed low field ${ }^{11} \mathrm{~B}$ NMR signals 
(40.7 and 43.0 ppm for $\mathbf{8 8}$ and $\mathbf{8 9}$, respectively) are indicative of tricoordinate B centres while the high field ${ }^{31} \mathrm{P}$ NMR signals ( -9.52 and $-5.3 \mathrm{ppm}, 88$ and 89 , respectively) support the lack of intramolecular $\mathrm{P} \rightarrow \mathrm{B}$ interactions. These spectroscopic data suggest that these products adopt open structures. The $B$ Lewis acidity is lower due to strong $O \rightarrow B \pi$-donation of the TEMPO substituent, similar to that encountered in the previously described phosphine-aminoboranes 73, 74 and 77a. These bonding situations were unambiguously confirmed in the solid state, finding trigonal planar $B$ centres $\left(\Sigma_{\alpha} B=358.8\right.$ and $357.9^{\circ}$ for 88 and 89 , respectively). The $P-B$ distances are long (2.922(2) and 2.901(2) $\AA, r=1.53$ and 1.52), while the B-O bond are short (1.376(3) and 1.385(2) $\AA, r=0.92$ for 88 and $\mathbf{8 9}$, respectively), suggesting double bond character. The naphthyl scaffold displays flexibility in allowing significant distortions of the peri groups from the mean naphthalene plane $\mathrm{P}$ $\mathrm{C}_{\text {peri }}-\mathrm{C}_{\text {peri- }} \mathrm{B}$ torsion angles of 30.3 and $12.6^{\circ}$ for $\mathbf{8 8}$ and $\mathbf{8 9}$, respectively) to avoid steric repulsions from the bulky groups on $\mathrm{P}$ and $\mathrm{B}$. In this case, heterocoupling selectively occurs at B where most of the spin density is concentrated. No coupling to the $p$ - $C_{\text {Naphthyl }}$ site was observed.

The phosphine-boryl radicals were also found to be reactive in radical chlorine transfer reactions, with trityl chloride $\left(\mathrm{Ph}_{3} \mathrm{CCl}\right)$, to give the corresponding phosphine-chloroboranes (90 and $\left.\mathbf{9 1}\right)$ in good yields (Scheme 28). The high field ${ }^{11} \mathrm{~B}$ NMR signals (5.3 and $1.5 \mathrm{ppm}$ for 90 and $\mathbf{9 1}$, respectively) are diagnostic of tetracoordinate $B$ centres. The ${ }^{31} \mathrm{P}$ NMR signals ( 2.1 and $15.4 \mathrm{ppm}$, respectively) are very similar to those of the related phosphine-bromoboranes 61 and 62 (1.8 and 14.1 ppm, respectively). The solid-state structure of $\mathbf{9 0}$ was analysed by $\mathrm{X}$-ray diffraction, showing a short $\mathrm{P}-\mathrm{B}$ bond (2.063(2) $\AA, r=1.08)$ and a pyramidal geometry at $\mathrm{B}\left(\Sigma_{\alpha} \mathrm{B}=339.8^{\circ}, \mathrm{THC}=56 \%\right)$. The formation of 90 and 91 represents rare examples of halogen transfer to a $B$ centred radical and highlights the spin density concentration at the $B$ centres. Despite increased steric crowding at $B$ in $\mathbf{8 5}$, radical reactivity is maintained at the $B$ centre, as demonstrated by its heterocoupling with TEMPO and radical halogen transfer reactions with $\mathrm{Ph}_{3} \mathrm{CCl}$ to give the corresponding 1:1 adduct (92) and phosphine-chloroborane (93), respectively (Scheme 28). 


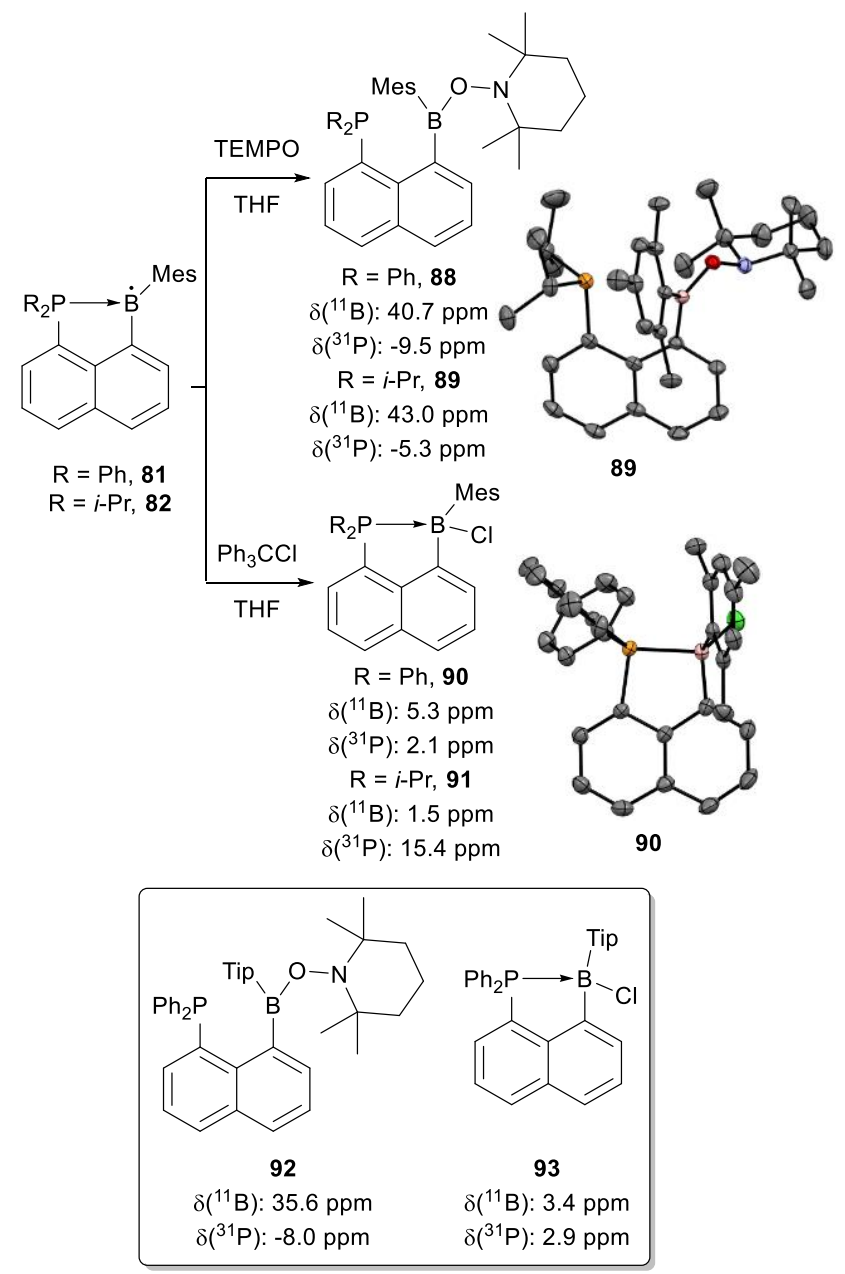

Scheme 28 Reactivity of the P-stabilised boryl radicals 81, 82 and 85 with TEMPO and $\mathrm{Ph}_{3} \mathrm{CCl}$; structures of $\mathbf{8 9}$ and $\mathbf{9 0}$ with carbon in grey, phosphorus in orange, nitrogen in blue, oxygen in red, boron in pink, chlorine in green and $\mathrm{H}$ atoms omitted for clarity.

\subsection{N/P-stabilised borylenes}

The synthesis, characterisation and reactivity of borylenes is an emerging field of research with increasing interest given to metal-free Lewis base stabilised borylenes (Chart 9). ${ }^{49,62-64}$ While Pbased exogenous Lewis bases have been used to stabilise and characterize borylene species, ${ }^{65,66}$ to date, there are no reports of isolated borylene derivatives incorporating the (ace)naphthalene with amino or phosphino groups at the peri position.<smiles>CN(C)C[B]C1N([O+])C(C)(C)CC12CCCC2</smiles><smiles>CC1(C)N[C@H]([B]NC(=O)c2ccccc2)N([13CH3])C1=O</smiles><smiles>CCP(C#N)[C]1N([Pb])C(C)(C)CC1(C)C</smiles>

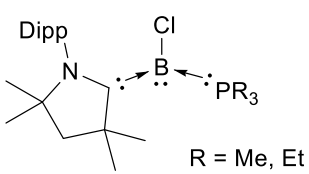

Chart 9 Selected examples of borylenes stabilised by one (top row) or two (bottom row) Lewis base(s). 
However, these systems have gained interest for their synthetic challenge, their unusual electronic structure and their potential reactivity. Lu, Wu et al. reported in 2019 a systematic study of a series of $L B \rightarrow B R$ borylenes, analysing the effect the Lewis base and substituent have on the electronic structure and geometry of these intriguing species. ${ }^{67}$ In particular, they optimized the structures and calculated singlet-triplet gap energies $\left(\Delta \mathrm{E}_{S T}\right)$ of 1-dimethylamino- (94) and 1dimethylphosphino-naphthyl (95) borylenes (Chart 10). The N-B derivative 94 is calculated to have a very small difference between its singlet and triplet state energies $\left(\Delta \mathrm{E}_{S T}=1 \mathrm{~kJ} / \mathrm{mol}\right.$ ) suggesting that both the singlet and triplet states may be accessible. The N-B bond in $\mathbf{9 4}$ is shorter in the triplet state $(1.62 \AA, r=1.09)$ than in the singlet state $(1.78, r=1.15)$. This is accompanied by a shortening of the $C-B$ bond (1.49 and $1.58 \AA, r=0.95$ and 1.00, for the triplet and singlet states, respectively), the length of which is suggestive of some double bond character. The N-B-C bond angle also widens in the triplet vs. singlet state $\left(106.5\right.$ vs. $\left.95.1^{\circ}\right)$. Both configurations display high coplanarity of the entire molecular structure, as apparent from the null $\mathrm{N}-\mathrm{C}_{\text {peri }}-\mathrm{C}_{\text {peri }}-\mathrm{B}$ torsion angle. Contrary to 94 , the triplet state is highly favored as ground state for the P-B derivative $95\left(\Delta \mathrm{E}_{S T}=-37 \mathrm{~kJ} / \mathrm{mol}\right)$. Similar bond contractions are observed from the singlet to the triplet state: the $\mathrm{P}-\mathrm{B}$ bond shortens from 2.00 to $1.89 \AA$ ( $r=1.05$ to 0.99 ) while the $\mathrm{C}-\mathrm{B}$ bond length decreases from 1.59 to $1.52 \AA$ ( $r=1.01$ to 0.97$)$. The P-B-C angle is also significantly more open in the triplet state $\left(104.6^{\circ}\right)$ than in the singlet state $\left(94.6^{\circ}\right)$. The optimised structure of 95 reveals significant distortions of both peri groups from the mean naphthalene plane $\left(\mathrm{P}-\mathrm{C}_{\text {peri }}-\mathrm{C}_{\text {peri }} \mathrm{B}\right.$ torsion of $\left.-10.1^{\circ}\right)$ as well as slight torsion of the naphthalene scaffold itself. In contrast, the structure of the triplet state displays high coplanarity, with no distortions of either peri group or the naphthalene backbone. While known examples of mono-Lewis base stabilised borylenes display near linear geometry (174.8-179.5 $), 94$ and 95 are anomalies with highly bent structures (the computed $\mathrm{E}^{15} \mathrm{~B}-\mathrm{C}$ bond angles are all below $106.5^{\circ}$ ). These geometrical constraints certainly play a role in the fact that the singlet state is not energetically favored for borylenes 94 and 95.

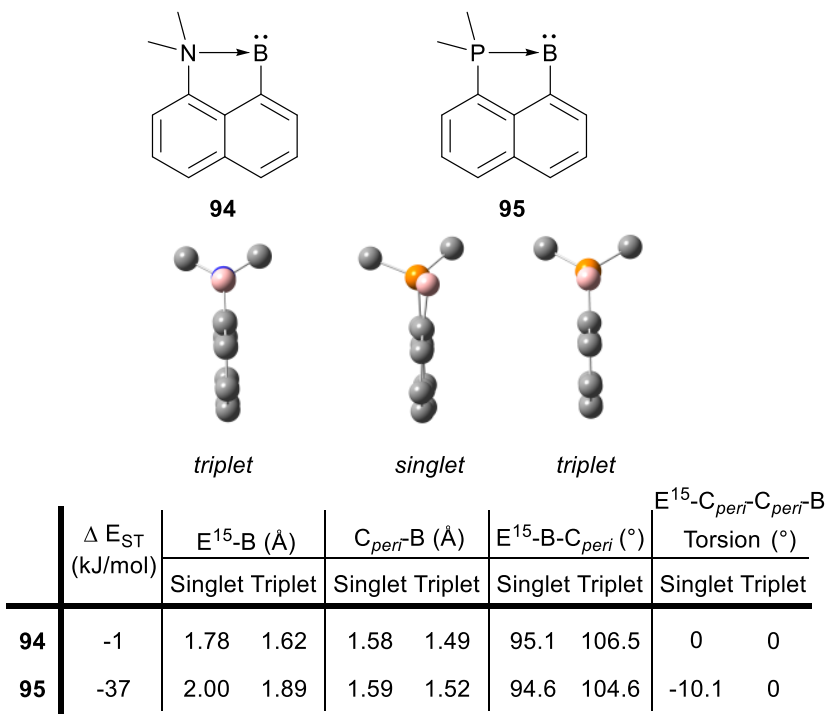

Chart $10 \mathrm{~N}$ - and P-stabilised borylenes $\mathbf{9 4}$ and $\mathbf{9 5}$ with key computed structural parameters; optimised structures (side views) with carbon in grey, nitrogen in blue, phosphorus in orange, boron in pink and $\mathrm{H}$ atoms omitted for clarity.

\section{Heavier pnictogen $\mathrm{E}^{15}-\mathrm{B}$ naphthalene derivatives}

As discussed above, numerous groups have investigated the ability of the naphthalene scaffold to enforce short contacts between $\mathrm{N}$ or $\mathrm{P}$ and $\mathrm{B}$ at the peri positions. The use of heavier group 15 
congeners is much more limited, with a single contribution. Gabbaï et al. reported in 2011 the synthesis and structure of $E^{15}$-B naphthyl derivatives with antimony (96) and bismuth (97) (Scheme 29). ${ }^{68}$ Their synthetic strategy leverages the ring strain of the dimesityl-1,8-naphthalenediylborate to react with either $\mathrm{Ph}_{2} \mathrm{SbCl}$ or $\mathrm{Ph}_{2} \mathrm{BiCl}$. Ring opening provides the corresponding $\mathrm{E}^{15}$ - $\mathrm{B}$ derivative in moderate to good yields. Steric crowding imposed by the substituents on both $E^{15}$ and $B$ results in unsymmetrical Mes groups, as evidenced by six distinct Me signals in the ${ }^{1} \mathrm{H}$ NMR spectra. However, ${ }^{11}$ B NMR signals (66 and 68 ppm for 96 and 97, respectively) are consistent with tricoordinate B centres, suggesting the absence of strong $E^{15} \rightarrow B$ interactions. This bonding situation was confirmed in the solid state, finding $E^{15}-B$ distances (3.216 and $3.330 \AA$ for 96 and $\mathbf{9 7}$, respectively) which are longer than the sum of their respective covalent radii $(2.23$ and $2.32 \AA$, for $\mathrm{Sb}-\mathrm{B}$ and $\mathrm{Bi}-\mathrm{B}$, respectively; $r=1.44)$ and trigonal planar $B$ centres $\left(\Sigma_{\alpha} B=358.7\right.$ and $359.2^{\circ}$ for 96 and 97, respectively). The naphthyl backbone accomodates the steric demand imposed by the substituents on $\mathrm{E}$ and $\mathrm{B}$ by deviating peri bond angles above the ideal $120^{\circ}\left(122.5(4)\right.$ to $\left.130.6(5)^{\circ}\right)$ as well as distorting both peri groups from the mean naphthalene plane ( 0.337 to $0.492 \AA$ ). As expected from the larger size of $\mathrm{Sb}$ and $\mathrm{Bi}$, the $\mathrm{E}^{15}-\mathrm{C}_{\text {Naphthyl }}$ bonds (2.157(6) and 2.268(6) $\AA$ for 96 and 97, respectively) are significantly longer than the $B-C_{\text {Naphthyl }}$ bonds (1.589(8) and 1.575(9) $\AA$ for 96 and 97, respectively), which places $E^{15}$ above $B$ in the plane of naphthalene scaffold and prevents strong $\mathrm{E}^{15} \rightarrow \mathrm{B}$ interactions (Scheme 29).

The DFT-optimised structures nicely reproduced those determined crystallographically, with the exception of slightly longer $E^{15}-B$ distances (3.410 and $3.448 \AA$ for 96 and 97 , respectively). Interestingly, $\mathrm{NBO}$ analyses indicate the presence of weak $\mathrm{E}^{15} \rightarrow \mathrm{B}$ interactions (deletion calculations lead to energy increases of $8.6 \mathrm{kcal} / \mathrm{mol}$ for 96 and $6.3 \mathrm{kcal} / \mathrm{mol}$ for 97$)$. The rigid naphthyl scaffold plays a major role in these weak $E^{15} \rightarrow B$ bonding interactions. Indeed, attempts to optimize Lewis pair structures for the corresponding intermolecular adducts $\mathrm{Ph}_{3} \mathrm{E}^{15} \rightarrow \mathrm{BPh}_{3}$ systematically led to complete dissociation.

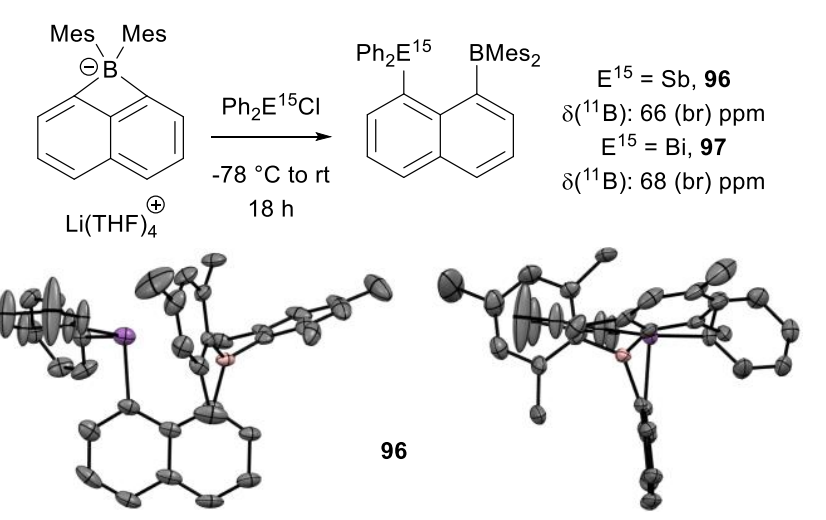

Scheme 29 Synthesis of the Sb- and Bi-B compounds 96 and 97; structures of 96 (front and side views) with carbon in grey, antimony in purple, boron in pink and $\mathrm{H}$ atoms omitted for clarity.

\section{Biphenylene, (Thio)Xanthene and Dibenzofuran-bridged P-B derivatives}

Biphenylene, (thio)xanthene and dibenzofuran scaffolds can be viewed as expanded naphthalene systems incorporating cyclobutadiene, (thio)pyran or furan moieties. P-B derivatives featuring these spacers have been studied and shown to display properties complementary to those of (ace)naphthyl-bridged compounds. As discussed, hereafter, the long distances imposed between $\mathrm{P}$ and $\mathrm{B}$ (Chart 11) impart unusual coordination modes and favors reversible interaction with small molecules such as $\mathrm{H}_{2}$ and $\mathrm{N}_{2} \mathrm{O}$. 


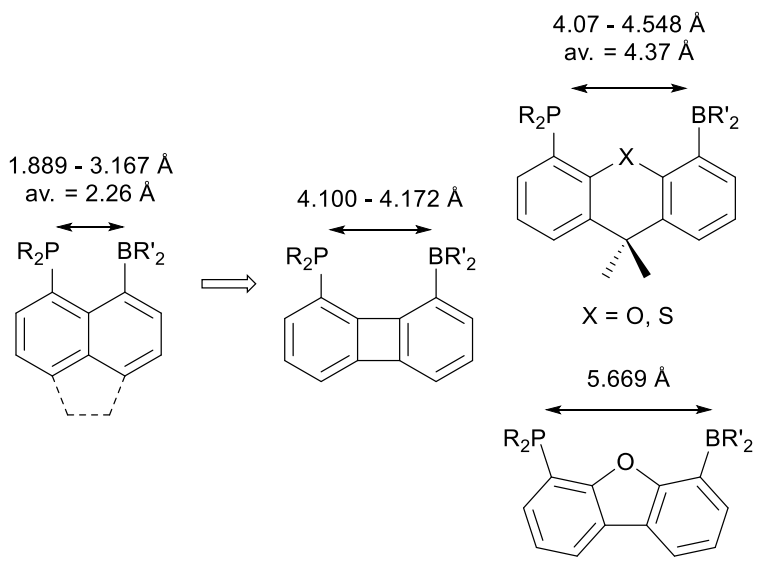

Chart 11 Comparison of ranges and average P-B distances in crystallographically characterised (ace)naphthalene, dibenzofuran, biphenylene, and (thio)xanthene compounds.

The first such P-B derivative featuring a rigid expanded spacer, 98, was reported by Emslie et al. in 2006 (Chart 12). ${ }^{69}$ It was obtained in $66 \%$ overall yield by stepwise lithiation phosphination and borylation. Reversible coordination of acetonitrile to boron was used to isolate $\mathbf{9 8}$ in pure form. Its extreme solubility even in apolar solvents prevents the growth of crystals and X-ray diffraction analysis, but spectroscopic data clearly indicate that no $P \rightarrow B$ interaction occurs, and the structure remains open. The reactivity of this derivative towards small molecules has not been reported, but its coordination properties have been extensively investigated. The ambiphilic nature of $\mathbf{9 8}$ results in original complexes featuring unusual coordination modes (see Chart 12 for representative examples). Due to the open nature of $\mathbf{9 8}$, the $P$ moiety is available to bind metals, while the Lewis acidic $B$ functionality is ready to interact with co-ligands in the second coordination sphere (such as in the $\mathrm{Pd}(\mathrm{dba})$ complex 99). ${ }^{69}$ The ?-delocalized $\mathrm{BPh}_{2}$ fragment is also prone to engage in multicenter $\eta^{2}-\mathrm{B} C_{i p s o}$ and $\eta^{3}-\mathrm{BC}_{i p s o} C_{\text {ortho }}$ coordination, ${ }^{70}$ as observed with $\mathrm{Rh}(\mathbf{1 0 0}),{ }^{71} \mathrm{Pd}(\mathbf{1 0 1})$ and $\mathrm{Ni}(\mathbf{1 0 2})^{72}$. Additionally, the P-B ligand 98 allowed the observation of bridging $\mathrm{M}-\mathrm{X}-\mathrm{B}$ interactions with $\mathrm{Pd}$ (103), Pt (104) ${ }^{72,73}$ and $\mathrm{Rh}(\mathbf{1 0 5 - 1 0 7})^{74}$. Of interest, reaction of 98 with [PtMe $\left.2(\mathrm{COD})\right]$ enables the detection and characterisation of the zwitterionic complex 108, en route to the rearranged complex 109 (with Ph groups now at Pt and Me groups now at B). Here, the Lewis acid moiety abstracts the co-ligand from the metal, opening the way for methyl/aryl exchange between the platinum and boron. $^{75}$ 
<smiles>CC(C)(C)c1cc(P)c2c(c1)C(C)(C)c1cc(C(C)(C)C)cc(P(c3ccccc3)c3ccccc3)c1S2</smiles>

$\delta\left({ }^{11} \mathrm{~B}\right): 69(\mathrm{v} \mathrm{br}) \mathrm{ppm}$ $\delta\left({ }^{31} \mathrm{P}\right):-8.65(\mathrm{~s}) \mathrm{ppm}$

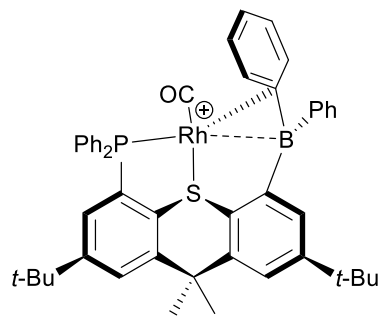

100

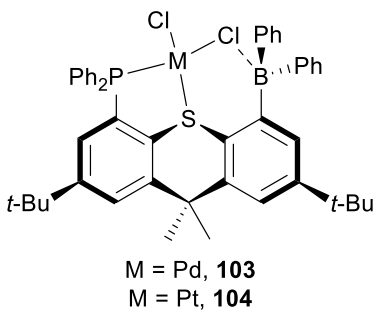

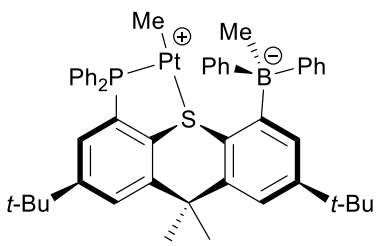

108

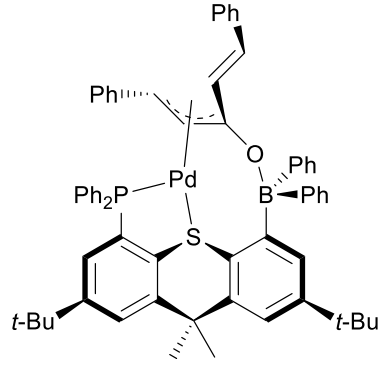

99<smiles>CC(C)(C)c1cc2c3c(c1)C(C)(C)c1cc(C(C)(C)C)cc(c1S3)[B-](c1ccccc1)(c1ccccc1)P2c1ccccc1</smiles>

$M=P d, 101$

$\mathrm{M}=\mathrm{Ni}, 102$

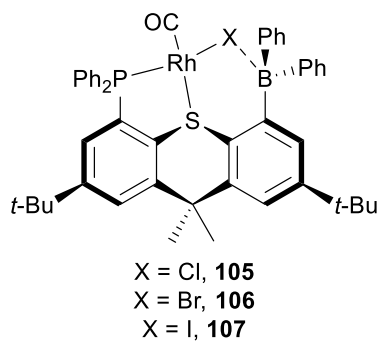<smiles>CB(C)c1cc(C(C)(C)C)cc2c1SB1c3c(cc(C(C)(C)C)cc3[PH]2P(c2ccccc2)c2ccccc2)P1c1ccccc1</smiles>

109

Chart 12 Thioxanthene-bridged P-B ligand 98 and representative complexes thereof.

Looking towards the development of FLPs for potential applications as chemical sensors and catalysis, several groups have investigated novel single component phosphine-boranes displaying reversibility in the activation of small molecules. They postulate that a geometrically constrained FLP with a P-B separation in the 4.2-4.8 $\AA$ range may allow for the reversible activation of $\mathrm{H}_{2} .{ }^{76,77}$ This supposition is built on the premise that once $\mathrm{H}_{2}$ is activated, the lack of conformational flexibility of the backbone and the confinement of the resultant hydridic/protic $\mathrm{H}$ atoms in close proximity preorganises the system for $\mathrm{H}_{2}$ release (Chart 13). In such a situation, the activation energies of both the forward and reverse processes were expected to be lowered.

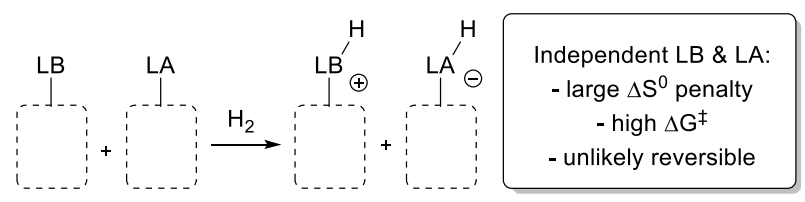

vs.

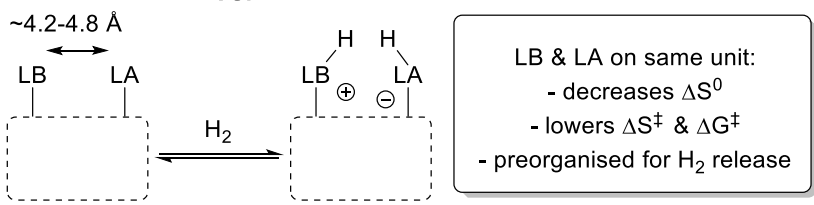


Chart 13 Concept and strategy of preorganised FLPs for the reversible activation of $\mathrm{H}_{2}$.

With this goal in mind, they turned to dibenzofuran and dimethylxanthene backbones, and prepared new P-B derivatives by stepwise lithiation phosphination and borylation (110 and 111-114, Scheme 30). ${ }^{76,77}$ All derivatives adopt FLP-type structures without $P \rightarrow B$ interactions. The ${ }^{11} B$ NMR chemical shifts (58.2-69.5 ppm) are diagnostic of tricoordinate $B$ centres, while the ${ }^{31} \mathrm{P} N M R$ shifts are indicative of free phosphines. This is further evidenced in $\mathrm{C}_{6} \mathrm{~F}_{5}$-containing derivatives 110-114 by large differences (>10 ppm) in ${ }^{19} \mathrm{~F}$ NMR chemical shifts between the $m$ - and $p$-F signals (Scheme 30). ${ }^{27}$ The lack of $P \rightarrow B$ interactions was confirmed in the solid-state for all derivatives, finding trigonal planar $\mathrm{B}$ centres $\left(\Sigma_{\alpha} \mathrm{B}=359.6-360^{\circ}\right)$ and long $\mathrm{P}-\mathrm{B}$ distances $(4.070(2)-5.669(1) \AA, r>2)$.

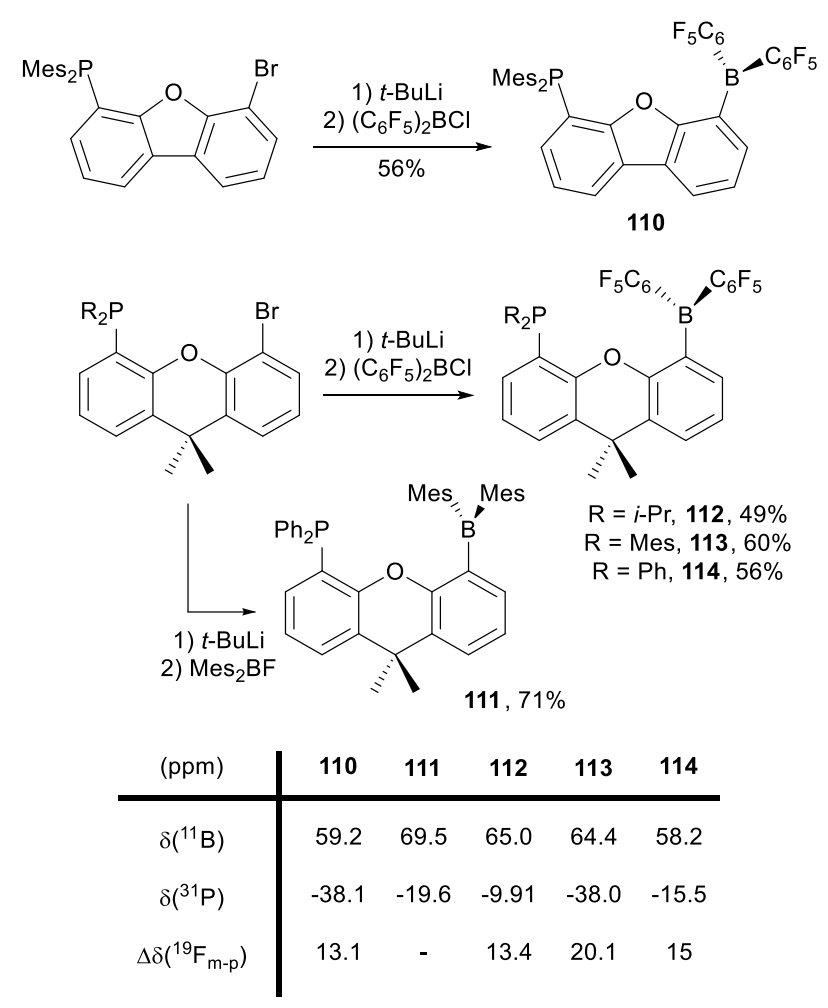

Scheme 30 Synthesis and key NMR data of dibenzofuran 110 and xanthene derivatives 111-114.

The propensity of these derivatives to activate $\mathrm{H}_{2}$ was then investigated. Both $\mathbf{1 1 0}$ and $\mathbf{1 1 1}$ were found to be unreactive towards $\mathrm{H}_{2}$. This was rationalised by the large $\mathrm{P}-\mathrm{B}$ separation in $\mathbf{1 1 0}$ and by the weak Lewis acidity/basicity of 111. Increasing both the Lewis acidity of $B$ and the Lewis basicity of $P$, such as in 112, allows for the activation of $\mathrm{H}_{2}$ (Scheme 31). The resulting phosphonium borate 115 was characterised in the solid-state, confirming the activation of $\mathrm{H}_{2}$. Upon $\mathrm{H}_{2}$ activation, the $B$ centre strongly pyramidalizes $\left(\Sigma_{\alpha} \mathrm{B}=335.3(2)^{\circ}, \mathrm{THC}=79 \%\right)$, the P-B distance shortens (from 4.487(3) $\AA$, $r=2.35$ in the parent FLP 112, to 4.104(3) $\AA, r=2.15$ in 115), while the $\mathrm{H}-\mathrm{H}$ separation is 2.07(5) A. The phosphonium borate 115 seems predisposed for $\mathrm{H}_{2}$ release, due to the rigid structure that confines the hydridic and protic components to the central cavity, but no detectable $\mathrm{H}_{2}$ release could be observed from 115 even upon heating to $80^{\circ} \mathrm{C}$. The lack of reversibility is attributed to the $\sigma$-donating $i$ - $\operatorname{Pr}$ substituents at $\mathrm{P}$, which make the reverse reaction energetically unfeasible. 


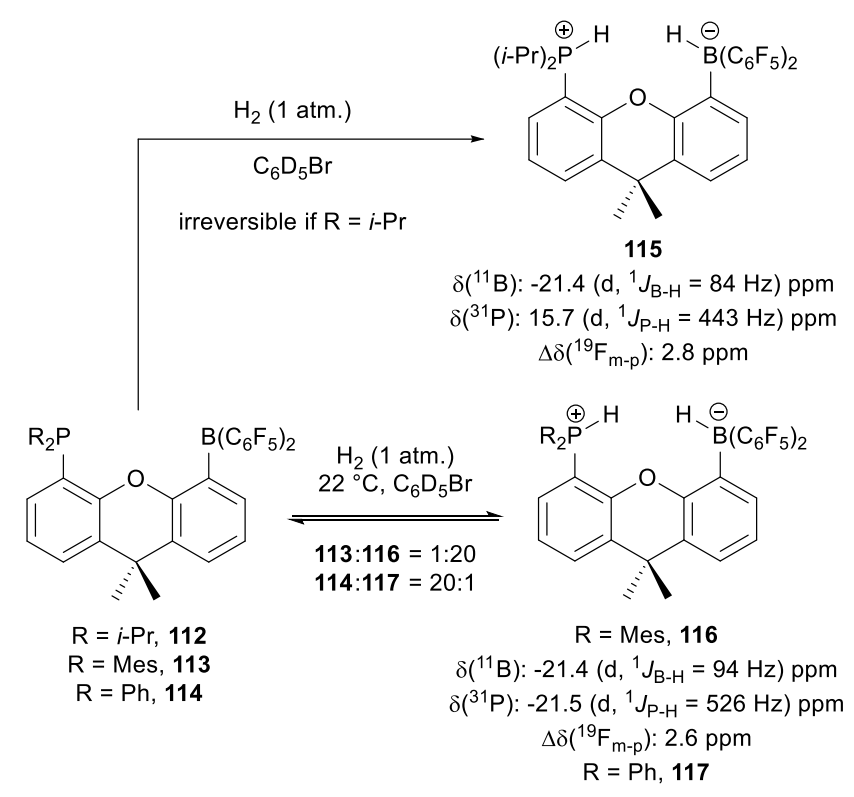

Scheme 31 (Reversible) activation of $\mathrm{H}_{2}$ by 112-114.

Upon decreasing the Lewis basicity with Mes groups at $\mathrm{P}$, activation of $\mathrm{H}_{2}$ is maintained but the process is now reversible. Compound $\mathbf{1 1 3}$ enables uptake and release of $\mathrm{H}_{2}$ (Scheme 31). The structure of the ensuing phosphonium borate $\mathbf{1 1 6}$ was confirmed spectroscopically and crystallographically, displaying similar characteristics to 115. $D_{5}$-bromobenzene solutions of 116 show an equilibrium between free FLP 113 and $116\left(1: 20\right.$, at $22{ }^{\circ} \mathrm{C}$, respectively). Varying the temperature allowed the determination of the thermodynamic parameters $\Delta H^{0}=38 \mathrm{~kJ} / \mathrm{mol}$ and $\Delta S^{0}$ $=102 \mathrm{~J} / \mathrm{mol} / \mathrm{K}$. This can be compared to the $p-\left(\mathrm{Mes}_{2} \mathrm{PH}\right)-\mathrm{C}_{6} \mathrm{~F}_{4}-\left[\mathrm{B}\left(\mathrm{C}_{6} \mathrm{~F}_{5}\right)_{2} \mathrm{H}\right]$ system described by Stephan et al. in which $\mathrm{H}_{2}$ release occurs at temperatures greater than $100{ }^{\circ} \mathrm{C}$, with the thermodynamic parameters $\Delta H^{0}=90 \mathrm{~kJ} / \mathrm{mol}$ and $\Delta S^{0}=96 \mathrm{~J} / \mathrm{mol} / \mathrm{K} .{ }^{78}$ The lower magnitude of the enthalpic term for $\mathbf{1 1 3}$, due to the lower Lewis acidity/basicity of $B$ and $P$, respectively, facilitates the release of $\mathrm{H}_{2}$ at much lower temperatures. The free energies for $\mathrm{H}_{2}$ release $\left(\Delta \mathrm{G}_{\mathrm{H}}\right)$ were calculated for the phosphonium borates deriving from $110(-6.40 \mathrm{kcal} / \mathrm{mol}), 112(-0.97 \mathrm{kcal} / \mathrm{mol})$ and $113(-1.85 \mathrm{kcal} / \mathrm{mol}) .{ }^{79}$ These data match well the experimental observations and highlight the effects of the backbone (110) and substituents on $P$ (112 vs. 113). Further reduction of the Lewis basicity of $\mathrm{P}$ by incorporating $\mathrm{Ph}$ groups (114) makes the uptake of $\mathrm{H}_{2}$ less favored thermodynamically (Scheme 31). Solutions of $\mathbf{1 1 4}$ in $d_{5}$-bromobenzene under 4 atm. of $\mathrm{H}_{2}$ show only $5 \%$ conversion to the phosphonium borate 117 at $22{ }^{\circ} \mathrm{C}$. Thermodynamic parameters could be determined, finding $\Delta H^{0}=34 \mathrm{~kJ} / \mathrm{mol}$ and $\Delta S^{0}=138 \mathrm{~J} / \mathrm{mol} / \mathrm{K}$.

The reversibility of $\mathrm{H}_{2}$ activation motivated the authors to investigate the xanthene-derived P-B compounds as catalysts for dehydrogenation reactions. In particular, $\mathbf{1 1 4}$ for which $\mathrm{H}_{2}$ release is facile, was shown to be capable of dehydrogenating dimethylamine-, methylamine- and amineborane under mild conditions $\left(1 \mathrm{~mol} \%, 55^{\circ} \mathrm{C}\right)$. This stands as a rare example of a metal-free catalyst for this process (Scheme 32). ${ }^{77}$ Detailed experimental mechanistic investigations were undertaken, involving stoichiometric reactions as well as the independent syntheses of off-cycle products and reaction intermediates. These studies allowed the authors to confirm that oligomerisation is initiated by $\mathrm{B}-\mathrm{H}$ activation, forming first the phosphonio-borate $\mathbf{1 1 8}$. This is followed by stepwise end-growth $\mathrm{B}-\mathrm{N}$ coupling (between a terminal $\mathrm{N}-\mathrm{H}$ bond of the bound fragment and a $\mathrm{B}-\mathrm{H}$ bond of the incoming monomer), releasing $\mathrm{H}_{2}$ and giving intermediate 119. After each monomer coupling, the resulting $\mathrm{P}$-bound amino-borane chain is engaged in $\mathrm{NH} \cdots \mathrm{HB}\left(\mathrm{C}_{6} \mathrm{~F}_{5}\right)_{2}$ hydrogen bonding (in 119, 
the $\mathrm{H}-\mathrm{H}$ distance is $1.85 \AA$ ). Coupling a third monomer results in the formation of the cyclic borazane, which finally affords the borazine upon dehydrogenation (Scheme 32).

The phosphine-borane $\mathbf{1 1 4}$ was also found competent in $\mathrm{B}-\mathrm{H}$ bond activation, albeit with a different mode of reactivity than that presented above. Reactions of $\mathbf{1 1 4}$ with pinacolborane (HBpin) and catecholborane (HBCat) induces boryl exchange at the xanthene backbone via $\mathrm{B}-\mathrm{C} / \mathrm{B}-\mathrm{H} \sigma-b o n d$ metathesis, and the released Piers' borane $\mathrm{HB}\left(\mathrm{C}_{6} \mathrm{~F}_{5}\right)_{2}$ is trapped by the $\mathrm{P}$ centre as a classic Lewis adduct (Scheme 33).80 The resulting derivatives 120 and 121 have been spectroscopically and crystallopgraphically characterized. They display two sets of ${ }^{11} \mathrm{~B}$ NMR signals in the typical range for tri- and tetracoordinate B centres. Interestingly, compounds 120 and 121 were independently synthetised from the analogous xanthene-bridged FLPs incorporating Bpin and Bcat moieties, 122 and 123, respectively (Scheme 33). Similar to the $B M e s_{2}$ and $B\left(C_{6} F_{5}\right)_{2}$ derivatives 111-114, the scaffold prevents the formation of $P \rightarrow B$ interactions in $\mathbf{1 2 2}$ and $\mathbf{1 2 3}$. The $B$ centres remain tricoordinate as apparent from ${ }^{11} \mathrm{~B} N M R$ spectroscopy (31.0 and $32.0 \mathrm{ppm}$, respectively), and X-ray diffraction analyses: the $B$ centres adopt trigonal planar environments $\left(\Sigma_{\alpha} B=360^{\circ}\right.$ and $359.9(2)^{\circ}$, respectively) and the $\mathrm{P}-\mathrm{B}$ distances are long $(4.548(2)$ and $4.377(2) \AA, r=2.38$ and 2.29, respectively).
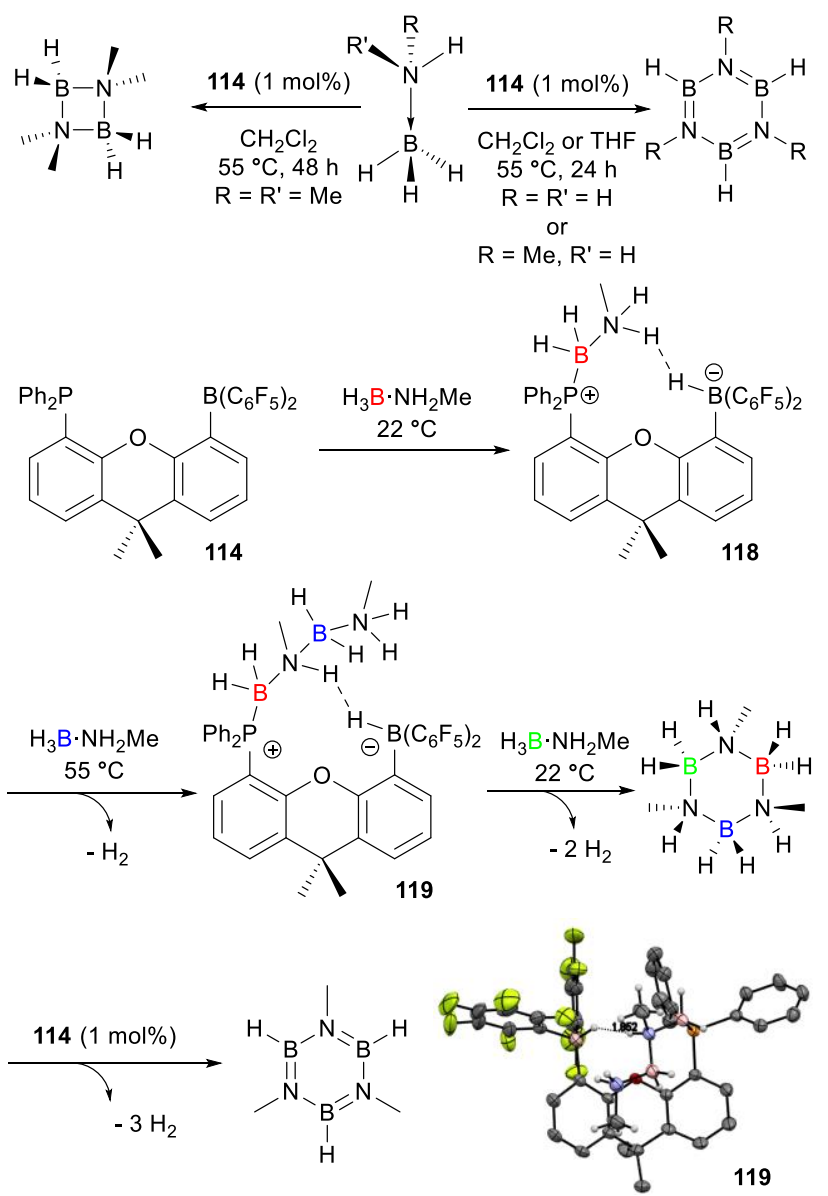

Scheme 32 Catalytic dehydrogenation of amino-boranes by $\mathbf{1 1 4}$ and associated mechanism; X-ray structure of intermediate $\mathbf{1 1 9}$ with carbon in grey, nitrogen in blue, boron in pink, oxygen in red, fluorine in green, phosphorus in orange, and $\mathrm{H}$ atoms of backbone omitted for clarity. 


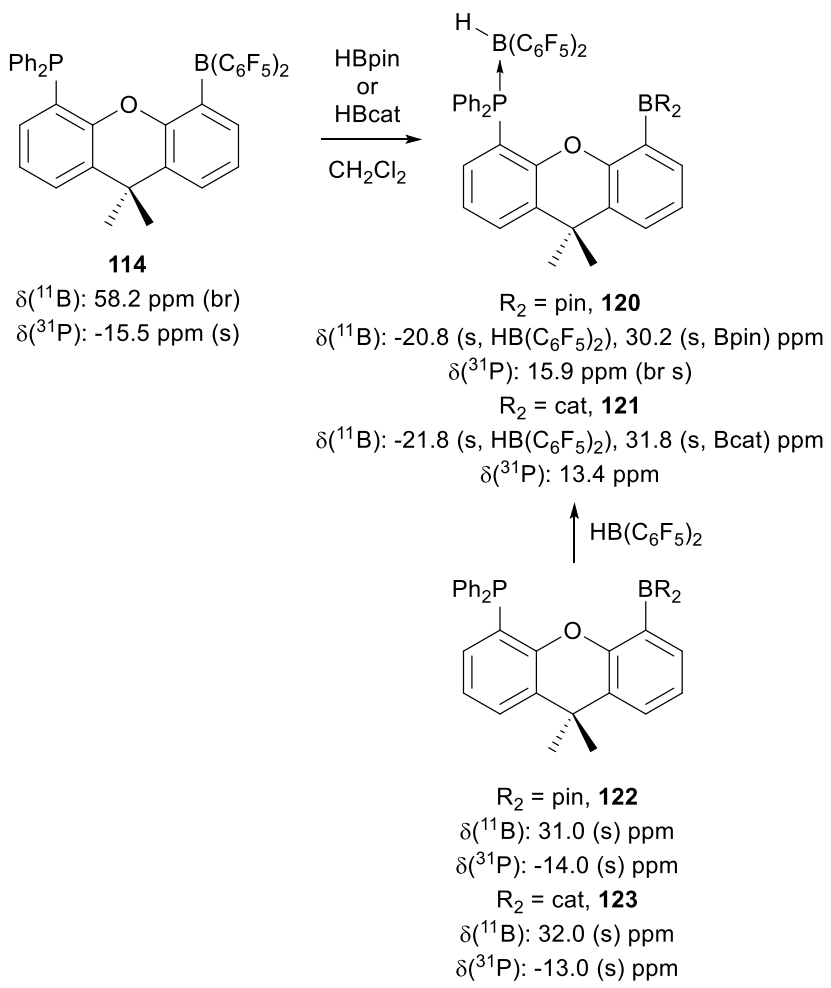

Scheme 33 Activation of B-H bonds and boryl exchange with 114.

In line with the reactivity of xanthene-bridged P-B derivatives described thus far, Vasko, Kamer, Aldridge et al. reported the ability of $\mathbf{1 1 3}$ and $\mathbf{1 1 4}$ to activate $\mathrm{C}(\mathrm{sp})-\mathrm{H}$ bonds. ${ }^{80}$ Derivatives 113 and 114 react with phenylacetylene ( $\mathrm{PhCCH}$ ) to provide the corresponding phosphonium alkynylborates 124 and 125, respectively (Scheme 34). Interestingly, the $\mathrm{C}(\mathrm{sp})-\mathrm{H}$ activation is reversible with the $\mathrm{PPh}_{2}$ compound $\mathbf{1 1 4}$ (solutions of $\mathbf{1 2 5}$ show signals related to 114 and free $\mathrm{PhCCH}$ ), but not with 113 featuring a more basic PMes, moiety. Solid-state analysis of $\mathbf{1 2 4}$ confirms the activation mode of the alkyne, finding a $\mathrm{P}-\mathrm{H}$ phosphonium group and a nearly linear $\mathrm{B}-\mathrm{CCPh}$ borate fragment $\left(171.7^{\circ}\right)$. While solutions of $\mathbf{1 2 4}$ are stable, $\mathbf{1 2 5}$ undergoes further transformation over the course of several hours to give the peculiar phosphonium borate 126 incorporating two additional molecules of phenylacetylene, as elucidated by X-ray crystallography (Scheme 34). The formation of 126 is inherently linked to the reversibility of the reaction of 114 with $\mathrm{PhCCH}$. It requires the presence of free alkyne in solution and most likely involves 1,2-addition of the $P-B$ derivative to the $C \equiv C$ bond. The feasibility of such a transformation was established using a more electron-rich alkyne, 4methoxyphenylacetylene (4- $\left.\mathrm{MeOC}_{6} \mathrm{H}_{4} \mathrm{CCH}\right)$. This affords the phosphonium borate $\mathbf{1 2 7}(79 \%$ yield) as the result of regioselective trans 1,2-addition of the $\mathrm{P}$ and $\mathrm{B}$ center to the alkyne. The structure of $\mathbf{1 2 7}$ was unambiguously authenticated thanks to multi-nuclear NMR spectroscopy and X-ray diffraction analyses. 


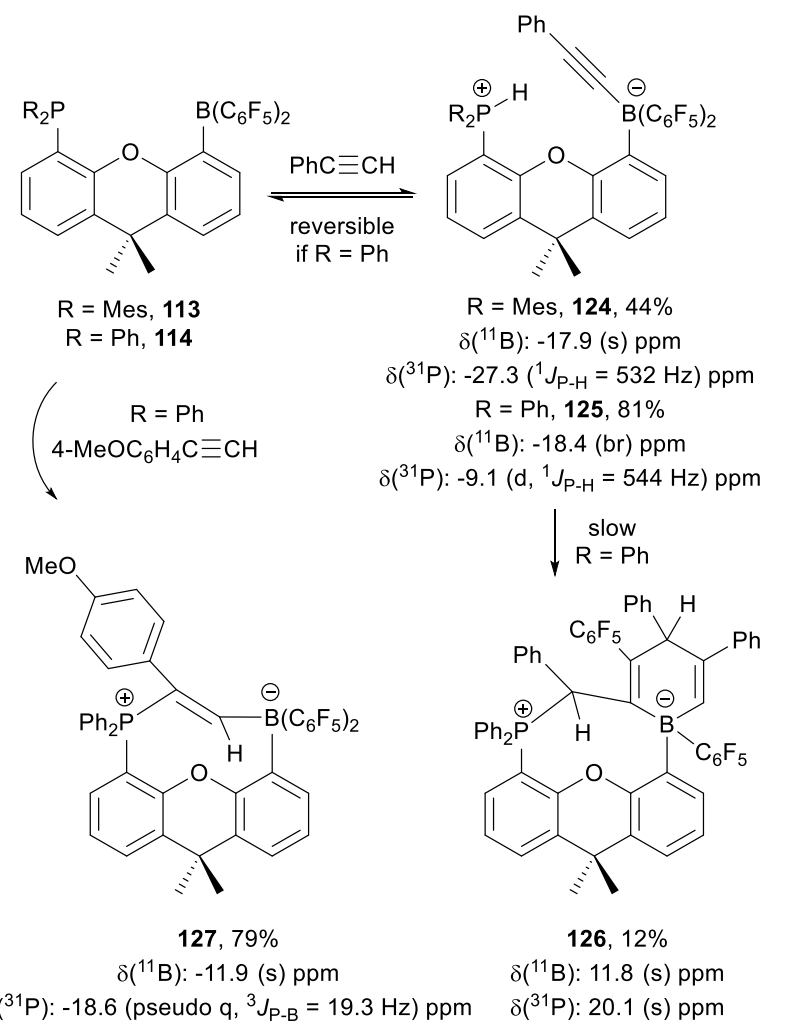

Scheme 34 Reaction of 113 and 114 with terminal alkynes: $\mathrm{C}(\mathrm{sp})-\mathrm{H}$ bond activation vs. 1,2addition.

Given the capacity of $\mathbf{1 1 4}$ to activate both B-H bonds and alkynes, it was tested for the catalytic hydroboration of alkynes with HBpin (Scheme 35). ${ }^{80}$ The reaction is complete within a few hours at room temperature with 10 mol\% catalytic loading. Given the boryl exchange reaction observed between 114 and HBpin, the active species is believed to be in fact $\mathrm{HB}\left(\mathrm{C}_{6} \mathrm{~F}_{5}\right)_{2},{ }^{81,82}$ and the slower catalytic performance with $\mathrm{PhCCH}$ compared to $\mathrm{PhCCMe}$ is attributed to the sequestering of 114 as unreactive 125 and 126.

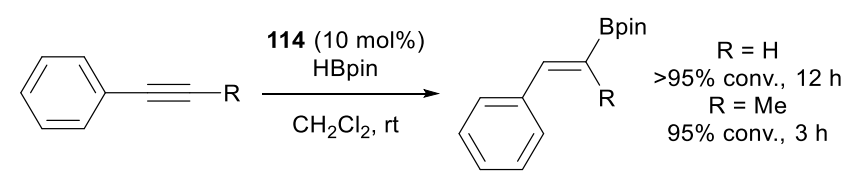

Scheme 35 Catalytic hydroboration of alkynes with 114.

The interaction of $\mathbf{1 1 3}$ and $\mathbf{1 1 4}$ with $\mathrm{O}-\mathrm{H}$ bonds was also investigated (Scheme 36). ${ }^{83}$ Initially, 114 was found to only form simple Lewis adducts with $\mathrm{H}_{2} \mathrm{O}, \mathrm{MeOH}$ and $i-\mathrm{PrOH}$, as established spectroscopically and crystallographically. The acidity of the $\mathrm{O}-\mathrm{H}$ bond was postulated to play a major role in its activation, and indeed upon reacting the more acidic 4-tert-butylphenol (4-t$\mathrm{BuC}_{6} \mathrm{H}_{4} \mathrm{OH}$ ) with 113 and 114, the resulting phosphonium borates 128 and 129 were obtained (Scheme 36). Spectroscopic data evidence the formation of phosphonium centres in both $\mathbf{1 2 8}$ and $\mathbf{1 2 9}$, and these structures were unambiguously confirmed by X-ray diffraction analyses. Intriguingly, when crystals of $\mathbf{1 2 9}$ were dissolved in $d_{6}$-benzene, NMR spectra consistent with the simple Lewis adduct $\mathbf{1 3 0}$, not $\mathbf{1 2 9}$, were obtained (Scheme 36 ). The reversibility of this process was further confirmed through VT-NMR experiments. The phosphonium borate $\mathbf{1 2 9}$ structure is found at low temperatures $\left(-16^{\circ} \mathrm{C}\right)$, while at higher temperatures, the Lewis adduct $\mathbf{1 3 0}$ predominates. Here, the reversibility of the $\mathrm{O}-\mathrm{H}$ activation process with $\mathbf{1 2 9}$ contrasts with the stability of $\mathbf{1 2 8}$. This is again 
attributed to the stronger basicity of the $\mathrm{PMes}_{2}$ moiety compared to $\mathrm{PPh}_{2}$. These findings were confirmed by DFT calculations: the Lewis adduct 130 was found to be $8.3 \mathrm{~kJ} / \mathrm{mol}$ more stable than 129 at $25^{\circ} \mathrm{C}$, and a transition state was located at $9.2 \mathrm{~kJ} / \mathrm{mol}$ confirming the lability of the $\mathrm{O}-\mathrm{H}$ bond in 129. On the other hand, 128 was found to be $34.6 \mathrm{~kJ} / \mathrm{mol}$ more stable than its corresponding Lewis adduct, highlighting the irreversibility of the process.

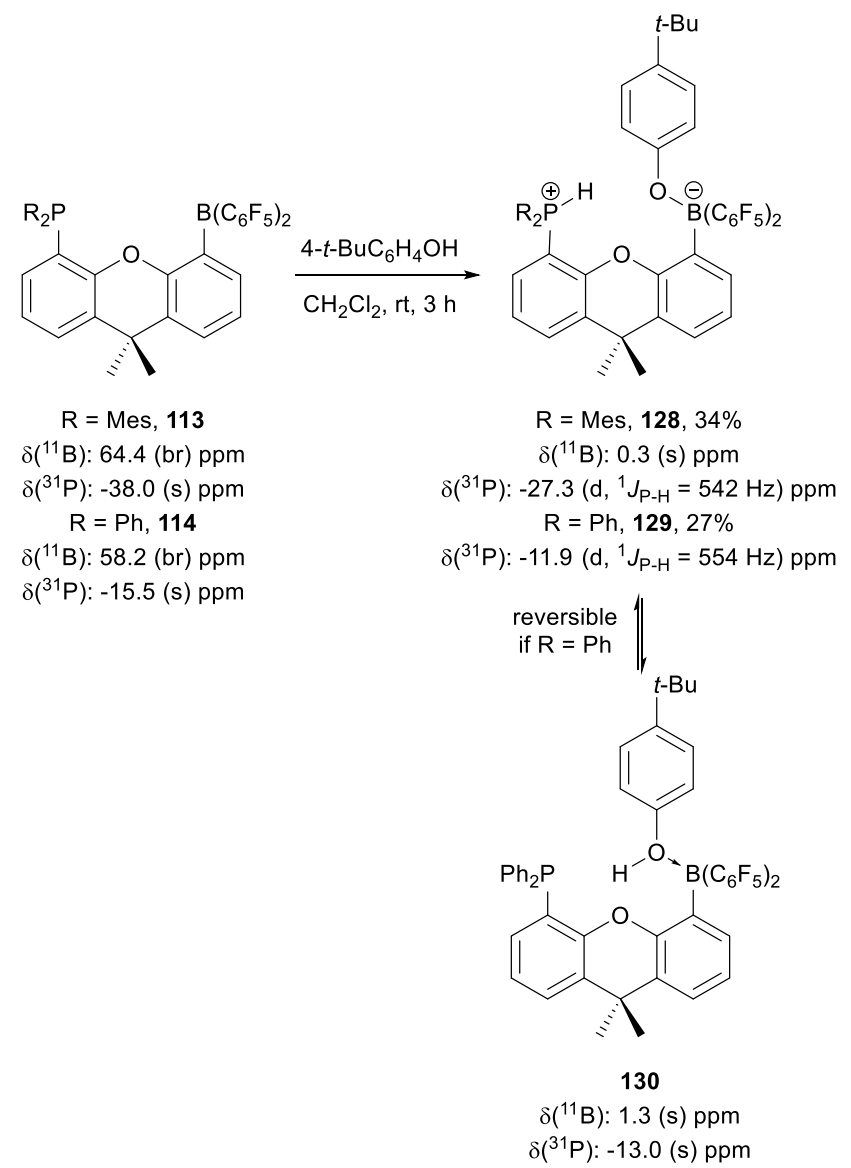

Scheme 36 Reactions of $\mathbf{1 1 3}$ and $\mathbf{1 1 4}$ with 4-tert-butylphenol.

Finally, Aldridge et al. also showed that the FLP cavity in $\mathbf{1 1 3}$ is appropriately sized for the capture and activation of nitrous oxide $\left(\mathrm{N}_{2} \mathrm{O}\right)$ (Scheme 37). ${ }^{76}$ Reacting a $\mathrm{CH}_{2} \mathrm{Cl}_{2}$ solution of 113 under a 1 atm. of $\mathrm{N}_{2} \mathrm{O}$ results in the formation of the $1: 1$ adduct 131 (75\% isolated yield). The upfield ${ }^{11} \mathrm{~B}$ NMR signal $(4.3 \mathrm{ppm})$ is indicative of a tetracoordinate B centre, while the downfield ${ }^{31} \mathrm{P}$ NMR signal (46.8 ppm) is consistent with quaternisation of the $P$ centre. The uptake of $\mathrm{N}_{2} \mathrm{O}$ was confirmed in the solidstate, revealing a PNNOB unit of W configuration bound in the cavity. Here, the dimethylxanthene scaffold displays some flexibility and responds to the incorporation of the $\mathrm{N}_{2} \mathrm{O}$ unit by expanding the $\mathrm{P}-\mathrm{B}$ separation by $\sim 0.3 \AA$ compared to 113 . This distortion is presumed to favour the release of $\mathrm{N}_{2} \mathrm{O}$ at elevated temperatures. Upon heating solutions of 131 at $50{ }^{\circ} \mathrm{C}$, the P-B derivative 113 was recovered quantitatively with no competing formation of phosphine oxide derivatives. This was the first example of reversible $\mathrm{N}_{2} \mathrm{O}$ fixation. 


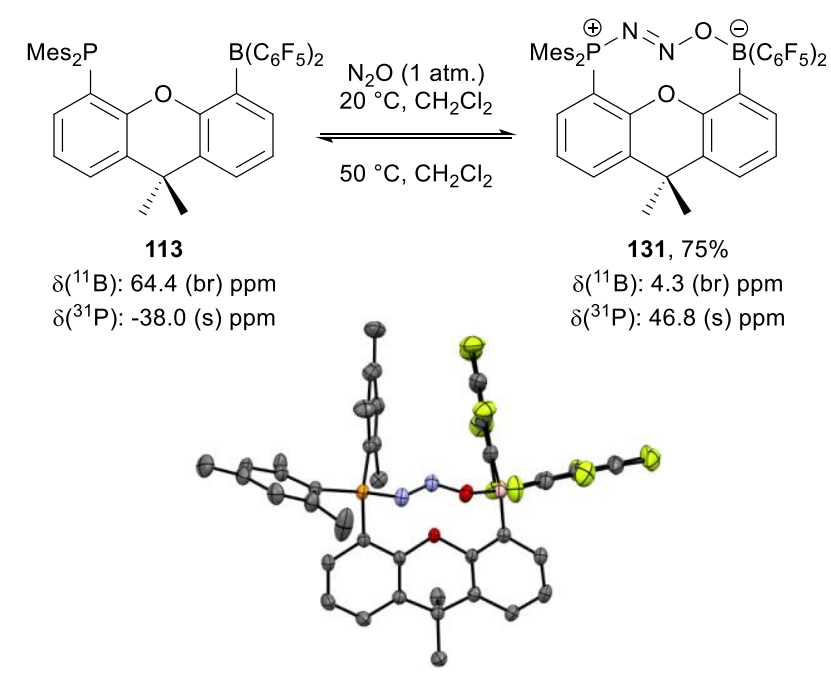

Scheme 37 Reversible fixation of $\mathrm{N}_{2} \mathrm{O}$ by 113; X-ray structure of 131 with carbon in grey, nitrogen in blue, boron in pink, oxygen in red, fluorine in green, phosphorous in orange, and $\mathrm{H}$ atoms omitted for clarity.

In 2018, the groups of Beckmann and Erker independently developed FLP derivatives based on the biphenylene scaffold ${ }^{84-86}$ They both relied on the premise that single component FLPs could offer potential advantages over two component FLP systems. In particular, Beckmann et al. surmised that a rigid scaffold maintaining donor and acceptor moieties at 3-5 $\AA$ may be necessary for high catalytic activity. ${ }^{87-90}$ In this context, they prepared the new P-B derivative $\mathbf{1 3 3}$ by stepwise lithiation, phosphination and borylation (Scheme 38 ).${ }^{84}$ While no ${ }^{11}$ B NMR signal could be observed for 133, the ${ }^{31} \mathrm{P}$ NMR signal at $-19.5 \mathrm{ppm}$ is highly indicative of the lack of $\mathrm{P} \rightarrow \mathrm{B}$ interaction. This bonding situation was confirmed in the solid state by $\mathrm{X}$-ray diffraction analysis, finding two independent molecules in the unit cell with trigonal planar $B$ centres $\left(\sum_{\alpha} B=359.3(1)\right.$ and $\left.359.5(1)^{\circ}\right)$ and long $P-B$ distances (4.100(2) and 4.172(2) $\AA, r>2$ ) confirming the FLP nature of 133. Despite the prerequisite $\mathrm{P}-\mathrm{B}$ distance, no reactivity with $\mathrm{H}_{2}$ or $\mathrm{CO}_{2}$ could be observed. The authors tentatively attribute the lack of reactivity to the low Lewis acidity of $B$. They attempted to incorporate $\mathrm{C}_{6} \mathrm{~F}_{5}$ groups onto $\mathrm{B}$ but only obtained a complex mixture of products. Synthesis of such a derivative, 135, was achieved by Erker et al. incorporating Mes and $\mathrm{C}_{6} \mathrm{~F}_{5}$ groups on $\mathrm{P}$ and $\mathrm{B}$, respectively (Scheme 38 ). ${ }^{85} \mathrm{NMR}$ spectroscopy confirms the FLP nature of $\mathbf{1 3 5}$ with a tricoordinate $B$ centre ( ${ }^{11} \mathrm{~B}$ signal at $63.2 \mathrm{ppm}$ ) and lack of $\mathrm{P} \rightarrow \mathrm{B}$ interaction ( ${ }^{31} \mathrm{P}$ signal at $-33.7 \mathrm{ppm}$ ). This is further supported by a large $\Delta \delta^{19} \mathrm{~F}_{\mathrm{m}-\mathrm{p}}$ $(15.3 \mathrm{ppm}) .^{27}$

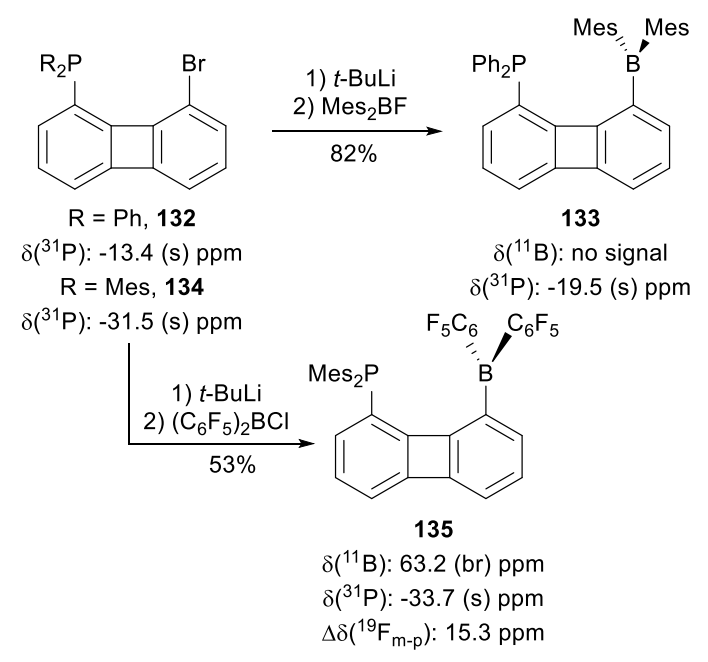


Scheme 38 Synthesis of the biphenylene-bridged P-B derivatives 133 and 135.

While 135 itself could not be characterised in the solid state, 136, its 1:1 adduct with the $N$ heterocyclic carbene ItBu, could be isolated and analysed by X-ray diffraction (Scheme 39). As expected, the ${ }^{11} \mathrm{~B}(-20.9 \mathrm{ppm}) \mathrm{NMR}$ signal now indicates a tetracoordinate $B$ centre. This is confirmed in the solid state, finding a pyramidalized $B$ centre $\left(\Sigma_{\alpha} B=359.5(1)^{\circ}, T H C=78 \%\right)$. However, solid state analysis also revealed an unexpected connectivity with the $\mathrm{B}$ centre attached to a remote olefinic atom $\left(C_{4}\right)$ and the respective hydrogen now bonded to the original carbene centre $\left(C_{2}\right)$. Derivative 135 was found to readily react with $\mathrm{H}_{2}$, providing the corresponding phosphonium borate 137 in 58\% yield (Scheme 39). X-ray diffraction analysis of 137 shows that activation of $\mathrm{H}_{2}$ results in pyramidalization of the $\mathrm{B}$ centre $\left(\sum_{\alpha} \mathrm{B}=337.9(1)^{\circ}, \mathrm{THC}=67 \%\right)$ and a $\mathrm{H}-\mathrm{H}$ separation of $2.11(5) \AA$. Despite the close proximity of the hydridic and protic moieties in $\mathbf{1 3 7}$, and an almost identical electronic situation to the dimethylxanthene-bridged derivative 116, activation of $\mathrm{H}_{2}$ is not reversible in this case. Nonetheless, the ability of $\mathbf{1 3 5}$ to activate $\mathrm{H}_{2}$ could be leveraged towards catalysis. Metal-free hydrogenation of a bulky imine and an enamine was achieved with 137.85

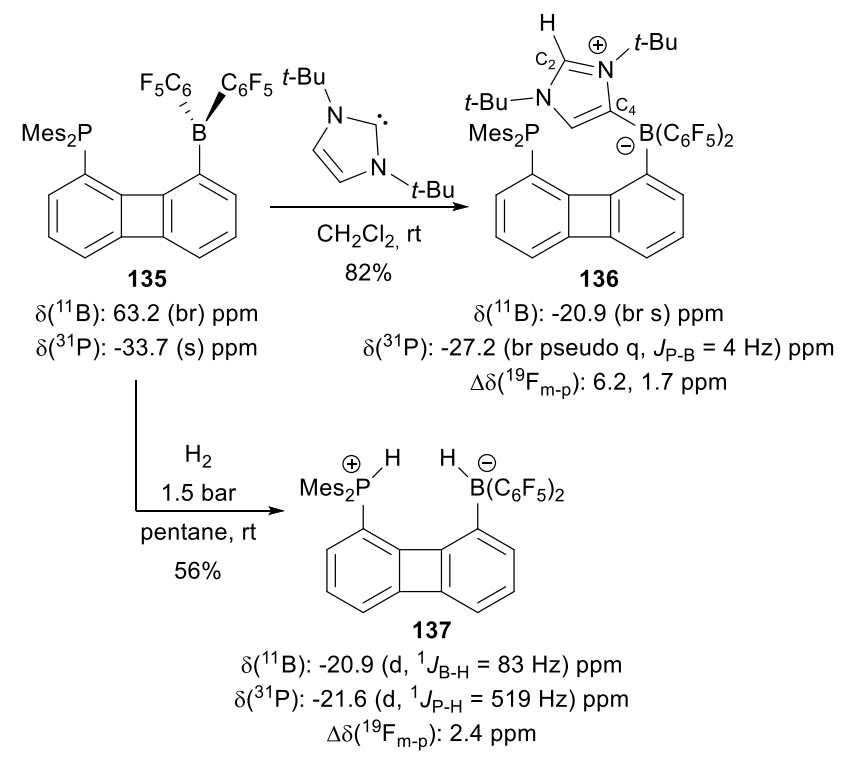

Scheme 39 Reaction of 135 with ItBu and $\mathrm{H}_{2}$.

In a similar fashion to the dimethylxanthene-bridged derivatives 113 and 114, biphenylene 135 activates $\mathrm{C}(\mathrm{sp})-\mathrm{H}$ bonds (Scheme 40 ) ${ }^{85}$ Cyclopropylacetylene reacts with 135 in $\mathrm{C}_{6} \mathrm{D}_{6}$ at room temperature to provide the regioselective trans 1,2-addition product 138 in $72 \%$ yield, as confirmed spectroscopically and in the solid state (Scheme $\mathbf{4 0}$ ). The reaction of $\mathbf{1 3 5}$ with isopropenylacetylene at room temperature provides the $\mathrm{C}-\mathrm{H}$ activation product $139 \mathrm{a}$ and is reminiscent of the reactivity observed with 114, showing apparent reversibility. Heating $C_{6} D_{6}$ solutions of 139 a induces formation of the trans 1,2-addition product 139. Trans addition of the P-B compound $\mathbf{1 3 5}$ could be extended to phenylacetylene, 1-pentyne and 4-phenyl-1-butyne leading to 140-142. The structures of 138-142 were unambiguously determined through multi-nuclear NMR spectroscopy and X-ray diffraction analyses. 


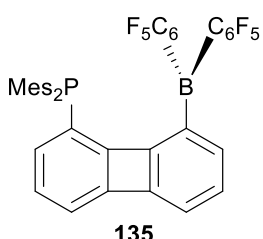

135

$\delta\left({ }^{11} \mathrm{~B}\right): 63.2(\mathrm{br}) \mathrm{ppm}$ $\delta\left({ }^{31} \mathrm{P}\right):-33.7(\mathrm{~s}) \mathrm{ppm}$

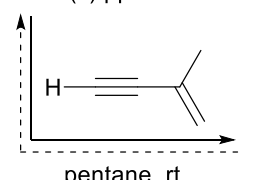

pentane, rt
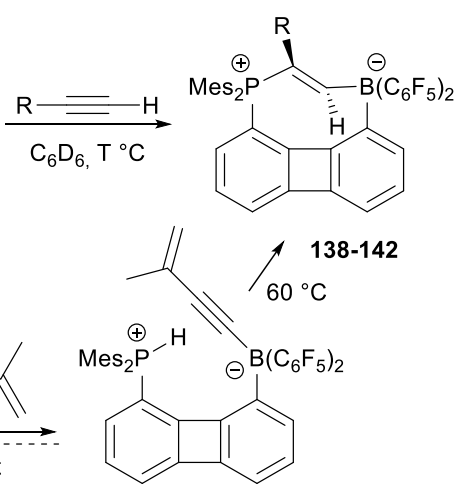

139a, $60 \%$

$\delta\left({ }^{11} \mathrm{~B}\right):-18.7(\mathrm{br}) \mathrm{ppm}$

$\delta\left({ }^{31} \mathrm{P}\right):-23.7\left(\mathrm{~d},{ }^{1} \mathrm{~J}_{\mathrm{P}-\mathrm{H}}=514 \mathrm{~Hz}\right) \mathrm{ppm}$

\begin{tabular}{c|ccccc} 
& $\mathrm{R}$ & Yield $(\%)$ & $\mathrm{T}{ }^{\circ} \mathrm{C}$ & $\delta\left({ }^{11} \mathrm{~B}\right)$ & $\delta\left({ }^{31} \mathrm{P}\right)$ \\
\hline $\mathbf{1 3 8}$ & cyclopropyl & 72 & $\mathrm{rt}$ & -14.6 & 6.5 \\
$\mathbf{1 3 9}$ & isopropenyl & 65 & 60 & -14.6 & 8.6 \\
$\mathbf{1 4 0}$ & $\mathrm{Ph}$ & 50 & 60 & -15.2 & 11.8 \\
$\mathbf{1 4 1}$ & $n-\mathrm{C}_{3} \mathrm{H}_{7}$ & 45 & 60 & -14.9 & 5.3 \\
$\mathbf{1 4 2}$ & $\mathrm{Ph}\left(\mathrm{CH}_{2}\right)_{2}$ & 13 & 60 & -14.7 & 6.6
\end{tabular}

Scheme 40 Trans 1,2-addition of alkynes to 135.

The biphenylene-bridged FLP 135 reacts with triplet dioxygen $\left({ }^{3} \mathrm{O}_{2}\right)$ to selectively furnish the dioxygenated product 143 (Scheme 41)..$^{85}$ The structure of 143 is very reminiscent of the product we obtained in 2010 by reacting an o-phenylene $\mathrm{P}-\mathrm{B}$ system with singlet dioxygen. ${ }^{91}$ One oxygen sits on phosphorus and is actually engaged in a $\mathrm{P}-\mathrm{O}-\mathrm{B}$ bridge. The other one has inserted into one of the $\mathrm{B}-\mathrm{C}_{6} \mathrm{~F}_{5}$ bonds. Oxidation of the phosphine moiety is apparent from the ${ }^{31} \mathrm{P}$ NMR chemical shift (39.6 ppm) while the ${ }^{11} \mathrm{~B}$ NMR signal at $8.2 \mathrm{ppm}$ indicates a tetracoordinate $\mathrm{B}$ centre. The oxygenation product 143 was characterized in the solid state, finding $P=O$ and $O-B$ bond lengths of $1.527(1)$ and $1.569(2) \AA$, respectively, while the geometry about $B$ is pyramidalized $\left(\Sigma_{\alpha} B=341.1(1)^{\circ}\right.$, $\mathrm{THC}=70 \%$ ). A radical pathway inspired from the reaction of trialkyl boranes with ${ }^{3} \mathrm{O}_{2}$ was proposed to account for the formation of 143.

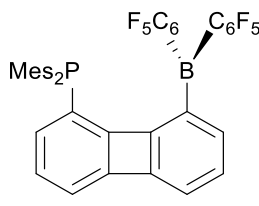

135

$\delta\left({ }^{11} \mathrm{~B}\right): 63.2(\mathrm{br}) \mathrm{ppm}$ $\delta\left({ }^{31} \mathrm{P}\right):-33.7(\mathrm{~s}) \mathrm{ppm}$

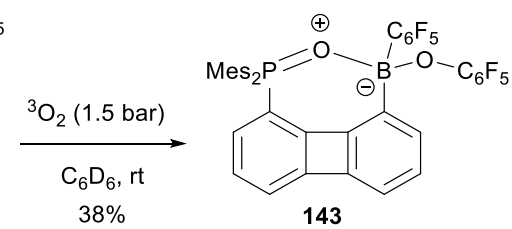

$\delta\left({ }^{11} \mathrm{~B}\right): 8.2(\mathrm{br}) \mathrm{ppm}$

$\delta\left({ }^{31} \mathrm{P}\right): 39.6(\mathrm{~s}) \mathrm{ppm}$ $\Delta \delta\left({ }^{19} \mathrm{~F}_{\mathrm{m}-\mathrm{p}}\right): 5.9 \mathrm{ppm}$

Scheme 41 Reaction of 135 with triplet dioxygen.

Finally, Erker et al. also demonstrated the ability of the biphenylene scaffold to form P-stabilised aryltriborane(7) compounds (Scheme 42). ${ }^{86}$ Lithiation of $\mathbf{1 3 4}$ followed by trapping with an excess of $\mathrm{Me}_{2} \mathrm{~S} \cdot \mathrm{BH}_{3}$ and treatment with TMSCl provided derivative 144 in $50 \%$ yield (Scheme 42 ). In solution, 144 shows three distinct ${ }^{11} \mathrm{~B}$ NMR signals at $-8.6,-24.1$ and $-36.7 \mathrm{ppm}$. The latter is attributed to the $P \rightarrow B_{2}$ unit due to the coupling observed $\left({ }^{1} J_{P-B}=91 \mathrm{~Hz}\right)$, this coupling is also evident on examination of ${ }^{31} \mathrm{P}$ NMR spectra finding a broad signal at $7.8 \mathrm{ppm}$. The structure is hindered from rotation as evidenced by ${ }^{1} \mathrm{H}$ NMR at room temperature showing six distinct Me and four aromatic $\mathrm{C}-\mathrm{H}$ signals 
over both of the Mes groups. The structure of 144 was confirmed by X-ray diffraction analysis finding two independent molecules in the unit cell. They both display short $P \rightarrow B_{2}$ interactions (1.943(6) and 1.963(4) $\AA, r=1.02$ and 1.03) and all B centres are significantly pyramidalized. Further derivatisation and reactivity of $\mathbf{1 4 4}$ was demonstrated by reacting it with two equivalents of $\mathrm{HB}\left(\mathrm{C}_{6} \mathrm{~F}_{5}\right)_{2}$ to provide the doubly $\mathrm{C}_{6} \mathrm{~F}_{5}$-substituted product $\mathbf{1 4 5}$. The structure of 145 was unambiguously confirmed by multi-nuclear NMR spectroscopy and X-ray diffraction.

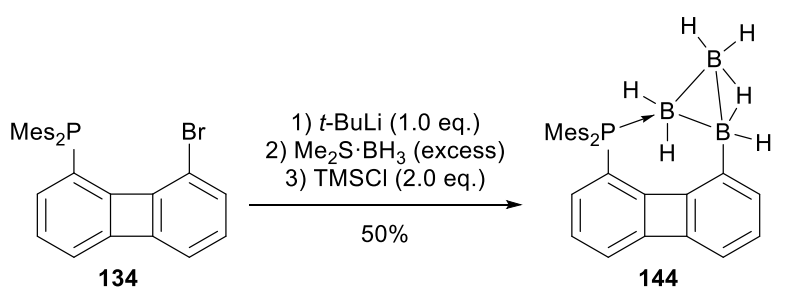

$\delta\left({ }^{31} \mathrm{P}\right):-31.5(\mathrm{~s}) \mathrm{ppm}$

$\delta\left({ }^{11} \mathrm{~B}\right): 8.6(\mathrm{br}),-24.1(\mathrm{br})$

$-36.7\left(\mathrm{~d},{ }^{1} \mathrm{~J}_{\mathrm{P}-\mathrm{B}}=91 \mathrm{~Hz}\right) \mathrm{ppm}$

$\delta\left({ }^{31} \mathrm{P}\right): 7.8$ (br pseudo q) ppm

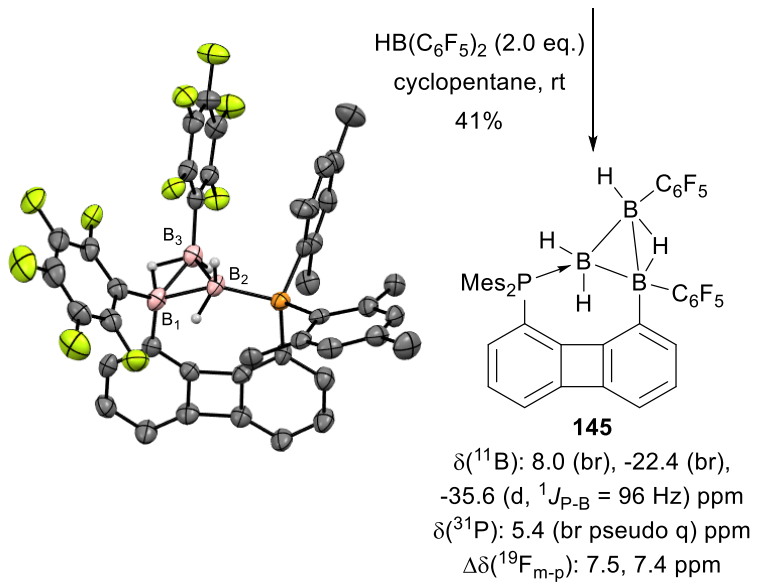

Scheme 42 Synthesis and reactivity of the P-stabilised aryltriborane(7) derivatives 144 and 145; Xray structure of $\mathbf{1 4 5}$ with carbon in grey, boron in pink, fluorine in green, phosphorus in orange, hydrogen in white, and the $\mathrm{H}$ atoms of the biphenylene backbone and Mes groups omitted for clarity.

\section{Conclusions}

As shown in this review, the combination of group 15 and group 13 elements on rigid carbon-based scaffolds give rise to original species presenting interesting structures and reactivity. To date, N-B and $\mathrm{P}-\mathrm{B}$ derivatives are the most common among all possible $\mathrm{E}^{13} / \mathrm{E}^{15}$ combinations, while the (ace)naphthalene and (thio)xanthene moieties have been the preferred scaffolds.

The unique geometric constraints imposed by (ace)naphthyl frameworks to the peri-substituents confer interesting structural and electronic properties to mixed $\mathrm{E}^{13} / \mathrm{E}^{15}$ derivatives. The synthesis, structure and reactivity of these derivatives have been thoroughly investigated by several research groups, with theoretical calculations playing a vital role in deciphering and understanding the bonding/non-bonding interaction between the peri-substituents. Modulation of the steric and electronic nature of the donor and acceptor moieties at the peri positions enables to control and tune the $D \rightarrow A$ interaction. Additional control is provided by the choice of scaffold, where the naphthalene framework is shown to enforce $E^{15} \rightarrow E^{13}$ interactions while the acenaphthalene scaffold can be used to disrupt this interaction by increasing the peri distance. The resulting FLPs may be used to activate small molecules as shown with $\mathrm{H}_{2} \mathrm{O}$. 
The other way around, the design of naphthalene compounds with strong $D \rightarrow A$ has been leveraged to prepare and study highly reactive species. A number of $\mathrm{P}$-stabilised borenium cations have been reported and shown to display rich reactivity, especially regarding the activation of strong ?-bonds $\left(\mathrm{H}_{2}, \mathrm{~N}-\mathrm{H}\right)$. Using the same approach of geometrically enforced P-stabilisation, persistent boryl radicals with very high spin densities at boron have been prepared. Original radical reactivities have been substantiated, including Gomberg-type dimerization, halogen abstraction and heterocoupling.

With rigid expanded spacers, $\mathrm{E}^{15} \rightarrow \mathrm{E}^{13}$ interactions are prevented geometrically. This results in enhanced and versatile ambiphilic behavior, as substantiated by the coordination properties of P-B thioxanthenes and FLP reactivity of $P$ - $B$ biphenylenes and xanthenes. Most noticeable is the impact of the rigid and preorganised structure of these systems on the reversibility of small molecule fixation/activation.

Given the progress achieved during the past two decades, it is likely that mixed $\mathrm{E}^{13} / \mathrm{E}^{15}$ derivatives featuring rigid backbones will continue to attract much interest in the future. New synthetic methodologies are worth developing to enable straightforward and efficient introduction of the $D$ and $\mathrm{A}$ groups. $\mathrm{C}-\mathrm{H}$ activation approaches taking advantage of the $\mathrm{D}$ site as directing group are certainly worthwhile to explore. The nature of the $D$ and $A$ sites can also be varied further to include low-valent as well as high-valent moieties in particular, besides the common amine, phosphine and borane motifs mainly studied so far. Mixed $E^{13} / E^{15}$ compounds hold great promise for small molecule activation and as ligands for transition metals. They may also open interesting avenues in other fields, such as chemical sensing, opto-electronic materials... The combination of $\mathrm{E}^{13}$ and $\mathrm{E}^{15}$ elements, and fine modulation of their interaction, are indeed very attractive to impart and control chemical and photophysical properties.

\section{Acknowledgments}

Support from the Centre National de la Recherche Scientifique, the Universite de Toulouse and the Agence Nationale de la Recherche is gratefully acknowledged.

\section{Notes and references}

¥ For a review dealing with naphthalene derivatives peri-substituted with group 13 elements, see: J. D. Hoefelmeyer, M. Schulte, M. Tschinkl and F. P. Gabbaï, Coord. Chem. Rev., 2002, 235, 93-103. For reviews dealing with naphthalenes and related derivatives peri-substituted with group 15 and 16 elements, see: P. Kilian, F. R. Knight and J. D. Woollins, Coord. Chem. Rev., 2011, 255, 1387-1413 and P. Kilian, F. R. Knight and J. D. Woollins, Chem. Eur. J., 2011, 17, 2302-2328. For an early review dealing with peri interactions in naphthalene derivatives, see: V. Balasubramaniyan, Chem. Rev., 1966, 66, 567-641. 


\section{References}

1 C. P. Brock and J. D. Dunitz, Acta Crystallogr., Sect. B: Struct. Sci., 1982, 38, 2218-2228.

2 A. C. Hazell, R. G. Hazell, L. Nørskov-Lauritsen, C. E. Briant and D. W. Jones, Acta Crystallogr., Sect. C: Cryst. Struct. Commun., 1986, 42, 690-693.

3 J. K. Fawcett and J. Trotter, Acta Crystallogr., 1966, 20, 87-93.

4 C. R. Groom, I. J. Bruno, M. P. Lightfoot and S. C. Ward, Acta Crystallogr. Sect. B: Struct. Sci., 2016, 72, 171-179.

5 J. A. Gillean III, D. W. Phelps and A. W. Cordes, Acta Crystallogr. Sect. B, 1973, 29, 2296-2298.

6 O. Dideberg, L. Dupont and J. M. André, Acta Crystallogr. Sect. B, 1972, 28, 1002-1007.

7 Z.-T. Jiang, B.-Q. Wang and Z.-J. Shi, Chin. J. Chem., 2018, 36, 950-954.

8 W. K. Chow, O. Y. Yuen, P. Y. Choy, C. M. So, C. P. Lau, W. T. Wong and F. Y. Kwong, RSC Adv., 2013, 3, 12518.

9 D. Pla, O. Sadek, S. Cadet, B. Mestre-Voegtlé and E. Gras, Dalton Trans., 2015, 44, 18340-18346.

10 S. Kawamorita, T. Miyazaki, H. Ohmiya, T. Iwai and M. Sawamura, J. Am. Chem. Soc., 2011, 133, 19310-19313.

11 Y. Kuninobu, T. Iwanaga, T. Omura and K. Takai, Angew. Chem. Int. Ed., 2013, 52, 4431-4434.

12 E. C. Keske, B. D. Moore, O. V. Zenkina, R. Wang, G. Schatte and C. M. Crudden, Chem. Commun., 2014, 50, 9883-9886.

13 J. A. Fernández-Salas, S. Manzini, L. Piola, A. M. Z. Slawin and S. P. Nolan, Chem. Commun., 2014, 50, 6782-6784.

14 S. Okada, T. Namikoshi, S. Watanabe and M. Murata, ChemCatChem, 2015, 7, 1531-1534.

15 S. De Sarkar, N. Y. P. Kumar and L. Ackermann, Chem. Eur. J., 2017, 23, 84-87.

16 T. Ikawa, A. Takagi, Y. Kurita, K. Saito, K. Azechi, M. Egi, K. Kakiguchi, Y. Kita and S. Akai, Angew. Chem. Int. Ed., 2010, 49, 5563-5566.

17 A. Takagi, T. Ikawa, Y. Kurita, K. Saito, K. Azechi, M. Egi, Y. Itoh, H. Tokiwa, Y. Kita and S. Akai, Tetrahedron, 2013, 69, 4338-4352.

18 H. Höpfl, J. Organomet. Chem., 1999, 581, 129-149.

19 E. Hupf, E. Lork, S. Mebs and J. Beckmann, Organometallics, 2015, 34, 3873-3887.

20 A. J. Kirby and J. M. Percy, Tetrahedron, 1988, 44, 6903-6910.

21 Š. Vyskočil, L. Meca, I. Tišlerová, I. Císařová, M. Polášek, S. R. Harutyunyan, Y. N. Belokon, R. M. J. Stead, L. Farrugia, S. C. Lockhart, W. L. Mitchell and P. Kočovský, Chem. Eur. J., 2002, 8, 4633-4648.

22 T. Leermann, F. R. Leroux and F. Colobert, Org. Lett., 2011, 13, 4479-4481.

23 R. L. Giles, J. A. K. Howard, L. G. F. Patrick, M. R. Probert, G. E. Smith and A. Whiting, J. Organomet. Chem., 2003, 680, 257-262.

24 B. Cordero, V. Gómez, A. E. Platero-Prats, M. Revés, J. Echeverría, E. Cremades, F. Barragán and S. Alvarez, Dalton Trans., 2008, 2832. 

Eur. J., 2012, 18, 9312-9320.

29 M. Yamashita, K. Kamura, Y. Yamamoto and K. Akiba, Chem. Eur. J., 2002, 8, 2976.

30 C. Böker, M. Noltemeyer, H. Gornitzka, B. O. Kneisel, M. Teichert, R. Herbst-Irmer and A. Melier, Main Group Met. Chem., 1998, 21, 565-579.

31 G. S. Hair, S. L. Battle, A. Decken, A. H. Cowley and R. A. Jones, Inorg. Chem., 2000, 39, 27-31.

32 H. Schumann, S. Dechert, M. Hummert, K. C. H. Lange, S. Schutte, B. C. Wassermann, K. Köhler and J. Eichhorn, Zeitschrift fur Anorg. und Allg. Chemie, 2004, 630, 1196-1204.

33 H. Schumann, B. C. Wassermann, S. Schutte, B. Heymer, S. Nickel, T. D. Seuß, S. Wernik, J. Demtschuk, F. Girgsdies and R. Weimann, Z. Anorg. Allg. Chem., 2000, 626, 2081-2095.

34 S. U. Ahmad and J. Beckmann, Main Group Met. Chem., 2012, 35, 29-33.

35 S. Bontemps, M. Devillard, S. Mallet-Ladeira, G. Bouhadir, K. Miqueu and D. Bourissou, Inorg. Chem., 2013, 52, 4714-4720.

36 J. Beckmann, E. Hupf, E. Lork and S. Mebs, Inorg. Chem., 2013, 52, 11881-11888.

37 Y. F. Li, Y. Kang, S. B. Ko, Y. Rao, F. Sauriol and S. Wang, Organometallics, 2013, 32, 3063-3068.

38 S. Furan, E. Hupf, E. Lork and J. Beckmann, Z. Anorg. Allg. Chem., 2021, zaac. 202000480.

39 E. Hupf, E. Lork, S. Mebs, L. Chęcińska and J. Beckmann, Organometallics, 2014, 33, 7247-7259.

40 A. Tsurusaki, T. Sasamori, A. Wakamiya, S. Yamaguchi, K. Nagura, S. Irle and N. Tokitoh, Angew. Chem. Int. Ed., 2011, 50, 10940-10943.

41 A. Tsurusaki, T. Sasamori and N. Tokitoh, Chem. Eur. J., 2014, 20, 3752-3758.

42 M. Yamashita, K. Watanabe, Y. Yamamoto and K. Akiba, Chem. Lett., 2001, 30, 1104-1105.

43 M. Devillard, R. Brousses, K. Miqueu, G. Bouhadir and D. Bourissou, Angew. Chem. Int. Ed., 2015, 54, $5722-5726$.

44 M. Devillard, S. Mallet-Ladeira, G. Bouhadir and D. Bourissou, Chem. Commun., 2016, 52, 8877-8880.

45 M. Devillard, G. Bouhadir, S. Mallet-Ladeira, K. Miqueu and D. Bourissou, Organometallics, 2016, 35, 3788-3794.

46 M. A. Dureen, A. Lough, T. M. Gilbert and D. W. Stephan, Chem. Commun., 2008, 913, 4303.

47 A. J. Rosenthal, M. Devillard, K. Miqueu, G. Bouhadir and D. Bourissou, Angew. Chem. Int. Ed., 2015, 54, 9198-9202.

48 A. J. Rosenthal, S. Mallet-Ladeira, G. Bouhadir, E.-D. Sosa-Carrizo, K. Miqueu and D. Bourissou, Organometallics, 2018, 37, 755-760.

49 F. Dahcheh, D. Martin, D. W. Stephan and G. Bertrand, Angew. Chem. Int. Ed., 2014, 53, 1315913163. 
51 S.-H. Ueng, A. Solovyev, X. Yuan, S. J. Geib, L. Fensterbank, E. Lacôte, M. Malacria, M. Newcomb, J. C. Walton and D. P. Curran, J. Am. Chem. Soc., 2009, 131, 11256-11262.

52 J. C. Walton, M. M. Brahmi, L. Fensterbank, E. Lacôte, M. Malacria, Q. Chu, S.-H. Ueng, A. Solovyev and D. P. Curran, J. Am. Chem. Soc., 2010, 132, 2350-2358.

53 P. Bissinger, H. Braunschweig, A. Damme, I. Krummenacher, A. K. Phukan, K. Radacki and S. Sugawara, Angew. Chem. Int. Ed., 2014, 53, 7360-7363.

54 T. Kushida and S. Yamaguchi, Organometallics, 2013, 32, 6654-6657.

55 R. G. Griffin and H. VAN Willigen, J. Chem. Phys., 1972, 57, 86-90.

56 L. Ji, R. M. Edkins, A. Lorbach, I. Krummenacher, C. Brückner, A. Eichhorn, H. Braunschweig, B. Engels, P. J. Low and T. B. Marder, J. Am. Chem. Soc., 2015, 137, 6750-6753.

57 J. E. Leffler, G. B. Watts, T. Tanigaki, E. Dolan and D. S. Miller, J. Am. Chem. Soc., 1970, 92, 6825-6830.

58 M. M. Olmstead and P. P. Power, J. Am. Chem. Soc., 1986, 108, 4235-4236.

59 M. Gomberg, J. Am. Chem. Soc., 1900, 22, 757-771.

60 M. Gomberg, Chem. Rev., 1924, 1, 91-141.

61 A. J. Rosenthal, S. Mallet-Ladeira, G. Bouhadir and D. Bourissou, Synthesis, 2018, 50, 3671-3678.

62 M. Soleilhavoup and G. Bertrand, Angew. Chem. Int. Ed., 2017, 56, 10282-10292.

63 M. Soleilhavoup and G. Bertrand, Chem, 2020, 6, 1275-1282.

64 A. D. Ledet and T. W. Hudnall, Dalton Trans., 2016, 45, 9820-9826.

65 M. Arrowsmith, D. Auerhammer, R. Bertermann, H. Braunschweig, G. Bringmann, M. A. Celik, R. D. Dewhurst, M. Finze, M. Grüne, M. Hailmann, T. Hertle and I. Krummenacher, Angew. Chem. Int. Ed., 2016, 55, 14464-14468.

66 M. Arrowsmith, J. I. Schweizer, M. Heinz, M. Härterich, I. Krummenacher, M. C. Holthausen and H. Braunschweig, Chem. Sci., 2019, 10, 5095-5103.

67 D. Lu, Y. He and C. Wu, Phys. Chem. Chem. Phys., 2019, 21, 23533-23540.

68 C. R. Wade, M. R. Saber and F. P. Gabbaï, Heteroatom Chem., 2011, 22, 500-505.

69 D. J. H. Emslie, J. M. Blackwell, J. F. Britten and L. E. Harrington, Organometallics, 2006, 25, 24122414.

70 D. J. H. Emslie, B. E. Cowie and K. B. Kolpin, Dalton Trans., 2012, 41, 1101-1117.

71 S. R. Oakley, K. D. Parker, D. J. H. Emslie, I. Vargas-Baca, C. M. Robertson, L. E. Harrington and J. F. Britten, Organometallics, 2006, 25, 5835-5838.

72 D. J. H. Emslie, L. E. Harrington, H. A. Jenkins, C. M. Robertson and J. F. Britten, Organometallics, 2008, 27, 5317-5325.

73 D. J. H. Emslie, B. E. Cowie, S. R. Oakley, N. L. Huk, H. A. Jenkins, L. E. Harrington and J. F. Britten, Dalton Trans., 2012, 41, 3523-3535.

74 B. E. Cowie, D. J. H. Emslie, H. A. Jenkins and J. F. Britten, Inorg. Chem., 2010, 49, 4060-4072. 
B. E. Cowie and D. J. H. Emslie, Organometallics, 2015, 34, 2737-2746.

76

Z. Mo, E. L. Kolychev, A. Rit, J. Campos, H. Niu and S. Aldridge, J. Am. Chem. Soc., 2015, 137, 1222712230.

77 Z. Mo, A. Rit, J. Campos, E. L. Kolychev and S. Aldridge, J. Am. Chem. Soc., 2016, 138, 3306-3309.

78 G. C. Welch, R. R. S. Juan, J. D. Masuda and D. W. Stephan, Science, 2006, 314, 1124-1126.

79 B. L. Rinne, A. P. Lathem and Z. M. Heiden, Dalton Trans., 2017, 46, 9382-9393.

80 P. Vasko, I. A. Zulkifly, M. Á. Fuentes, Z. Mo, J. Hicks, P. C. J. Kamer and S. Aldridge, Chem. Eur. J., 2018, 24, 10531-10540.

81 M. Fleige, J. Möbus, T. vom Stein, F. Glorius and D. W. Stephan, Chem. Commun., 2016, 52, 1083010833.

82 D. J. Parks, R. E. von H. Spence and W. E. Piers, Angew. Chem. Int. Ed. English, 1995, 34, 809-811.

83 P. Vasko, M. Á. Fuentes, J. Hicks and S. Aldridge, Dalton Trans., 2019, 48, 2896-2899.

84 F. Kutter, E. Lork and J. Beckmann, Z. Anorg. Allg. Chem., 2018, 644, 1234-1237.

85 J. Li, C. G. Daniliuc, G. Kehr and G. Erker, Chem. Commun., 2018, 54, 6344-6347.

86 J. Li, C. G. Daniliuc, G. Kehr and G. Erker, Chem. Commun., 2018, 54, 12606-12609.

87 L. L. Zeonjuk, N. Vankova, A. Mavrandonakis, T. Heine, G.-V. Röschenthaler and J. Eicher, Chem. Eur. J., 2013, 19, 17413-17424.

88 G. Skara, B. Pinter, J. Top, P. Geerlings, F. De Proft and F. De Vleeschouwer, Chem. Eur. J., 2015, 21, 5510-5519.

89 G. Bistoni, A. A. Auer and F. Neese, Chem. Eur. J., 2017, 23, 865-873.

90 Y. Shao, J. Zhang, Y. Li, Y. Liu and Z. Ke, Org. Lett., 2018, 20, 1102-1105.

91 S. Porcel, G. Bouhadir, N. Saffon, L. Maron and D. Bourissou, Angew. Chem. Int. Ed., 2010, 49, 61866189. 
Entry for the Table of Contents

\section{Tuning Into Lewis Pairing or Frustration}

\section{Lewis Basicity Lewis Acidity}

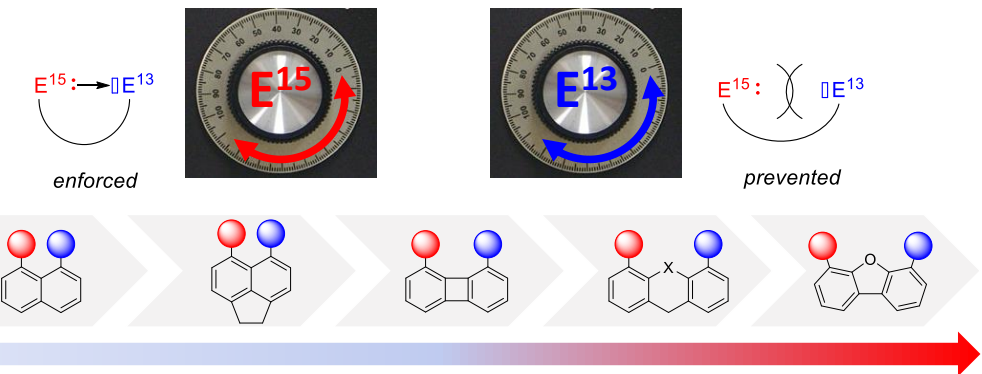

increasing separation

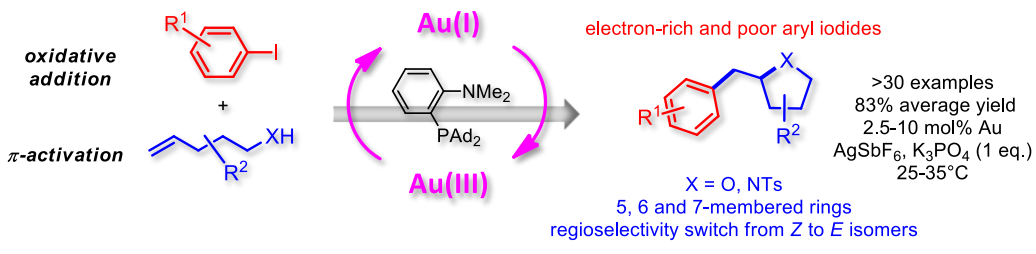

